dem Markt präsent zu sein. Der intensive Austausch von strategischer und produktspezifischer Information mit den Tochtergesellschaften ist deshalb ein fester Bestandteil der Produktinnovationsstrategie von Sandoz.

\section{Globalisierung $v s$. lokales Marketing}

Für das internationale Marketing gibt es zwei extreme Positionen:
- völlige Globalisierung, welche die Welt als einen einzigen homogenen Markt betrachtet (Fig. 3),

- völlige Anpassung an die lokalen Bedürfnisse.

Sandoz hat sich für eine differenzierte Lösung entschieden, die zwischen beiden Extremen liegt, nämlich für einen transnationalen Ansatz, der so viel Globalisierung wie möglich und so viel nationale Differen- zierung wie nötig ermöglicht. Dabei soll ein Höchstmass an internationaler Wettbewerbsfähigkeit bei gleichzeitiger nationaler Flexibilität erzielt werden. Nicht nur die intensive Zusammenarbeit zwischen Konzernzentrale und den Tochtergesellschaften, sondern auch die intensive Zusammenarbeit zwischen Forschung, Entwicklung, Marketing und Produktion sind zur Erreichung dieses Zieles ein wichtiger Faktor.

\title{
Innovative Produkte als Resultat gemeinsamer Anstrengungen von Marketing, Forschung und Produktion
}

\author{
Martin G. Syz*
}

Die Farbenindustrie hat in der Vergangenheit einige Innovations- und Erfolgshöhepunkte zu verzeichnen: der spektakuläre Anfang dieser Industrie mit der Einführung synthetischer Farbstoffe, die Erfindung der höchstechten Indanthren-Farbstoffe, das Aufkommen der synthetischen Fasern mit einer massiven Folge neuartiger Farbstoffe und Färbesysteme. Seitdem, also seit gut zwanzig Jahren, spricht man von reifer Industrie.

Heute richtet sich die Forschung mehr auf ökologische, toxikologische und arbeitshygienische Zielrichtungen. Die Aufwendungen dafür sind hoch, die erzielten Ergebnisse meist wenig werbewirksam. So entsteht der Eindruck eines Fortschritts in nur noch kleinen Quantensprüngen. Ein markanter werbewirksamer Innovationsschub, zumindest aber eine etwas ergiebigere Innovation ist also durchaus erwünscht. Dies natürlich ganz im Sinne, dass die industrielle Innovation als Triebkraft der wirtschaftlichen Entwicklung verstanden wird. Der Begriff Innovation bedeutet hierbei die Schaffung eines technischen Produktes mit neuartigem, deutlich erweitertem Leistungsvermögen.

Eine technische Innovation kann aus durchaus bekannten Elementen bestehen, die jedoch durch eine bisher nicht bekannte Kombination einen unerwarteten

\footnotetext{
- Korrespondenz: Dr. M.G. Syz

Sandoz Chemikalien $A G$

$\mathrm{CH}-4002$ Basel
}

Effekt bewirken. Kombinationen oder Zusammensetzung, materiell oder prozessural, deuten an, dass es sich um eine Komplexität handelt, die ein grundlegendes Phänomen unserer heutigen technischen Welt ist. Die Erarbeitung von Lösungen zu solchen Problemen höherer Ordnung erfordert eine Vielzahl von koordinierten Aktivitäten, die von einer einzigen Stelle, geschweige denn von einer Person nicht geleistet werden kann.

Eine erfolgreiche, d.h. verkaufswirksame Innovation ist nur durch gleichgerichtete, wenn möglich synergistische Interaktionen all der Stellen erreichbar, die auch nur entfernt mit dem neuen Produkt zu tun haben. Das heisst aber auch, dass die Innovation nicht von einer einzigen Disziplin getragen wird. Wohl kann sie von einem einzelnen Punkt, einer brauchbaren Idee, ausgehen, die man nicht nach Belieben generieren kann. Die Lebensfähigkeit wird ihr aber von der Arbeit einer Gruppe eingehaucht. $\mathrm{Zu}$ einer wirklich überzeugenden Lösung bedarf es einer zündenden Idee. Sobald eine Idee geboren ist, muss sie sich viele Fragen und Kritik gefallen lassen:

- nach prinzipieller Machbarkeit

- nach technischer Realisierbarkeit

- nach Wirtschaftlichkeit

- nach universeller, zumindest breiter Anwendbarkeit.

Die Konfrontation der Meinungen ist erwünscht. Sie stellt einen unerlässlichen Faktor für eine kreative Projektoptimie-

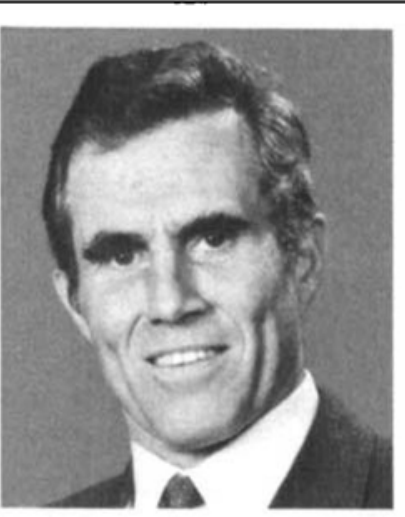

Martin G. Syz: Geboren 1936. 1957-1962 Chemiestudium an der ETH in Zürich. 1964 Promotion Dr. sc. tech. bei Prof. Dr. H. Zollinger. 1964-1966 Forschungstätigkeit beim Stanford Research Institute (SRI) Menlo Park, Kalifornien. 1966-1967 Ciba, Monthey, Entwicklungschemiker Agrochemie. Seit 1967 bei Sandoz $A G$, Basel. Diverse Funktionen in Produktion, Entwicklung, Sicherheitswesen, Marketing. Seit 1990 verantwortlich für Geschäftsbereich Textil der Sandoz Chemikalien AG und Leiter der Sandoz Produkte (Schweiz) $A G$.

rung dar. Die Reibungsflächen der verschiedenen Bereiche führen zur Infragestellung vieler Einzelaspekte. Sie sind jeweils eine Aufforderung, die Details zu überdenken, um die optimale Lösung zu finden und um zu einem Konsens zu kommen. Die Motivation in einer Projektgruppe, eine gemeinsame Anstrengung zu vollbringen, muss durch die Überzeugungskraft des Wertes einer Innovation geschehen. Zeit und Personal für ein Projekt zur Verfügung zu stellen, das möglicherweise längere Zeit dauert, bedeutet für die Produktion - neben ihrer eigentlichen Auf: gabe, Ware zu produzieren - das Erbringen einer Extraleistung.

Auch das Marketing hat eine Sonderleistung in Form von Marktinnovationsforschung zu erbringen. Andererseits dient sie dazu, die eigentliche Existenzberechtigung beider, Produktion und Marketing, abzusichern.

Anders ist der Fall bei F + E und Engineering. Beider Aufgabe ist es, zukunftsgerichtete Arbeit zu leisten.

Wesentlich für den Projekterfolg ist die Überwindung der funktionalen Aufteilung zum Abbau der Friktionen an den Schnittstellen, zum Sicherstellen des unge- 
dem Markt präsent zu sein. Der intensive Austausch von strategischer und produktspezifischer Information mit den Tochtergesellschaften ist deshalb ein fester Bestandteil der Produktinnovationsstrategie von Sandoz.

\section{Globalisierung $v s$. lokales Marketing}

Für das internationale Marketing gibt es zwei extreme Positionen:
- völlige Globalisierung, welche die Welt als einen einzigen homogenen Markt betrachtet (Fig. 3),

- völlige Anpassung an die lokalen Bedürfnisse.

Sandoz hat sich für eine differenzierte Lösung entschieden, die zwischen beiden Extremen liegt, nämlich für einen transnationalen Ansatz, der so viel Globalisierung wie möglich und so viel nationale Differen- zierung wie nötig ermöglicht. Dabei soll ein Höchstmass an internationaler Wettbewerbsfähigkeit bei gleichzeitiger nationaler Flexibilität erzielt werden. Nicht nur die intensive Zusammenarbeit zwischen Konzernzentrale und den Tochtergesellschaften, sondern auch die intensive Zusammenarbeit zwischen Forschung, Entwicklung, Marketing und Produktion sind zur Erreichung dieses Zieles ein wichtiger Faktor.

\title{
Innovative Produkte als Resultat gemeinsamer Anstrengungen von Marketing, Forschung und Produktion
}

\author{
Martin G. Syz*
}

Die Farbenindustrie hat in der Vergangenheit einige Innovations- und Erfolgshöhepunkte zu verzeichnen: der spektakuläre Anfang dieser Industrie mit der Einführung synthetischer Farbstoffe, die Erfindung der höchstechten Indanthren-Farbstoffe, das Aufkommen der synthetischen Fasern mit einer massiven Folge neuartiger Farbstoffe und Färbesysteme. Seitdem, also seit gut zwanzig Jahren, spricht man von reifer Industrie.

Heute richtet sich die Forschung mehr auf ökologische, toxikologische und arbeitshygienische Zielrichtungen. Die Aufwendungen dafür sind hoch, die erzielten Ergebnisse meist wenig werbewirksam. So entsteht der Eindruck eines Fortschritts in nur noch kleinen Quantensprüngen. Ein markanter werbewirksamer Innovationsschub, zumindest aber eine etwas ergiebigere Innovation ist also durchaus erwünscht. Dies natürlich ganz im Sinne, dass die industrielle Innovation als Triebkraft der wirtschaftlichen Entwicklung verstanden wird. Der Begriff Innovation bedeutet hierbei die Schaffung eines technischen Produktes mit neuartigem, deutlich erweitertem Leistungsvermögen.

Eine technische Innovation kann aus durchaus bekannten Elementen bestehen, die jedoch durch eine bisher nicht bekannte Kombination einen unerwarteten

\footnotetext{
- Korrespondenz: Dr. M.G. Syz

Sandoz Chemikalien $A G$

$\mathrm{CH}-4002$ Basel
}

Effekt bewirken. Kombinationen oder Zusammensetzung, materiell oder prozessural, deuten an, dass es sich um eine Komplexität handelt, die ein grundlegendes Phänomen unserer heutigen technischen Welt ist. Die Erarbeitung von Lösungen zu solchen Problemen höherer Ordnung erfordert eine Vielzahl von koordinierten Aktivitäten, die von einer einzigen Stelle, geschweige denn von einer Person nicht geleistet werden kann.

Eine erfolgreiche, d.h. verkaufswirksame Innovation ist nur durch gleichgerichtete, wenn möglich synergistische Interaktionen all der Stellen erreichbar, die auch nur entfernt mit dem neuen Produkt zu tun haben. Das heisst aber auch, dass die Innovation nicht von einer einzigen Disziplin getragen wird. Wohl kann sie von einem einzelnen Punkt, einer brauchbaren Idee, ausgehen, die man nicht nach Belieben generieren kann. Die Lebensfähigkeit wird ihr aber von der Arbeit einer Gruppe eingehaucht. $\mathrm{Zu}$ einer wirklich überzeugenden Lösung bedarf es einer zündenden Idee. Sobald eine Idee geboren ist, muss sie sich viele Fragen und Kritik gefallen lassen:

- nach prinzipieller Machbarkeit

- nach technischer Realisierbarkeit

- nach Wirtschaftlichkeit

- nach universeller, zumindest breiter Anwendbarkeit.

Die Konfrontation der Meinungen ist erwünscht. Sie stellt einen unerlässlichen Faktor für eine kreative Projektoptimie-

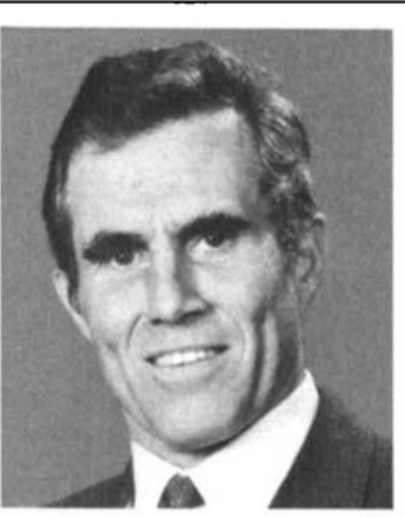

Martin G. Syz: Geboren 1936. 1957-1962 Chemiestudium an der ETH in Zürich. 1964 Promotion Dr. sc. tech. bei Prof. Dr. H. Zollinger. 1964-1966 Forschungstätigkeit beim Stanford Research Institute (SRI) Menlo Park, Kalifornien. 1966-1967 Ciba, Monthey, Entwicklungschemiker Agrochemie. Seit 1967 bei Sandoz $A G$, Basel. Diverse Funktionen in Produktion, Entwicklung, Sicherheitswesen, Marketing. Seit 1990 verantwortlich für Geschäftsbereich Textil der Sandoz Chemikalien AG und Leiter der Sandoz Produkte (Schweiz) $A G$.

rung dar. Die Reibungsflächen der verschiedenen Bereiche führen zur Infragestellung vieler Einzelaspekte. Sie sind jeweils eine Aufforderung, die Details zu überdenken, um die optimale Lösung zu finden und um zu einem Konsens zu kommen. Die Motivation in einer Projektgruppe, eine gemeinsame Anstrengung zu vollbringen, muss durch die Überzeugungskraft des Wertes einer Innovation geschehen. Zeit und Personal für ein Projekt zur Verfügung zu stellen, das möglicherweise längere Zeit dauert, bedeutet für die Produktion - neben ihrer eigentlichen Auf: gabe, Ware zu produzieren - das Erbringen einer Extraleistung.

Auch das Marketing hat eine Sonderleistung in Form von Marktinnovationsforschung zu erbringen. Andererseits dient sie dazu, die eigentliche Existenzberechtigung beider, Produktion und Marketing, abzusichern.

Anders ist der Fall bei F + E und Engineering. Beider Aufgabe ist es, zukunftsgerichtete Arbeit zu leisten.

Wesentlich für den Projekterfolg ist die Überwindung der funktionalen Aufteilung zum Abbau der Friktionen an den Schnittstellen, zum Sicherstellen des unge- 


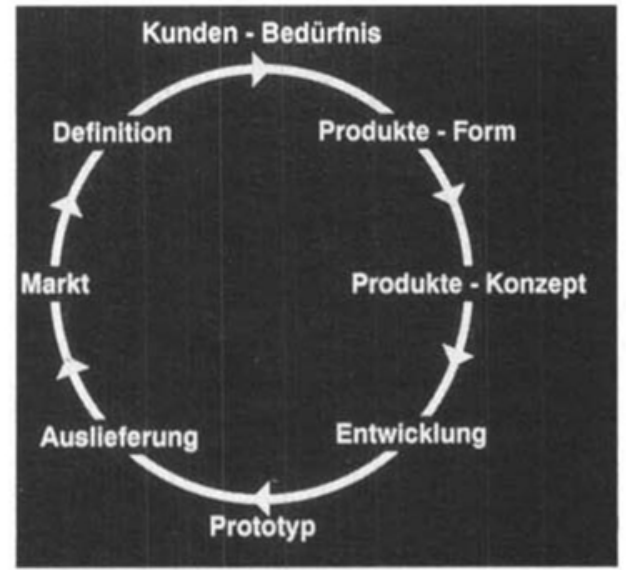

Fig. 1. Sequentielle Innovation

hinderten Informationsflusses; denn innovative Projekte verlangen ein komplexes Feed-back von Informationen zwischen den einzelnen Funktionen, wie aus dem Interaktionsschema (Fig. 1) zu erkennen ist.

Die Planung und Abwicklung eines innovativen Projektes hat viele Wirtschaftstheoretiker beschäftigt. Verschiedene Modelle sind meist post festum mit dem Ziel, den Mechanismus einer erfolgreichen Innovation zu ergründen, aufgestellt worden. Das ist nur zum Teil gelungen. Fast immer blieb ein irrationaler Rest, für den die $\mathrm{Er}$ klärung 'glückliche Umstände' oder 'visionäre Gaben des Marketing' herhalten mussten.

So spricht man heute von sequentiellen Innovationsschritten linear oder als Kreis dargestellt, wie etwa das 4-D-Modell von A.B. Cohen mit Defining, Designing, Developing und Delivering. Bei ihnen folgt ganz streng ein Schritt auf den anderen. Sie wurden praktisch angewandt bei Projekten, bei denen man ganz auf Nummer sicher gehen wollte. Streng genommen ist es ein stufenweises Weitergehen der Verantwortung ohne grosse Rückkupplung und mit grossem Zeitbedarf. Dabei ist es irrelevant, welche Funktion am Ursprung der Sequenz steht, so z.B. in dem von uns zu behandelnden Fall, das Engineering als Teilfunktion der Produktion. Eine abgewandelte Form ist das serielle Modell, wo innerhalb des sequentiellen Ablaufes gewisse interfunktionelle Rückkoppelungen zur Anwendung kommen (Fig. 2).

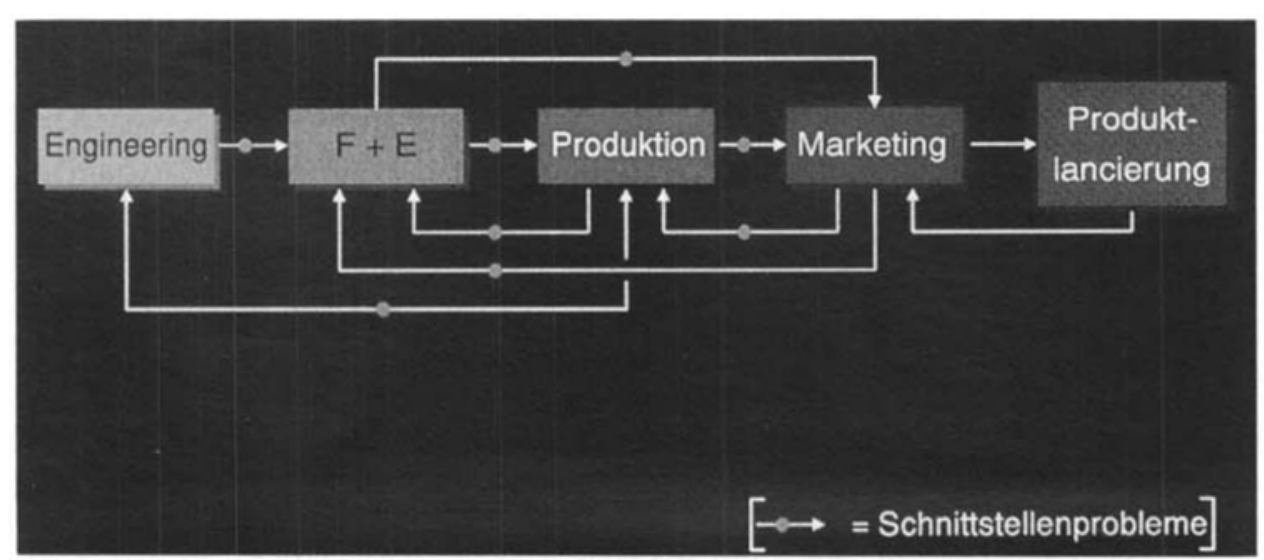

Fig. 2. Serielle Innovation
Heute, wo Innovation in beschleunigter Folge und mit verkürzten Entwicklungsund Einführungszeiten gefordert werden, sind Modelle mit sich überschneidenden Zyklen in Diskussion, in allgemeiner Form die Darstellung als Parallelmodell von $L$. Kohn (Fig. 3). Der Extremfall ist das von den Japanern $H$. Takeuchi und I. Nonaka geprägte Bild des holistischen Rugby-Modells: die gesamte Projektgruppe startet praktisch gleichzeitig, stürmt gemeinsam sich gegenseitig den Ball zuspielend vorwärts, um möglichst rasch den Ball sprich das Innovationsziel - ins Tor zu bringen. In der Praxis wird kaum je ein Projekt in der einen oder anderen modellhaften Form durchgezogen. Das hier zu behandelnde Projekt gleicht allenfalls einer Mischform.

Kommen wir nun zur Schilderung des praktischen Beispiels, welches die verschiedenen Interaktionen der Geschäftsfunktionen illustrieren soll. In der Rückschau liest sich die Entwicklung der Granulierung von Farbstoffen, die im folgenden als Beispiel einer gelungenen Innovation dienen soll, nicht wie das Muster eines Lehrbuches. Der Beginn war eher spielerisch, vom Managementstandpunkt aus als waghalsige und teure Entwicklung einzustufen und kommerziell wenig versprechend. Farbstoffe in Granulatform waren als Zerstäubungsgranulate schon lange bekannt. Heute bezeichnen wir sie als Mikrogranulate: wegen ihrer Kleinheit kaum rieselfähig, abriebempfindlich und zur Staubentwicklung neigend.

Die Idee eines Einzelgängers mit technischer Vision war, grössere stabile Granulate in einem kontinuierlichen Prozess herzustellen. Als Ingenieur sah er dies hauptblem an. Die Machbarkeit konnte im Labor nachgewiesen werden, eine kontinuierliche Pilotanlage wurde konstruiert, gebaut und leidlich brauchbare Granulate hergestellt. Ein Lösungsansatz war damit gegeben. In dieser Pionierphase existierte noch kein Marketingkonzept. Es interessierte lediglich, ob mechanisch stabile Granulate herstellbar sind. Kaum war jedoch ein positives Ergebnis sichtbar, wenn auch noch mit vielen Vorbehalten, sah das Marketing eine gewisse Chance: eine Gamme sächlich als maschinentechnisches Pro-

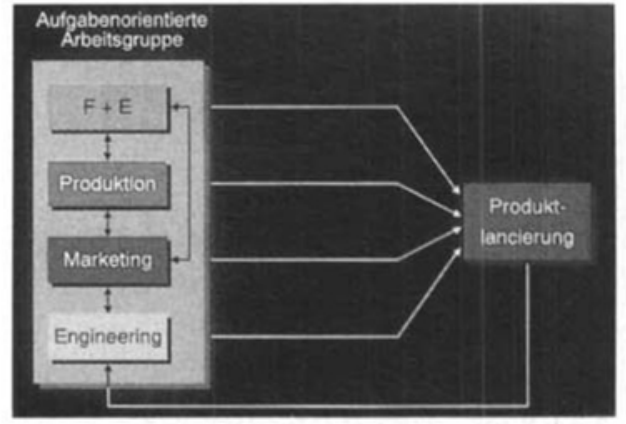

Fig. 3. Parallele Innovation

von Druckfarbstoffen sollte in eine staubarme, gut einstreubare Form gebracht werden. Natürlich hat das Marketing schon in dieser frühen Phase dem Ingenieur und dem Entwicklungschemiker, der schon bald hinzugezogen wurde, die Frage nach der Wirtschaftlichkeit stellen müssen. Die Antwort konnte zu diesem Zeitpunkt nur spekulativ sein, aber sie war spekulativ optimistisch. Zweifel gab es noch zuhauf.

Sobald die Pilot Plant arbeitete, konnten Daten über die Kosten gewonnen werden. Naturgemäss lagen sie bei dieser neuen Anlage, mit ihrem hohen Bedienungsaufwand und dem vergleichsweise sehr geringen Durchsatz, hoch. Die Berücksichtigung der Economy of Scale und Hochrechnungen liessen aber wirtschaftlich vertretbare Kosten erwarten. Allerdings musste auch das Verkaufsvolumen in Relation zur notwendigen Investitionssumme genügend gross sein. Das Marketing hielt Ausschau nach weiteren Kandidaten und entschied sich für eine Reihe wichtiger Reaktivfarbstoffe aus der Reihe der hochreaktiven Gamme.

Schwierigkeiten ergaben sich aus der Forderung des Marketings, dass die wesentlichen färberischen Eigenschaften wie Löslichkeiten und färberische Ausbeute, denen der eingeführten Pulver genau entsprechen müssten. Das bedingte häufige Intervention vom Marketing und Einschaltung von $\mathrm{F}+\mathrm{E}$, um qualitativ entgleiste Produkte zu korrigieren. Schliesslich wurden von diversen Produkten 0-Serien produziert, die man für ein Testmarketing vorgesehen hatte. Soweit also ein schön geplantes Vorgehen im sequentiellen Muster - fast noch Lehrbuch.

Es sollte anders kommen. In England haben sich zwei Unfälle ereignet, bei denen Arbeiter Staub von Reaktivfarbstoff eingeatmet hatten, durch die schwere Allergisierungen ausgelöst wurden. Die Behörden schritten sofort ein. Der Gebrauch der Pulver wurde untersagt. Diese plötzliche Lücke konnten wir mit unserem Angebot an nicht stäubenden Granulaten füllen. Die begreiflicherweise damals übermässig strengen Anforderungen an Staubarmut konnten erfüllt werden. Die Ereignisse in England lösten ein eindeutiges Marktsignal aus, wie man es besser sich nicht wünschen kann. Um einen etwas gewagten Vergleich anzuführen: Es war wie der Sputnikschock, der die amerikanische 


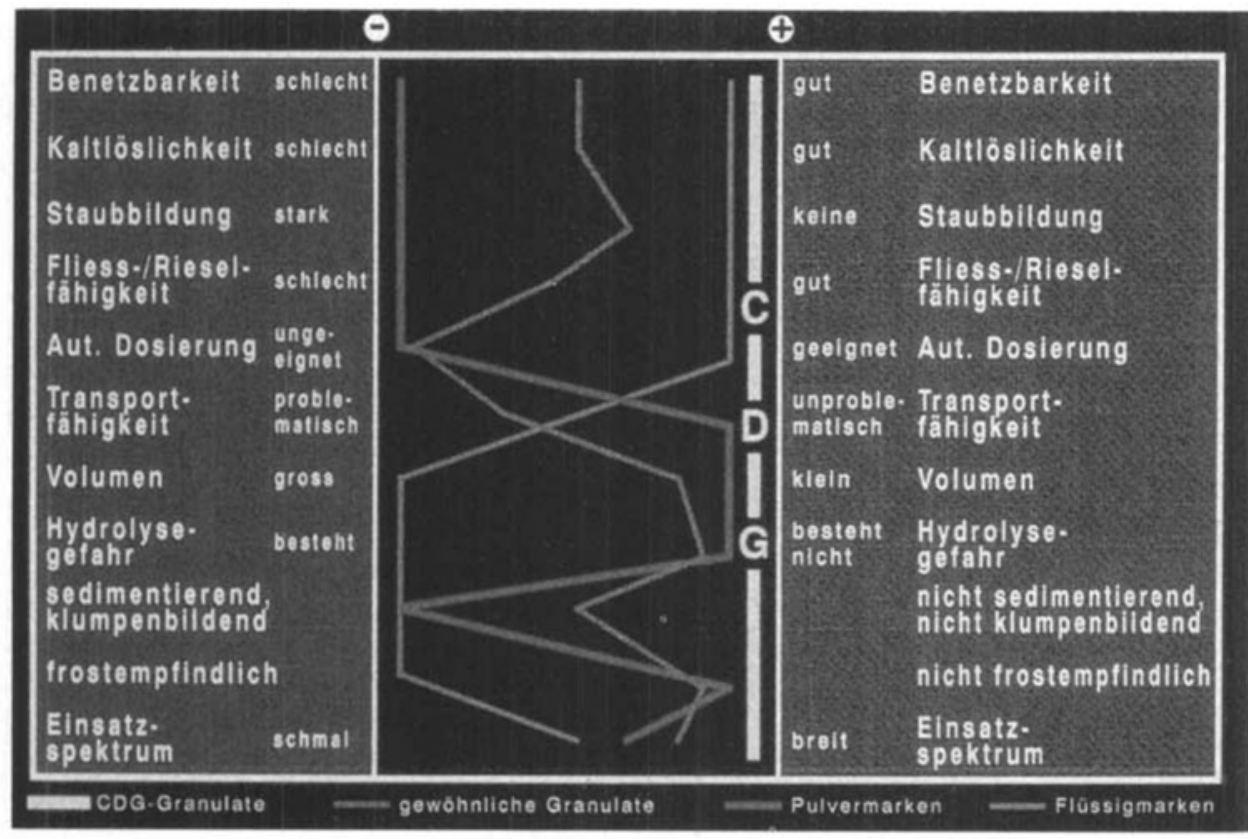

Fig. 4. Einsatzeigenschaften
Raumfahrt in Gang brachte. Das lange schwelende Feuer der Vorbereitungsphase wurde plötzlich zu einem Brand mächtiger Aktivität angefacht.

Der Nutzen der scheinbar übermässig langen Vorbereitungsphase sollte sich nun zeigen. Ohne deren Erkenntnisse wäre es nicht möglich gewesen, die dann in Gang gesetzte Beschleunigungsphase zu bewältigen. Sie bewirkte eine Konzentration der Kräfte und eine starke Intensivierung der Zusammenarbeit, ganz besonders bei der Planung, beim Bau und der Inbetriebnahme der Produktionsanlagen. Die Planung stützte sich auf neue und grössere Bedarfsprognosen des Marketings, auf Standortstudien der Produktion und des Ingenieurwesens.

Bei der Berechnung der Amortisation gingen auch die Produktkosten, basierend auf den Arbeiten von F + E, ein. Der Zeitrahmen wurde eng gezogen, da man sich auf die bereits vorhandenen Erfahrungen stützte. Die geschwindigkeitsbestimmenden Schritte waren dann fast nur noch die Lieferfristen der Apparatehersteller und die Montage.

Die Erkenntnis, dass definitiv ein grosses Marktbedürfnis und -potential bestand, liess die Frage des Testmarketings irrelevant werden. Das Marketing konnte schlicht darauf verzichten. Durch eine nochmalige gründliche Produkteevaluation konnte ein deutlich grösseres Eigenschaftspotential erkannt und definiert werden. Dies führte zu einer neuen Produktebzw. Gammenidentität, den CDG-Marken (cold dissolving granules), mit einem gegenüber den bisher angebotenen Pulvern markant verbreitertem Einsatzpotential (Fig. 4). Die Bezeichnung CDG beinhaltet mehr als die Abkürzung. Es ist eine neue Handelsform für hochreaktive, bei tiefen Färbetemperaturen einsetzbare Baumwollfarbstoffe. Sie sind wegen ihrer guten
Nassechtheiten im Markt längst wohl etabliert.

Die Staubentwicklung der bisher vertriebenen Pulvermarken ist aus heutiger Sicht ein schwerer Nachteil. Mit Flüssigmarken liess sich das Staubproblem leicht umgehen. Die flüssige Form ist natürlich ideal zum automatischen Dosieren, also dem computergesteuerten volumetrischen oder gravimetrischen Abmessen und Rezeptieren. Dem steht die Unwirtschaftlichkeit des Totvolumens an Wasser bei Lagerung und Transport entgegen. Das riesel- oder fliessfähige Granulat vereinigt die vorteilhaften Eigenschaften der festen Form (lagerstabil, konzentriert) und der flüssigen Form (durch Leitungen pumpbar, leicht dosierbar) und vermeidet weitgehend deren Nachteile (Hydrolyse, Staub).

Die Überlegungen des Marketing forderten schliesslich als weitere Eigenschaft die Kaltwasserlöslichkeit als sehr hochgesteckte Zielsetzung. Damit wurde das Eigenschaftsspektrum der Granulate nochmals erweitert und eine weitere Annäherung an den Flüssigzustand erreicht, indem Färbeflotten mit geringstem Aufwand, durch einfaches schnelles Lösen in kaltem Wasser, hergestellt werden können.

Der plötzlich einsetzende Bedarf konnte zunächst nur über die Pilot Plant befriedigt werden, wobei es gelang, den Ausstoss in ungeahntem Ausmass zu vergrössern. Es war der bekannte Lerneffekt, der Beeinflussungsmöglichkeiten erkennen liess, die mit sehr deutlichem Effekt zur Produktionssteigerung ausgenutzt wurden. Diese Phase erforderte ständigen Kontakt zwischen Marketing und Produktion, um Termine und verfügbare Mengen abzustimmen. Parallel dazu erfolgten nun mit konzentrierten und konzertierten Bemühungen die Planung und Realisierung einer regulären Marktbelieferung, für die die Maschinen und die komplette Produktelinie hergestellt werden mussten. Die Aufgabe der Anlagenerstellung konnte im Wechselspiel von Engineering und Produktion, nach dem Bedarfsinput des Marketing, relativ einfach gelöst werden. Man konnte sich auf die umfangreichen Erfahrungen der Pionierphase stützen und somit das angeben. Die zu tätigende Investition in Millionenhöhe musste sich in Sensibilitätsanalysen auf vernünftige IRR-Sätze und Pay-back-Perioden abstützen. Die gegenüber Pulvermarken eintretende geringfügige Erhöhung wurde von der Kundschaft wegen den überzeugenden Eigenschaften klaglos honoriert. Mit wachsender Erfahrung auf den Produktionsanlagen wurde vor allem, dank Verbesserung des Durchsatzes, der ursprüngliche Kostennachteil zusehends kleiner.

Komplizierter war die Bereitstellung der Rezepturen für eine grosse Anzahl von Produkten durch $\mathrm{F}+\mathrm{E}$. Das Marketing musste jedes einzelne Anforderungsprofil spezifisch definieren. Die F+E-Arbeit konnte erst dann begonnen werden, nachdem die Ausgangsfarbstoffe produziert worden waren; sie war also in ihrer Zeitplanung gebunden. Bei gewissen Produkten musste das Marketing Abstriche an Ziel sehr direkt und ohne grosse Umwege

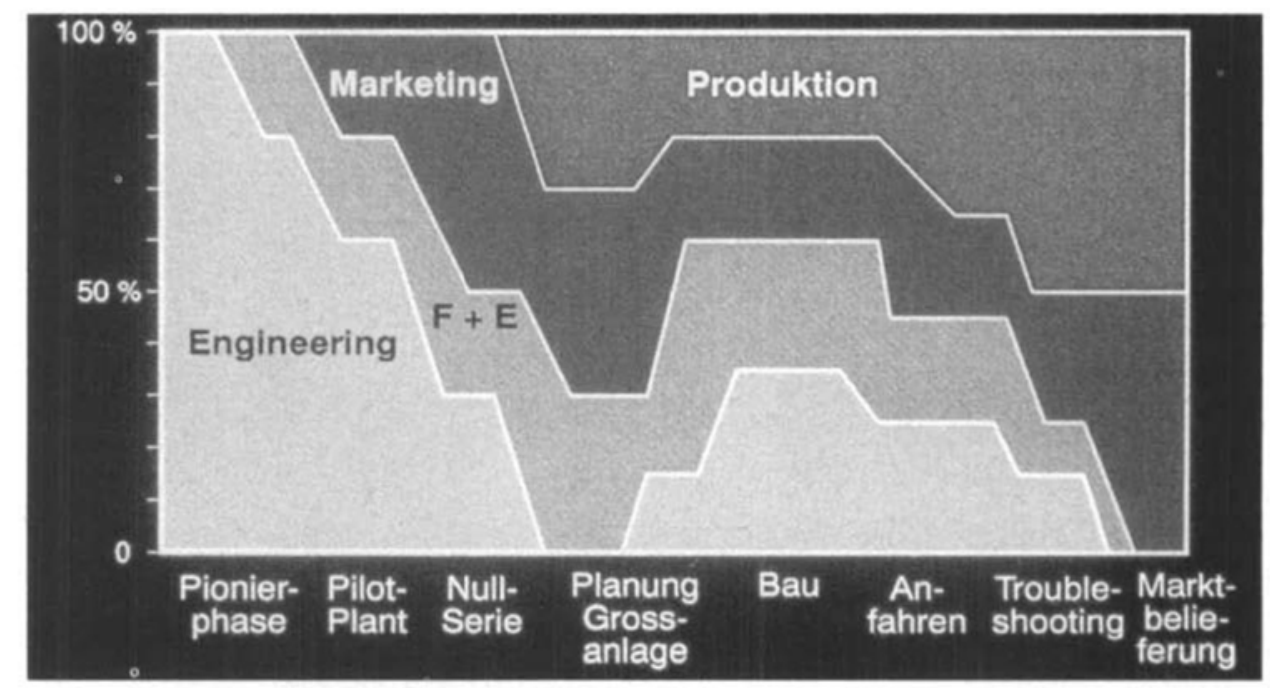

Fig. 5. Relative Aktivitätsphasen der Funktionen 
den ursprünglichen Forderungen, fast durchwegs bei den Löslichkeiten, machen, weil molekülinhärent die höchsten Ziele realistischerweise nicht zu erreichen waren.

So wurden im Dia- und Trialog optimierte, technisch machbare Gammen geschaffen. Das Marketing musste Qualitätszugeständnisse machen, da nicht alle Produkte dem höchsten CDG-Ideal entsprachen. In einem Fall musste denn auch gänzlich auf das CDG-Etikett verzichtet werden, allerdings nur im Hinblick auf die den Grenzwert nicht erreichende Kaltwasserlöslichkeit. Für die Beteiligten ging dies in die Projektgeschichte der Phase der 'zähneknirschenden Zustimmung' ein. Jede Konzession war ein schmerzhafter Abschied, da damit das CDG-Konzept ein weiteres Mal durchlöchert schien.

Eine erste grössere Vorstellung der CDG-Markenprodukte erfolgte 1987 an der ITMA (Internationale Textilmaschinenausstellung) in Paris, zusammen mit Herstellern von automatischen Dosieranlagen. Dies, um den neuen Anwendungsbereich der CDG-Handelsform ins rechte Licht zu setzen. Die Promotion in Publikationen und Vorträgen hielt sich in relativ engem Rahmen. Dies war einerseits der Ausdruck dafür, dass das Marktinteresse sehr gross war, andererseits, dass das Hochfahren der Produktionsanlagen mit dem Ansteigen der Nachfrage nicht Schritt hielt. Ein Planungsfehler? Die durch Hochkonjunktur bedingte Produkteknappheit zwang besonders zu dem Zeitpunkt, an dem lediglich die erste Stufe der Kapazitätserweiterung erreicht war, paral- lel zu arbeiten und den Markt teilweise immer noch mit Pulver zu beliefern. Eine Periode schwieriger Entscheidungen. Die Verhandlungen Marketing/Produktion gerieten öfters in die Nähe des Siedepunkts, weil die Produktion aus Kostengründen möglichst lange das gleiche Produkt fahren und das Marketing möglichst schnell viele verschiedene Produkte verkaufen wollte.

Naturgemäss änderten sich Aufgaben und Aktivitäten der einzelnen Bereiche des Projektteams mit dem Fortschritt des Projektes (Fig. 5). Das Engineering hatte deutlich zwei Aktivitätsphasen: die Pionierphase, verbunden mit der ersten PilotPlant-Periode; zweitens die Periode der Planung und des Baues der Produktionsanlagen. Die Produktion wuchs aus einer Experimentierphase über die Kleinproduktion schliesslich mit den Produktionsanlagen in immer grössere Aufgaben hinein. Der Bereich Forschung-Entwicklung erlebte nach anfänglich bescheidenem Aufwand seine Hauptaktivität bei der Formulierung ganzer Gammen, um nach assistierender Tätigkeit bei Produktionseinführung schliesslich in die Rolle des trouble shooters zurückzufallen.

Das Marketing begann mit Marktrecherche, definierte die neue Produktelinie, erstellte Bedarfsprognosen, wirkte aktiv in der Markteinführung, um endlich wieder bei den eigentlichen Aufgaben der Marktversorgung anzulangen.

Planung und Abwicklung des Innovationsprojektes 'Farbstoffgranulierung' entsprach in vieler Hinsicht nicht den Vorstellungen und Modellen neuerer Manage- menttheorien. Versucht man zu kategorisieren, kann man verschiedene Perioden unterscheiden. Die lineare und deshalb langsame Pionierphase war geprägt von grosser Unsicherheit und Zweifeln. Der Schwierigkeitsgrad und vor allem das finanzielle Risiko wurden hoch eingeschätzt. Entsprechend gering war anfangs die Unterstützung des Projektes. Der Punkt hinter diesem Anfang war das Englandereignis. Die dadurch ausgelöste Beschleunigungsphase ist gekennzeichnet durch konzentriertes, zielgenaues Handeln auf vielen parallelen Ebenen. Durch die koordinierte Interaktion gewann die Projektbearbeitung an Breite und Tiefe, was sich in einem weitgehend reibungslosen Fortschritt und ein von wenig Pannen geplagtem Produktionsbeginn manifestierte. Die hohe Identifikation aller Beteiligten mit dem Projekt entsprang der überzeugenden Idee und der zwingenden Notwendigkeit, sie zu verwirklichen. Die Interaktionen ergaben sich dabei fast automatisch und spontan aus den erkannten Notwendigkeiten. Es gab nur sehr wenige Gelegenheiten, bei denen die Leitung ordnend eingreifen musste.

Mit diesem Beispiel sollte gezeigt werden, dass das erfolgreiche Durchziehen des Projektes geprägt war vom Willen zum Konsens, dem gegenseitigen Vertrauen und dem allseitigen Enthusiasmus, ein sichtbares Ziel zu erreichen; alles menschliche Aspekte, die zum Teil ebenso wichtig, wenn nicht noch wichtiger sind, als Strukturen und Projektorganisation.

\section{Chemistry and Structure.}

\section{A Symposium in Honour of Professor J.D. Dunitz}

Die Schweizerische Gesellschaft für Kristallographie führte am 14. und 15. März $1990 \mathrm{im}$ Auditorium Maximum der ETH Zürich zu Ehren von Prof. J.D. Dunitz ein Symposium 'Chemistry and Structure' durch. Anlass war der altersbedingte Rücktritt von Prof. J.D. Dunitz von seinem Lehrstuhl 'Chemische Kristallographie', den er seit 1957 am Laboratorium für organische Chemie der ETH innehatte. Die Kollegen und Freunde der Gesellschaft für Kristallographie wollten damit die 'Anerkennung seiner bahnbrechenden wissenschaftlichen Arbeiten auf dem Gebiet der chemischen Kristallographie, und den Dank für sein langjähriges, fruchtbares Wirken in der Schweiz als Forscher, Lehrer und Gründungsmitglied der Gesellschaft' ausdrücken, wie es in der Ernennungsurkunde zum Ehrenmitglied der Gesellschaft heisst.
Dass der Rücktritt von J.D. Dunitz keineswegs das Ende seiner wissenschaftlichen Laufbahn bedeutet, wurde eindringlich durch seinen Vortrag 'Chemical Aspects of Phase Transitions in Molecular Crystals' belegt. Der Polymorphismus molekularer Verbindungen ist noch immer ein weit offenes Problem. Unsere Einsicht darüber, wie sich Moleküle in Kristallen zu periodischen Mustern anordnen, ist ebenso rudimentär wie unser Verständnis der oft sehr bedeutenden Umlagerungen bei polymorphen Übergängen oder Festkörperreaktionen. Man hat auch lange nicht realisiert, dass Polymorphie wohl eher die Regel als die Ausnahme ist: McCrone hat 1965 gesagt, die Anzahl polymorpher Formen einer Substanz sei proportional zur Zeit, die man zur Kristallisation unter verschiedenen Bedingungen aufwende! Phasenübergänge in Festkörpern sind auf verschiedene Weise klassifiziert worden, zum Beispiel thermodynamisch als Übergänge 1. und 2. Ordnung. Dies wurde auch kritisiert, weil bei solchen Übergängen Überhitzen oder Unterkühlen notwendig ist, und im thermodynamischen Gleichgewicht nichts passieren kann. Demnach wären alle Phasenumwandlungen als Kernbildung an einem geeigneten Kristalldefekt und anschliessendem Wachstum zu verstehen. Wenn von polymorphen Verbindungen Kristallstrukturen bekannt sind, könnte man aus ihrer Überlagerung ableiten, wie die einzelnen Moleküle sich verschieben, rotieren oder konformationell ändern müssen, um von der einen zur anderen Struktur zu gelangen. Dieses Bild erscheint jedoch als zu einfach, denn im allgemeinen bewegen sich die Moleküle in einer Phase kaum, vielmehr werden sie irgendwie Stück um Stück aus der 
den ursprünglichen Forderungen, fast durchwegs bei den Löslichkeiten, machen, weil molekülinhärent die höchsten Ziele realistischerweise nicht zu erreichen waren.

So wurden im Dia- und Trialog optimierte, technisch machbare Gammen geschaffen. Das Marketing musste Qualitätszugeständnisse machen, da nicht alle Produkte dem höchsten CDG-Ideal entsprachen. In einem Fall musste denn auch gänzlich auf das CDG-Etikett verzichtet werden, allerdings nur im Hinblick auf die den Grenzwert nicht erreichende Kaltwasserlöslichkeit. Für die Beteiligten ging dies in die Projektgeschichte der Phase der 'zähneknirschenden Zustimmung' ein. Jede Konzession war ein schmerzhafter Abschied, da damit das CDG-Konzept ein weiteres Mal durchlöchert schien.

Eine erste grössere Vorstellung der CDG-Markenprodukte erfolgte 1987 an der ITMA (Internationale Textilmaschinenausstellung) in Paris, zusammen mit Herstellern von automatischen Dosieranlagen. Dies, um den neuen Anwendungsbereich der CDG-Handelsform ins rechte Licht zu setzen. Die Promotion in Publikationen und Vorträgen hielt sich in relativ engem Rahmen. Dies war einerseits der Ausdruck dafür, dass das Marktinteresse sehr gross war, andererseits, dass das Hochfahren der Produktionsanlagen mit dem Ansteigen der Nachfrage nicht Schritt hielt. Ein Planungsfehler? Die durch Hochkonjunktur bedingte Produkteknappheit zwang besonders zu dem Zeitpunkt, an dem lediglich die erste Stufe der Kapazitätserweiterung erreicht war, paral- lel zu arbeiten und den Markt teilweise immer noch mit Pulver zu beliefern. Eine Periode schwieriger Entscheidungen. Die Verhandlungen Marketing/Produktion gerieten öfters in die Nähe des Siedepunkts, weil die Produktion aus Kostengründen möglichst lange das gleiche Produkt fahren und das Marketing möglichst schnell viele verschiedene Produkte verkaufen wollte.

Naturgemäss änderten sich Aufgaben und Aktivitäten der einzelnen Bereiche des Projektteams mit dem Fortschritt des Projektes (Fig. 5). Das Engineering hatte deutlich zwei Aktivitätsphasen: die Pionierphase, verbunden mit der ersten PilotPlant-Periode; zweitens die Periode der Planung und des Baues der Produktionsanlagen. Die Produktion wuchs aus einer Experimentierphase über die Kleinproduktion schliesslich mit den Produktionsanlagen in immer grössere Aufgaben hinein. Der Bereich Forschung-Entwicklung erlebte nach anfänglich bescheidenem Aufwand seine Hauptaktivität bei der Formulierung ganzer Gammen, um nach assistierender Tätigkeit bei Produktionseinführung schliesslich in die Rolle des trouble shooters zurückzufallen.

Das Marketing begann mit Marktrecherche, definierte die neue Produktelinie, erstellte Bedarfsprognosen, wirkte aktiv in der Markteinführung, um endlich wieder bei den eigentlichen Aufgaben der Marktversorgung anzulangen.

Planung und Abwicklung des Innovationsprojektes 'Farbstoffgranulierung' entsprach in vieler Hinsicht nicht den Vorstellungen und Modellen neuerer Manage- menttheorien. Versucht man zu kategorisieren, kann man verschiedene Perioden unterscheiden. Die lineare und deshalb langsame Pionierphase war geprägt von grosser Unsicherheit und Zweifeln. Der Schwierigkeitsgrad und vor allem das finanzielle Risiko wurden hoch eingeschätzt. Entsprechend gering war anfangs die Unterstützung des Projektes. Der Punkt hinter diesem Anfang war das Englandereignis. Die dadurch ausgelöste Beschleunigungsphase ist gekennzeichnet durch konzentriertes, zielgenaues Handeln auf vielen parallelen Ebenen. Durch die koordinierte Interaktion gewann die Projektbearbeitung an Breite und Tiefe, was sich in einem weitgehend reibungslosen Fortschritt und ein von wenig Pannen geplagtem Produktionsbeginn manifestierte. Die hohe Identifikation aller Beteiligten mit dem Projekt entsprang der überzeugenden Idee und der zwingenden Notwendigkeit, sie zu verwirklichen. Die Interaktionen ergaben sich dabei fast automatisch und spontan aus den erkannten Notwendigkeiten. Es gab nur sehr wenige Gelegenheiten, bei denen die Leitung ordnend eingreifen musste.

Mit diesem Beispiel sollte gezeigt werden, dass das erfolgreiche Durchziehen des Projektes geprägt war vom Willen zum Konsens, dem gegenseitigen Vertrauen und dem allseitigen Enthusiasmus, ein sichtbares Ziel zu erreichen; alles menschliche Aspekte, die zum Teil ebenso wichtig, wenn nicht noch wichtiger sind, als Strukturen und Projektorganisation.

\section{Chemistry and Structure.}

\section{A Symposium in Honour of Professor J.D. Dunitz}

Die Schweizerische Gesellschaft für Kristallographie führte am 14. und 15. März $1990 \mathrm{im}$ Auditorium Maximum der ETH Zürich zu Ehren von Prof. J.D. Dunitz ein Symposium 'Chemistry and Structure' durch. Anlass war der altersbedingte Rücktritt von Prof. J.D. Dunitz von seinem Lehrstuhl 'Chemische Kristallographie', den er seit 1957 am Laboratorium für organische Chemie der ETH innehatte. Die Kollegen und Freunde der Gesellschaft für Kristallographie wollten damit die 'Anerkennung seiner bahnbrechenden wissenschaftlichen Arbeiten auf dem Gebiet der chemischen Kristallographie, und den Dank für sein langjähriges, fruchtbares Wirken in der Schweiz als Forscher, Lehrer und Gründungsmitglied der Gesellschaft' ausdrücken, wie es in der Ernennungsurkunde zum Ehrenmitglied der Gesellschaft heisst.
Dass der Rücktritt von J.D. Dunitz keineswegs das Ende seiner wissenschaftlichen Laufbahn bedeutet, wurde eindringlich durch seinen Vortrag 'Chemical Aspects of Phase Transitions in Molecular Crystals' belegt. Der Polymorphismus molekularer Verbindungen ist noch immer ein weit offenes Problem. Unsere Einsicht darüber, wie sich Moleküle in Kristallen zu periodischen Mustern anordnen, ist ebenso rudimentär wie unser Verständnis der oft sehr bedeutenden Umlagerungen bei polymorphen Übergängen oder Festkörperreaktionen. Man hat auch lange nicht realisiert, dass Polymorphie wohl eher die Regel als die Ausnahme ist: McCrone hat 1965 gesagt, die Anzahl polymorpher Formen einer Substanz sei proportional zur Zeit, die man zur Kristallisation unter verschiedenen Bedingungen aufwende! Phasenübergänge in Festkörpern sind auf verschiedene Weise klassifiziert worden, zum Beispiel thermodynamisch als Übergänge 1. und 2. Ordnung. Dies wurde auch kritisiert, weil bei solchen Übergängen Überhitzen oder Unterkühlen notwendig ist, und im thermodynamischen Gleichgewicht nichts passieren kann. Demnach wären alle Phasenumwandlungen als Kernbildung an einem geeigneten Kristalldefekt und anschliessendem Wachstum zu verstehen. Wenn von polymorphen Verbindungen Kristallstrukturen bekannt sind, könnte man aus ihrer Überlagerung ableiten, wie die einzelnen Moleküle sich verschieben, rotieren oder konformationell ändern müssen, um von der einen zur anderen Struktur zu gelangen. Dieses Bild erscheint jedoch als zu einfach, denn im allgemeinen bewegen sich die Moleküle in einer Phase kaum, vielmehr werden sie irgendwie Stück um Stück aus der 
unstabilen Phase über die Phasengrenze in die neu wachsende Phase transferiert.

Phasenübergänge finden auch bei Festkörperreaktionen statt. Im allgemeinen wird dabei die Reaktionsgeschwindigkeit im Kristall kleiner sein als in Lösung. Wenn aber durch speziell günstige $\mathrm{Pak}$ kung im Kristall nur minimale Atombewegungen nötig sind, um vom Ausgangs- zum Endmolekül zu gelangen, sind auch höhere Reaktionsgeschwindigkeiten als in Lösung möglich. In solchen Fällen spricht man von topochemischen Reaktionen. Ein sehr schönes Beispiel für eine solche Reaktion ist der Me-Transfer bei $p$ - $N, N$-dimethylaminobenzolsulfonsäure-methylester. Aus der Kristallstrukturanalyse lässt sich zeigen, dass die Sulfonat-Gruppen stark um die (C-S)-Bindungen librieren und dadurch günstige Bedingungen für einen intermolekularen Übergang der Me-Gruppe schaffen. Bei anderen Reaktionen finden sich allerdings auch solche ohne topochemische Kontrolle. Ein ausserordentlich interessanter und komplizierter Fall ist der Polymorphismus von Dimethyl-3,6-dichloro2,5-dihydroxyterephthalat, der seit längerer Zeit in der Dunitz-Gruppe untersucht wird. Bereits 1915 hatte Hantsch über weisse und gelbe Kristalle berichtet, und bei Strukturuntersuchungen hat ein Mitarbeiter von Dunitz noch eine dritte, hellgelbe, Modifikation gefunden. Die Kristallstrukturen unterscheiden sich beträchtlich: In den gelben Kristallen sind die Moleküle beinahe koplanar mit intramolekularen $\mathrm{H}$-Brücken, in den weissen Kristallen sind die MeOCO-Gruppen senkrecht zum Rest des Moleküls und das $\mathrm{H}$-Brückennetzwerk ist intermolekular, und in den hellgelben Kristallen sind diese Gruppen in einer Zwischenstellung. Ein kurzer Videofilm, aufgenommen an einem DSC-Gerät, zeigte eindrücklich, dass die Umwandlungen in vielen Richtungen erfolgen können und ein erratisches Verhalten zeigen, ein Hinweis darauf, wie wichtig statistisch verteilte Kristalldefekte als Auslöser sind. Dieses und weitere Beispiele zeigen, dass die traditionellen Einteilungen von Phasenübergängen in Molekülkristallen oft unzureichend sind, und unser Verständnis der Mechanismen zu wünschen übrig lässt. Das Hauptproblem der Untersuchung solcher Phänomene mit Kristallstrukturanalysen liegt in der Methode selbst. Sie liefert uns sehr gute Bilder einer über die Zeit und den Raum gemittelten Struktur, aber keine Information über die Natur der in diesem Zusammenhang so wichtigen Abweichungen vom Mittel. Andere Methoden, zum Beispiel moleküldynamische Simulationen, können vielleicht in Zukunft zu besseren Erkenntnissen führen. Dunitz schloss mit einem Brecht-Zitat aus dem 'Galileo Galilei': 'Wir wissen bei weitem nicht genug, Giuseppe. Wir stehen wirklich ganz am Beginn.'

Auch zwei weitere Vorträge waren der Thematik Polymorphismus und Kristallpackung gewidmet. Prof. Joel Bernstein von der Ben-Gurion University of the $\mathrm{Ne}$ -

gev, Beer Sheva, Israel, sprach über 'Polymorphism in Organic Crystals: Utilizing and Understanding the Differences between Structures'. Er sieht polymorphe Kristalle als ausgezeichnete Fälle zur Untersuchung von Zusammenhängen zwischen Struktur und Eigenschaft. Da die Substanz gleich bleibt und nur die Struktur ändert, sollten sich unterschiedliche Eigenschaften direkt auf strukturelle Unterschiede zurückführen lassen. Auch Bernstein ist der Meinung, dass Polymorphismus organischer Substanzen eher die Regel ist. In der Cambridge-Strukturdatenbank

sind über 3000 Fälle dokumentiert, und man könnte pointiert sagen, dass sich mit genügend Geduld von jeder Substanz polymorphe Formen kristallisieren lassen. Bernstein zeigte dann eine Möglichkeit, Kristallstrukturen zu klassifizieren, die vor allem durch $\mathrm{H}$-Brücken stabilisiert werden. Mit Hilfe der Graphentheorie lassen sich solche Netzwerke mit relativ wenigen Deskriptoren erfassen. Interessanterweise stellt man fest, dass polymorphe Kristalle, auch wenn sie auf den ersten und zweiten Blick nichts Gemeinsames aufweisen, frappante Ähnlichkeiten ihrer Deskriptoren

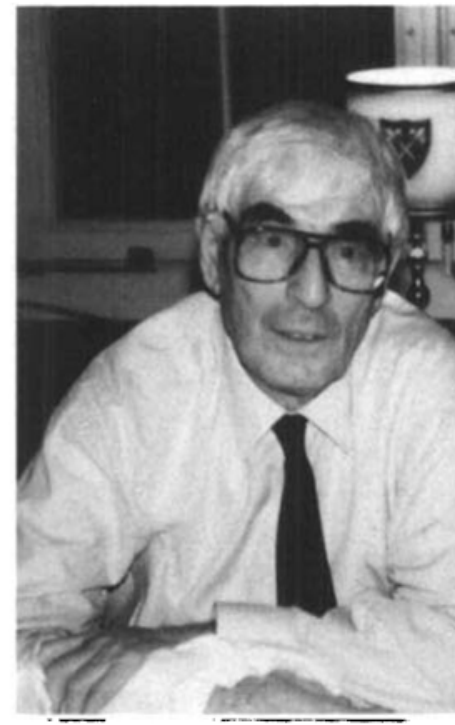

J.D. Dunitz

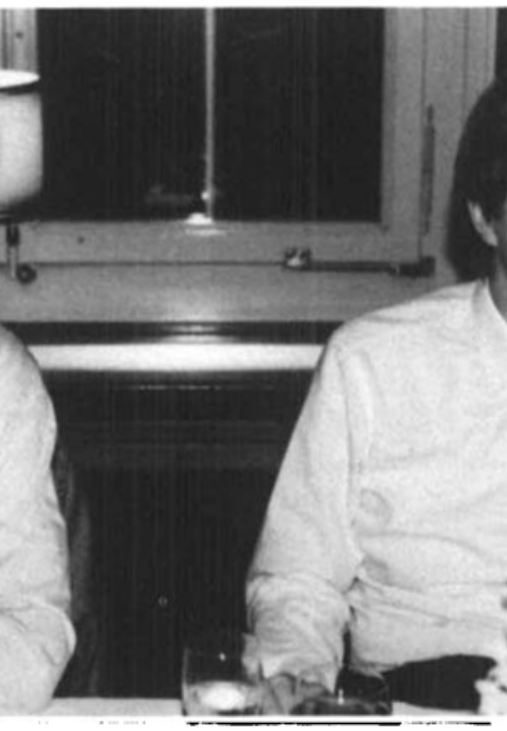

(Foto: Dr. D. Felix)

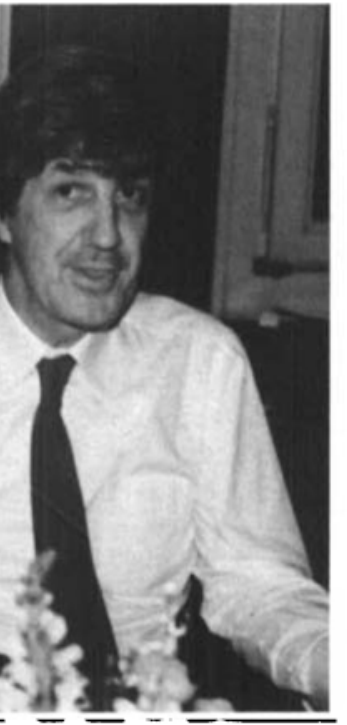

J. Daly

(Präsident der SGK)

You're Not Old, Father Dunitz

'You're not old, Father Dunitz', the young man said

Though your hair is exceedingly white It's but an illusion that years have gone by Since you listened for bombers at night.

And crossed the great ocean to bask in the sun While absorbing the wisdom of sages, From Linus ${ }^{1}$ ) and Verner ${ }^{2}$ ) and all of the rest. It might seem, but it hasn't been, ages.

Then Oxford again, and the beauty at Blackwell's

Where you'd gone, you said, just for a look, And came away with the gift of a lifetime ${ }^{3}$ ) Without even buying a book.

The move to the ETH turned out to be The next best of the many you have made, For the Swiss and for you, and for so many more,

Who came oft and would love to have stayed.

Your lab is acclaimed, its air still perfumed By your pipe, as the structures enthrall The eager young scholars, all nurtered and led By Lucie $)$, by Bernd ${ }^{5}$ ) and by Paul 6 ).

'A third of a century can't have gone by' Said the youth, with a bit of a frown, Since Ruzicka confronted the young JDD With an offer he couldn't turn down.'

Father Dunitz, bemused, as is often his wont, Regarded the youth with a stare,

'If it's all an illusion, as you try to claim, What's the point of this gala affair?' zeigen. Die Möglichkeiten einer solchen Klassifizierung lassen sich noch nicht abschätzen, da insbesondere Bezüge zur Geometrie der H-Brücken noch fehlen.

Der dritte Vortrag befasste sich vorwiegend mit den Fragen der Vorhersage von Kristallstrukturen bei bekannter Molekülstruktur: 'The Crystal Packing of Organic Molecules: Geometry and Forces'. Gehalten wurde er durch Prof. Angelo Gavezzotti von der Universität Mailand. Gavezzotti war ein Mitglied der bekannten SimonettaGruppe, zu der Dunitz enge wissenschaftliche und persönliche Beziehungen hatte. Gavezzotti sieht im Prinzip zwei unterschiedliche, aber sich ergänzende Wege bei der Untersuchung dieses Problems. Auf der einen Seite kennen wir heute die Kristallstrukturen von über 80000 organischen Verbindungen, die in der Cambridge-Strukturdatenbank greifbar sind. Daraus lassen sich eine Vielzahl molekularer Deskriptoren (z.B. Masse, Stöchiometrie, Volumen, Oberfläche, Trägheitsmoment), wie auch Kristalldeskriptoren (z.B.

\footnotetext{
I) Linus Pauling

2) Verner Schomaker

3) seine Frau Barbara.

) Lucie a Marca, Sekretärin seit 1968

5) Bernd Schweizer, Doktorand 1973, Mitarbeiter seit 1977.

6) Paul Seiler, Mitarbeiter seit 1971
} 
Packungskoeffizient, Gitterenergie) ableiten. Damit kann man Korrelationen zwischen Molekül- und Kristallstrukturen suchen. Gavezzotti nennt das den geometrischen Weg.

Andererseits muss wohl die Kristallstruktur einem Minimum eines geeigneten Potentials entsprechen. Es liesse sich argumentieren, man müsse nur alle möglichen Kristallstrukturen für ein Molekül generieren, deren potentielle Energie berechnen, um so das Minimum oder in Frage kommende Minima aufzuspüren. Der Umfang einer solchen Rechnerei verlangt allerdings nach Einschränkungen. Dabei geht Gavezzotti von der bekannten Tatsache aus, dass $74 \%$ aller organischen Kristallstrukturen sich auf nur 7 Raumgruppen aufteilen. Diese lassen sich durch Kombination von nur 3 Symmetrieoperatoren (Symmetriezentrum, Schraubenachse, Gleitspiegelebene) erzeugen. Für relativ einfache Moleküle ohne polare Gruppen lassen sich so in gewissen Fällen $a b$ initio Voraussagen machen, die mit der beobachteten Struktur gut übereinstimmen. Gavezzotti zeigte auch einige Voraussagen für Moleküle, deren Kristallstrukturen bis heute unbekannt sind.

Als Vertreter der ehemaligen Doktoranden der Dunitz-Gruppe sprach Prof. HansBeat Bürgi, Universität Bern, über 'Reaction Rate and Geometrical Structure'. Das Konzept der Entwicklung von Reaktionswegen aus Kristallstrukturdaten ist ein hervorragendes Ergebnis der jahrelangen Zusammenarbeit dieser beiden Forscher. Verständnis der chemischen Reaktivität bedingt Kenntnis der Zusammenhänge zwischen Struktur und Energie sowohl im Grund- wie im Übergangszustand. Be-

\section{Universität Bern}

Seminar in Anorganischer und Physikalischer Chemie Programm

für das Sommersemester 1990

Die Vorträge finden donnerstags um $11.15 \mathrm{Uhr}$ im Hörsaal S 481 statt. Andere Zeiten oder Hörsäle sind jeweils angegeben. Gäste willkommen!

\subsection{5 .90}

Prof. G. Wilke, Max-Planck-Institut für Kohlenforschung, Mülheim

'Catalytic Cyclooligomerizations of Olefins and Acetylenes by Titanium-, Chromium-, Cobald-, and Nicke] Complexes'

Freitag, 01.06.90, S 465

Prof. R. L. Carlin, University of Illinois, Chicago

'Low-temperature magnetism of $\mathrm{Cr}$ (III) and $\mathrm{Fe}$ (III) coordination compounds'

07.06 .90

Prof. M. Parrinello, IBM Forschungslaboratorium Zürich

'Ab initio Molecular Dynamics' (vorläufiger Titel)

14.06 .90

Frau Dr. Cornell, PSI

'Chemical Aspects of Disposal of Radioactive Vaste'

21.06 .90

Prof. R. Hoppe, Institut für anorg. und analytische Chemie, Justus-Liebig-Universität Giessen

'Das Periodensystem der Elemente als Richtschnur experimentellen Handelns: Neues über Metalloxide'

28.06 .90

Dr. O. Enea, CNRS, Université de Poitiers

'Metallized Membranes' kannt sind aber nur die Struktur im Grundzustand und die Höhe der Energiebarriere im Übergangszustand. Reaktionsgeschwindigkeiten für ähnliche Umwandlungen verwandter Moleküle unterscheiden sich oft um Grössenordnungen, während die Strukturunterschiede im Grundzustand im Bereich einiger Hundertstel $\AA$ liegen. Damit sind sehr kleine Effekte verantwortlich für sehr viel schnellere Reaktionen, also brechen leicht längere Bindungen viel schneller als etwas kürzere. Bürgi hat diese Zusammenhänge als Potentialenergiehyperflächen modelliert und festgestellt, dass die Unterschiede in den Energieoberflächen verwandter Moleküle als einfache Funktionen der Reaktionskoordinate darstellbar sind. Sie lassen sich somit als energetische Störungen des unterliegenden Reaktionsprofils betrachten. Das entwickelte Modell erlaubt die Vorhersagen von Reaktionsgeschwindigkeiten aus der Struktur im Grundzustand und der Geometrie im Übergangszustand aus ausschliesslich beobachtbaren Grössen. Anwendungen, auch auf Moleküle, die quantenchemischen Berechnungen gegenwärtig nicht zugänglich sind, betreffen das Aufbrechen und die Neubildung von Bindungen und Ligandaustausch bei Koordinationsverbindungen.

Den letzten Vortrag hielt Prof. Roald Hoffmann von der Cornell University. Unter dem Titel 'Waiting to be Made' stellte er eine ganze Reihe von Verbindungen vor, die bis jetzt noch nicht hergestellt wurden. Dabei handelte es sich um Weiterführungen bekannter Strukturen mit ein-, zweioder dreidimensionaler Periodizität, wie Schichten oder Stapel aus Thiolenen und Tetrathiolaten, Polymere aus $\mathrm{Pt}_{3} \mathrm{~L}_{6}$ mit

\section{Mittwoch-Chemie in Bern}

Chemische Institute, Universität Bern Freiestrasse 3, 3012 Bern

Vorträge jeweils 16.30, Hörsaal EG 16

Programm Sommersemester 1990

06. Juni, CIBe

Prof. E. Rickl

'Sequenzanalytik von Proteinen'

Prof. A. Ludi

'Rutheniumverbindungen - Neue Spezialitäten der Platinmetallchemie'

13. Juni, BCC

Dr. J. Stähelin, ETH Zürich

'Ist der Ozonschild in Gefahr? Diskussion anhand der langjährigen schweizerischen Messreihen'

20. Juni, CIBe

'Lumineszierende Komplexe'

Prof. W. Eichenberger

'Lipide in Pflanzen'

(Infochemie Nr. 4, 1990)
Prof. H.U. Güdel

oder ohne $\mathrm{Hg}$, Ketten aus $\mathrm{Ta}_{4} \mathrm{Te}_{4}$ mit Metalleinschlüssen, Bänder auf der Grundlage von Acetylenen und $\mathrm{Pt}$, oder eine $\mathrm{Te}-$ trahelix aus $\mathrm{ML}_{4}$-Tetraedern mit gemeinsamen Seiten.

Neben diesen Hauptvorträgen waren am 15. März über 25 Poster zu besichtigen, die einen Überblick gaben über die vielfältigen Möglichkeiten des Einsatzes kristallographischer Methoden zur Untersuchung strukturchemischer Probleme. Überhaupt machte diese Veranstaltung wieder einmal deutlich, wie die chemische Kristallographie, insbesondere die $\mathrm{Kri}-$ stallstrukturanalyse, von einem in den sechziger Jahren geheimnisvollen, zeitaufwendigen, wenigen Auserwählten vorbehaltenen Verfahren zu einer beinahe Routinemethode wurde. Dabei verschob sich der Schwerpunkt mehr und mehr in Richtung Interpretation von Resultaten, mithin auch von Strukturen zur Chemie.

Nach seriöser wissenschaftlicher Arbeit bot dieses Symposium ehemaligen und gegenwärtigen Mitgliedern der DunitzGruppe auch Gelegenheit, alte Freundschaften aufzufrischen und nostalgische Erinnerungen zu pflegen. Eine Party, im stimmigen Rahmen der mineralogisch-petrographischen Sammlung im NO-Gebäude der ETH vereinigte am 14. März etwa 120 Gäste, und an einem gemeinsamen Essen mit der Schweizerischen Chemischen Gesellschaft am 15. März wurden die Leistungen von Prof. Dunitz von dieser Seite gewürdigt. Nichts könnte die Stimmung besser beschreiben, als ein von Prof. Ken Trueblood verfasstes und vorgetragenes Gedicht, das in der Mitte dieses Berichtes steht.

Max Dobler

27. Juni, BCG

Prof. P. Schindler, Universität Bern

'Schwermetalle in der Umwelt'

BCG : Berner Chemische Gesellschaft

CIBe: Forschung an den Chemischen Instituten der Universität Bern, Kurzvorträge über aktuelle Forschungsthemen

\section{Energieverbrauch 1989 \\ der Schweizer Chemie}

I.C. - Der Energieverbrauch der schweizerischen chemischen Industrie ist im Jahr 1989 gegenüber dem Vorjahr um 1,7\% angestiegen, während der Produktionsindex der Schweizerischen Gesellschaft für Chemische Industrie (SGCI) im selben Zeitraum um 8,8\% zunahm. Damit bestätigt sich der Trend, wonach die chemische Industrie vor allem durch Sparmassnahmen und Verfahrensverbesserungen mit verhältnismässig weniger Energieaufwand mehr herstellt.

Dieser Trend geht auch aus der nachstehenden Aufstellung für die Jahre 1986-89 hervor:

\begin{tabular}{lllll}
\hline & 1986 & 1987 & 1988 & 1989 \\
\hline Energieverbrauch (in Tera Joules) & 24515 & 24174 & 24838 & 25266 \\
Produktionsindex SGCI & 123,9 & 124,3 & 134,8 & 146,6 \\
Energie/Produktion & 197,9 & 194,5 & 184,3 & 172,3 \\
\hline
\end{tabular}


Packungskoeffizient, Gitterenergie) ableiten. Damit kann man Korrelationen zwischen Molekül- und Kristallstrukturen suchen. Gavezzotti nennt das den geometrischen Weg.

Andererseits muss wohl die Kristallstruktur einem Minimum eines geeigneten Potentials entsprechen. Es liesse sich argumentieren, man müsse nur alle möglichen Kristallstrukturen für ein Molekül generieren, deren potentielle Energie berechnen, um so das Minimum oder in Frage kommende Minima aufzuspüren. Der Umfang einer solchen Rechnerei verlangt allerdings nach Einschränkungen. Dabei geht Gavezzotti von der bekannten Tatsache aus, dass $74 \%$ aller organischen Kristallstrukturen sich auf nur 7 Raumgruppen aufteilen. Diese lassen sich durch Kombination von nur 3 Symmetrieoperatoren (Symmetriezentrum, Schraubenachse, Gleitspiegelebene) erzeugen. Für relativ einfache Moleküle ohne polare Gruppen lassen sich so in gewissen Fällen $a b$ initio Voraussagen machen, die mit der beobachteten Struktur gut übereinstimmen. Gavezzotti zeigte auch einige Voraussagen für Moleküle, deren Kristallstrukturen bis heute unbekannt sind.

Als Vertreter der ehemaligen Doktoranden der Dunitz-Gruppe sprach Prof. HansBeat Bürgi, Universität Bern, über 'Reaction Rate and Geometrical Structure'. Das Konzept der Entwicklung von Reaktionswegen aus Kristallstrukturdaten ist ein hervorragendes Ergebnis der jahrelangen Zusammenarbeit dieser beiden Forscher. Verständnis der chemischen Reaktivität bedingt Kenntnis der Zusammenhänge zwischen Struktur und Energie sowohl im Grund- wie im Übergangszustand. Be-

\section{Universität Bern}

Seminar in Anorganischer und Physikalischer Chemie Programm

für das Sommersemester 1990

Die Vorträge finden donnerstags um $11.15 \mathrm{Uhr}$ im Hörsaal S 481 statt. Andere Zeiten oder Hörsäle sind jeweils angegeben. Gäste willkommen!

\subsection{5 .90}

Prof. G. Wilke, Max-Planck-Institut für Kohlenforschung, Mülheim

'Catalytic Cyclooligomerizations of Olefins and Acetylenes by Titanium-, Chromium-, Cobald-, and Nicke] Complexes'

Freitag, 01.06.90, S 465

Prof. R. L. Carlin, University of Illinois, Chicago

'Low-temperature magnetism of $\mathrm{Cr}$ (III) and $\mathrm{Fe}$ (III) coordination compounds'

07.06 .90

Prof. M. Parrinello, IBM Forschungslaboratorium Zürich

'Ab initio Molecular Dynamics' (vorläufiger Titel)

14.06 .90

Frau Dr. Cornell, PSI

'Chemical Aspects of Disposal of Radioactive Vaste'

21.06 .90

Prof. R. Hoppe, Institut für anorg. und analytische Chemie, Justus-Liebig-Universität Giessen

'Das Periodensystem der Elemente als Richtschnur experimentellen Handelns: Neues über Metalloxide'

28.06 .90

Dr. O. Enea, CNRS, Université de Poitiers

'Metallized Membranes' kannt sind aber nur die Struktur im Grundzustand und die Höhe der Energiebarriere im Übergangszustand. Reaktionsgeschwindigkeiten für ähnliche Umwandlungen verwandter Moleküle unterscheiden sich oft um Grössenordnungen, während die Strukturunterschiede im Grundzustand im Bereich einiger Hundertstel $\AA$ liegen. Damit sind sehr kleine Effekte verantwortlich für sehr viel schnellere Reaktionen, also brechen leicht längere Bindungen viel schneller als etwas kürzere. Bürgi hat diese Zusammenhänge als Potentialenergiehyperflächen modelliert und festgestellt, dass die Unterschiede in den Energieoberflächen verwandter Moleküle als einfache Funktionen der Reaktionskoordinate darstellbar sind. Sie lassen sich somit als energetische Störungen des unterliegenden Reaktionsprofils betrachten. Das entwickelte Modell erlaubt die Vorhersagen von Reaktionsgeschwindigkeiten aus der Struktur im Grundzustand und der Geometrie im Übergangszustand aus ausschliesslich beobachtbaren Grössen. Anwendungen, auch auf Moleküle, die quantenchemischen Berechnungen gegenwärtig nicht zugänglich sind, betreffen das Aufbrechen und die Neubildung von Bindungen und Ligandaustausch bei Koordinationsverbindungen.

Den letzten Vortrag hielt Prof. Roald Hoffmann von der Cornell University. Unter dem Titel 'Waiting to be Made' stellte er eine ganze Reihe von Verbindungen vor, die bis jetzt noch nicht hergestellt wurden. Dabei handelte es sich um Weiterführungen bekannter Strukturen mit ein-, zweioder dreidimensionaler Periodizität, wie Schichten oder Stapel aus Thiolenen und Tetrathiolaten, Polymere aus $\mathrm{Pt}_{3} \mathrm{~L}_{6}$ mit

\section{Mittwoch-Chemie in Bern}

Chemische Institute, Universität Bern Freiestrasse 3, 3012 Bern

Vorträge jeweils 16.30, Hörsaal EG 16

Programm Sommersemester 1990

06. Juni, CIBe

Prof. E. Rickl

'Sequenzanalytik von Proteinen'

Prof. A. Ludi

'Rutheniumverbindungen - Neue Spezialitäten der Platinmetallchemie'

13. Juni, BCC

Dr. J. Stähelin, ETH Zürich

'Ist der Ozonschild in Gefahr? Diskussion anhand der langjährigen schweizerischen Messreihen'

20. Juni, CIBe

'Lumineszierende Komplexe'

Prof. W. Eichenberger

'Lipide in Pflanzen'

(Infochemie Nr. 4, 1990)
Prof. H.U. Güdel

oder ohne $\mathrm{Hg}$, Ketten aus $\mathrm{Ta}_{4} \mathrm{Te}_{4}$ mit Metalleinschlüssen, Bänder auf der Grundlage von Acetylenen und $\mathrm{Pt}$, oder eine $\mathrm{Te}-$ trahelix aus $\mathrm{ML}_{4}$-Tetraedern mit gemeinsamen Seiten.

Neben diesen Hauptvorträgen waren am 15. März über 25 Poster zu besichtigen, die einen Überblick gaben über die vielfältigen Möglichkeiten des Einsatzes kristallographischer Methoden zur Untersuchung strukturchemischer Probleme. Überhaupt machte diese Veranstaltung wieder einmal deutlich, wie die chemische Kristallographie, insbesondere die $\mathrm{Kri}-$ stallstrukturanalyse, von einem in den sechziger Jahren geheimnisvollen, zeitaufwendigen, wenigen Auserwählten vorbehaltenen Verfahren zu einer beinahe Routinemethode wurde. Dabei verschob sich der Schwerpunkt mehr und mehr in Richtung Interpretation von Resultaten, mithin auch von Strukturen zur Chemie.

Nach seriöser wissenschaftlicher Arbeit bot dieses Symposium ehemaligen und gegenwärtigen Mitgliedern der DunitzGruppe auch Gelegenheit, alte Freundschaften aufzufrischen und nostalgische Erinnerungen zu pflegen. Eine Party, im stimmigen Rahmen der mineralogisch-petrographischen Sammlung im NO-Gebäude der ETH vereinigte am 14. März etwa 120 Gäste, und an einem gemeinsamen Essen mit der Schweizerischen Chemischen Gesellschaft am 15. März wurden die Leistungen von Prof. Dunitz von dieser Seite gewürdigt. Nichts könnte die Stimmung besser beschreiben, als ein von Prof. Ken Trueblood verfasstes und vorgetragenes Gedicht, das in der Mitte dieses Berichtes steht.

Max Dobler

27. Juni, BCG

Prof. P. Schindler, Universität Bern

'Schwermetalle in der Umwelt'

BCG : Berner Chemische Gesellschaft

CIBe: Forschung an den Chemischen Instituten der Universität Bern, Kurzvorträge über aktuelle Forschungsthemen

\section{Energieverbrauch 1989 \\ der Schweizer Chemie}

I.C. - Der Energieverbrauch der schweizerischen chemischen Industrie ist im Jahr 1989 gegenüber dem Vorjahr um 1,7\% angestiegen, während der Produktionsindex der Schweizerischen Gesellschaft für Chemische Industrie (SGCI) im selben Zeitraum um 8,8\% zunahm. Damit bestätigt sich der Trend, wonach die chemische Industrie vor allem durch Sparmassnahmen und Verfahrensverbesserungen mit verhältnismässig weniger Energieaufwand mehr herstellt.

Dieser Trend geht auch aus der nachstehenden Aufstellung für die Jahre 1986-89 hervor:

\begin{tabular}{lllll}
\hline & 1986 & 1987 & 1988 & 1989 \\
\hline Energieverbrauch (in Tera Joules) & 24515 & 24174 & 24838 & 25266 \\
Produktionsindex SGCI & 123,9 & 124,3 & 134,8 & 146,6 \\
Energie/Produktion & 197,9 & 194,5 & 184,3 & 172,3 \\
\hline
\end{tabular}


Packungskoeffizient, Gitterenergie) ableiten. Damit kann man Korrelationen zwischen Molekül- und Kristallstrukturen suchen. Gavezzotti nennt das den geometrischen Weg.

Andererseits muss wohl die Kristallstruktur einem Minimum eines geeigneten Potentials entsprechen. Es liesse sich argumentieren, man müsse nur alle möglichen Kristallstrukturen für ein Molekül generieren, deren potentielle Energie berechnen, um so das Minimum oder in Frage kommende Minima aufzuspüren. Der Umfang einer solchen Rechnerei verlangt allerdings nach Einschränkungen. Dabei geht Gavezzotti von der bekannten Tatsache aus, dass $74 \%$ aller organischen Kristallstrukturen sich auf nur 7 Raumgruppen aufteilen. Diese lassen sich durch Kombination von nur 3 Symmetrieoperatoren (Symmetriezentrum, Schraubenachse, Gleitspiegelebene) erzeugen. Für relativ einfache Moleküle ohne polare Gruppen lassen sich so in gewissen Fällen $a b$ initio Voraussagen machen, die mit der beobachteten Struktur gut übereinstimmen. Gavezzotti zeigte auch einige Voraussagen für Moleküle, deren Kristallstrukturen bis heute unbekannt sind.

Als Vertreter der ehemaligen Doktoranden der Dunitz-Gruppe sprach Prof. HansBeat Bürgi, Universität Bern, über 'Reaction Rate and Geometrical Structure'. Das Konzept der Entwicklung von Reaktionswegen aus Kristallstrukturdaten ist ein hervorragendes Ergebnis der jahrelangen Zusammenarbeit dieser beiden Forscher. Verständnis der chemischen Reaktivität bedingt Kenntnis der Zusammenhänge zwischen Struktur und Energie sowohl im Grund- wie im Übergangszustand. Be-

\section{Universität Bern}

Seminar in Anorganischer und Physikalischer Chemie Programm

für das Sommersemester 1990

Die Vorträge finden donnerstags um $11.15 \mathrm{Uhr}$ im Hörsaal S 481 statt. Andere Zeiten oder Hörsäle sind jeweils angegeben. Gäste willkommen!

\subsection{5 .90}

Prof. G. Wilke, Max-Planck-Institut für Kohlenforschung, Mülheim

'Catalytic Cyclooligomerizations of Olefins and Acetylenes by Titanium-, Chromium-, Cobald-, and Nicke] Complexes'

Freitag, 01.06.90, S 465

Prof. R. L. Carlin, University of Illinois, Chicago

'Low-temperature magnetism of $\mathrm{Cr}$ (III) and $\mathrm{Fe}$ (III) coordination compounds'

07.06 .90

Prof. M. Parrinello, IBM Forschungslaboratorium Zürich

'Ab initio Molecular Dynamics' (vorläufiger Titel)

14.06 .90

Frau Dr. Cornell, PSI

'Chemical Aspects of Disposal of Radioactive Vaste'

21.06 .90

Prof. R. Hoppe, Institut für anorg. und analytische Chemie, Justus-Liebig-Universität Giessen

'Das Periodensystem der Elemente als Richtschnur experimentellen Handelns: Neues über Metalloxide'

28.06 .90

Dr. O. Enea, CNRS, Université de Poitiers

'Metallized Membranes' kannt sind aber nur die Struktur im Grundzustand und die Höhe der Energiebarriere im Übergangszustand. Reaktionsgeschwindigkeiten für ähnliche Umwandlungen verwandter Moleküle unterscheiden sich oft um Grössenordnungen, während die Strukturunterschiede im Grundzustand im Bereich einiger Hundertstel $\AA$ liegen. Damit sind sehr kleine Effekte verantwortlich für sehr viel schnellere Reaktionen, also brechen leicht längere Bindungen viel schneller als etwas kürzere. Bürgi hat diese Zusammenhänge als Potentialenergiehyperflächen modelliert und festgestellt, dass die Unterschiede in den Energieoberflächen verwandter Moleküle als einfache Funktionen der Reaktionskoordinate darstellbar sind. Sie lassen sich somit als energetische Störungen des unterliegenden Reaktionsprofils betrachten. Das entwickelte Modell erlaubt die Vorhersagen von Reaktionsgeschwindigkeiten aus der Struktur im Grundzustand und der Geometrie im Übergangszustand aus ausschliesslich beobachtbaren Grössen. Anwendungen, auch auf Moleküle, die quantenchemischen Berechnungen gegenwärtig nicht zugänglich sind, betreffen das Aufbrechen und die Neubildung von Bindungen und Ligandaustausch bei Koordinationsverbindungen.

Den letzten Vortrag hielt Prof. Roald Hoffmann von der Cornell University. Unter dem Titel 'Waiting to be Made' stellte er eine ganze Reihe von Verbindungen vor, die bis jetzt noch nicht hergestellt wurden. Dabei handelte es sich um Weiterführungen bekannter Strukturen mit ein-, zweioder dreidimensionaler Periodizität, wie Schichten oder Stapel aus Thiolenen und Tetrathiolaten, Polymere aus $\mathrm{Pt}_{3} \mathrm{~L}_{6}$ mit

\section{Mittwoch-Chemie in Bern}

Chemische Institute, Universität Bern Freiestrasse 3, 3012 Bern

Vorträge jeweils 16.30, Hörsaal EG 16

Programm Sommersemester 1990

06. Juni, CIBe

Prof. E. Rickl

'Sequenzanalytik von Proteinen'

Prof. A. Ludi

'Rutheniumverbindungen - Neue Spezialitäten der Platinmetallchemie'

13. Juni, BCC

Dr. J. Stähelin, ETH Zürich

'Ist der Ozonschild in Gefahr? Diskussion anhand der langjährigen schweizerischen Messreihen'

20. Juni, CIBe

'Lumineszierende Komplexe'

Prof. W. Eichenberger

'Lipide in Pflanzen'

(Infochemie Nr. 4, 1990)
Prof. H.U. Güdel

oder ohne $\mathrm{Hg}$, Ketten aus $\mathrm{Ta}_{4} \mathrm{Te}_{4}$ mit Metalleinschlüssen, Bänder auf der Grundlage von Acetylenen und $\mathrm{Pt}$, oder eine $\mathrm{Te}-$ trahelix aus $\mathrm{ML}_{4}$-Tetraedern mit gemeinsamen Seiten.

Neben diesen Hauptvorträgen waren am 15. März über 25 Poster zu besichtigen, die einen Überblick gaben über die vielfältigen Möglichkeiten des Einsatzes kristallographischer Methoden zur Untersuchung strukturchemischer Probleme. Überhaupt machte diese Veranstaltung wieder einmal deutlich, wie die chemische Kristallographie, insbesondere die $\mathrm{Kri}-$ stallstrukturanalyse, von einem in den sechziger Jahren geheimnisvollen, zeitaufwendigen, wenigen Auserwählten vorbehaltenen Verfahren zu einer beinahe Routinemethode wurde. Dabei verschob sich der Schwerpunkt mehr und mehr in Richtung Interpretation von Resultaten, mithin auch von Strukturen zur Chemie.

Nach seriöser wissenschaftlicher Arbeit bot dieses Symposium ehemaligen und gegenwärtigen Mitgliedern der DunitzGruppe auch Gelegenheit, alte Freundschaften aufzufrischen und nostalgische Erinnerungen zu pflegen. Eine Party, im stimmigen Rahmen der mineralogisch-petrographischen Sammlung im NO-Gebäude der ETH vereinigte am 14. März etwa 120 Gäste, und an einem gemeinsamen Essen mit der Schweizerischen Chemischen Gesellschaft am 15. März wurden die Leistungen von Prof. Dunitz von dieser Seite gewürdigt. Nichts könnte die Stimmung besser beschreiben, als ein von Prof. Ken Trueblood verfasstes und vorgetragenes Gedicht, das in der Mitte dieses Berichtes steht.

Max Dobler

27. Juni, BCG

Prof. P. Schindler, Universität Bern

'Schwermetalle in der Umwelt'

BCG : Berner Chemische Gesellschaft

CIBe: Forschung an den Chemischen Instituten der Universität Bern, Kurzvorträge über aktuelle Forschungsthemen

\section{Energieverbrauch 1989 \\ der Schweizer Chemie}

I.C. - Der Energieverbrauch der schweizerischen chemischen Industrie ist im Jahr 1989 gegenüber dem Vorjahr um 1,7\% angestiegen, während der Produktionsindex der Schweizerischen Gesellschaft für Chemische Industrie (SGCI) im selben Zeitraum um 8,8\% zunahm. Damit bestätigt sich der Trend, wonach die chemische Industrie vor allem durch Sparmassnahmen und Verfahrensverbesserungen mit verhältnismässig weniger Energieaufwand mehr herstellt.

Dieser Trend geht auch aus der nachstehenden Aufstellung für die Jahre 1986-89 hervor:

\begin{tabular}{lllll}
\hline & 1986 & 1987 & 1988 & 1989 \\
\hline Energieverbrauch (in Tera Joules) & 24515 & 24174 & 24838 & 25266 \\
Produktionsindex SGCI & 123,9 & 124,3 & 134,8 & 146,6 \\
Energie/Produktion & 197,9 & 194,5 & 184,3 & 172,3 \\
\hline
\end{tabular}


Packungskoeffizient, Gitterenergie) ableiten. Damit kann man Korrelationen zwischen Molekül- und Kristallstrukturen suchen. Gavezzotti nennt das den geometrischen Weg.

Andererseits muss wohl die Kristallstruktur einem Minimum eines geeigneten Potentials entsprechen. Es liesse sich argumentieren, man müsse nur alle möglichen Kristallstrukturen für ein Molekül generieren, deren potentielle Energie berechnen, um so das Minimum oder in Frage kommende Minima aufzuspüren. Der Umfang einer solchen Rechnerei verlangt allerdings nach Einschränkungen. Dabei geht Gavezzotti von der bekannten Tatsache aus, dass $74 \%$ aller organischen Kristallstrukturen sich auf nur 7 Raumgruppen aufteilen. Diese lassen sich durch Kombination von nur 3 Symmetrieoperatoren (Symmetriezentrum, Schraubenachse, Gleitspiegelebene) erzeugen. Für relativ einfache Moleküle ohne polare Gruppen lassen sich so in gewissen Fällen $a b$ initio Voraussagen machen, die mit der beobachteten Struktur gut übereinstimmen. Gavezzotti zeigte auch einige Voraussagen für Moleküle, deren Kristallstrukturen bis heute unbekannt sind.

Als Vertreter der ehemaligen Doktoranden der Dunitz-Gruppe sprach Prof. HansBeat Bürgi, Universität Bern, über 'Reaction Rate and Geometrical Structure'. Das Konzept der Entwicklung von Reaktionswegen aus Kristallstrukturdaten ist ein hervorragendes Ergebnis der jahrelangen Zusammenarbeit dieser beiden Forscher. Verständnis der chemischen Reaktivität bedingt Kenntnis der Zusammenhänge zwischen Struktur und Energie sowohl im Grund- wie im Übergangszustand. Be-

\section{Universität Bern}

Seminar in Anorganischer und Physikalischer Chemie Programm

für das Sommersemester 1990

Die Vorträge finden donnerstags um $11.15 \mathrm{Uhr}$ im Hörsaal S 481 statt. Andere Zeiten oder Hörsäle sind jeweils angegeben. Gäste willkommen!

\subsection{5 .90}

Prof. G. Wilke, Max-Planck-Institut für Kohlenforschung, Mülheim

'Catalytic Cyclooligomerizations of Olefins and Acetylenes by Titanium-, Chromium-, Cobald-, and Nicke] Complexes'

Freitag, 01.06.90, S 465

Prof. R. L. Carlin, University of Illinois, Chicago

'Low-temperature magnetism of $\mathrm{Cr}$ (III) and $\mathrm{Fe}$ (III) coordination compounds'

07.06 .90

Prof. M. Parrinello, IBM Forschungslaboratorium Zürich

'Ab initio Molecular Dynamics' (vorläufiger Titel)

14.06 .90

Frau Dr. Cornell, PSI

'Chemical Aspects of Disposal of Radioactive Vaste'

21.06 .90

Prof. R. Hoppe, Institut für anorg. und analytische Chemie, Justus-Liebig-Universität Giessen

'Das Periodensystem der Elemente als Richtschnur experimentellen Handelns: Neues über Metalloxide'

28.06 .90

Dr. O. Enea, CNRS, Université de Poitiers

'Metallized Membranes' kannt sind aber nur die Struktur im Grundzustand und die Höhe der Energiebarriere im Übergangszustand. Reaktionsgeschwindigkeiten für ähnliche Umwandlungen verwandter Moleküle unterscheiden sich oft um Grössenordnungen, während die Strukturunterschiede im Grundzustand im Bereich einiger Hundertstel $\AA$ liegen. Damit sind sehr kleine Effekte verantwortlich für sehr viel schnellere Reaktionen, also brechen leicht längere Bindungen viel schneller als etwas kürzere. Bürgi hat diese Zusammenhänge als Potentialenergiehyperflächen modelliert und festgestellt, dass die Unterschiede in den Energieoberflächen verwandter Moleküle als einfache Funktionen der Reaktionskoordinate darstellbar sind. Sie lassen sich somit als energetische Störungen des unterliegenden Reaktionsprofils betrachten. Das entwickelte Modell erlaubt die Vorhersagen von Reaktionsgeschwindigkeiten aus der Struktur im Grundzustand und der Geometrie im Übergangszustand aus ausschliesslich beobachtbaren Grössen. Anwendungen, auch auf Moleküle, die quantenchemischen Berechnungen gegenwärtig nicht zugänglich sind, betreffen das Aufbrechen und die Neubildung von Bindungen und Ligandaustausch bei Koordinationsverbindungen.

Den letzten Vortrag hielt Prof. Roald Hoffmann von der Cornell University. Unter dem Titel 'Waiting to be Made' stellte er eine ganze Reihe von Verbindungen vor, die bis jetzt noch nicht hergestellt wurden. Dabei handelte es sich um Weiterführungen bekannter Strukturen mit ein-, zweioder dreidimensionaler Periodizität, wie Schichten oder Stapel aus Thiolenen und Tetrathiolaten, Polymere aus $\mathrm{Pt}_{3} \mathrm{~L}_{6}$ mit

\section{Mittwoch-Chemie in Bern}

Chemische Institute, Universität Bern Freiestrasse 3, 3012 Bern

Vorträge jeweils 16.30, Hörsaal EG 16

Programm Sommersemester 1990

06. Juni, CIBe

Prof. E. Rickl

'Sequenzanalytik von Proteinen'

Prof. A. Ludi

'Rutheniumverbindungen - Neue Spezialitäten der Platinmetallchemie'

13. Juni, BCC

Dr. J. Stähelin, ETH Zürich

'Ist der Ozonschild in Gefahr? Diskussion anhand der langjährigen schweizerischen Messreihen'

20. Juni, CIBe

'Lumineszierende Komplexe'

Prof. W. Eichenberger

'Lipide in Pflanzen'

(Infochemie Nr. 4, 1990)
Prof. H.U. Güdel

oder ohne $\mathrm{Hg}$, Ketten aus $\mathrm{Ta}_{4} \mathrm{Te}_{4}$ mit Metalleinschlüssen, Bänder auf der Grundlage von Acetylenen und $\mathrm{Pt}$, oder eine $\mathrm{Te}-$ trahelix aus $\mathrm{ML}_{4}$-Tetraedern mit gemeinsamen Seiten.

Neben diesen Hauptvorträgen waren am 15. März über 25 Poster zu besichtigen, die einen Überblick gaben über die vielfältigen Möglichkeiten des Einsatzes kristallographischer Methoden zur Untersuchung strukturchemischer Probleme. Überhaupt machte diese Veranstaltung wieder einmal deutlich, wie die chemische Kristallographie, insbesondere die $\mathrm{Kri}-$ stallstrukturanalyse, von einem in den sechziger Jahren geheimnisvollen, zeitaufwendigen, wenigen Auserwählten vorbehaltenen Verfahren zu einer beinahe Routinemethode wurde. Dabei verschob sich der Schwerpunkt mehr und mehr in Richtung Interpretation von Resultaten, mithin auch von Strukturen zur Chemie.

Nach seriöser wissenschaftlicher Arbeit bot dieses Symposium ehemaligen und gegenwärtigen Mitgliedern der DunitzGruppe auch Gelegenheit, alte Freundschaften aufzufrischen und nostalgische Erinnerungen zu pflegen. Eine Party, im stimmigen Rahmen der mineralogisch-petrographischen Sammlung im NO-Gebäude der ETH vereinigte am 14. März etwa 120 Gäste, und an einem gemeinsamen Essen mit der Schweizerischen Chemischen Gesellschaft am 15. März wurden die Leistungen von Prof. Dunitz von dieser Seite gewürdigt. Nichts könnte die Stimmung besser beschreiben, als ein von Prof. Ken Trueblood verfasstes und vorgetragenes Gedicht, das in der Mitte dieses Berichtes steht.

Max Dobler

27. Juni, BCG

Prof. P. Schindler, Universität Bern

'Schwermetalle in der Umwelt'

BCG : Berner Chemische Gesellschaft

CIBe: Forschung an den Chemischen Instituten der Universität Bern, Kurzvorträge über aktuelle Forschungsthemen

\section{Energieverbrauch 1989 \\ der Schweizer Chemie}

I.C. - Der Energieverbrauch der schweizerischen chemischen Industrie ist im Jahr 1989 gegenüber dem Vorjahr um 1,7\% angestiegen, während der Produktionsindex der Schweizerischen Gesellschaft für Chemische Industrie (SGCI) im selben Zeitraum um 8,8\% zunahm. Damit bestätigt sich der Trend, wonach die chemische Industrie vor allem durch Sparmassnahmen und Verfahrensverbesserungen mit verhältnismässig weniger Energieaufwand mehr herstellt.

Dieser Trend geht auch aus der nachstehenden Aufstellung für die Jahre 1986-89 hervor:

\begin{tabular}{lllll}
\hline & 1986 & 1987 & 1988 & 1989 \\
\hline Energieverbrauch (in Tera Joules) & 24515 & 24174 & 24838 & 25266 \\
Produktionsindex SGCI & 123,9 & 124,3 & 134,8 & 146,6 \\
Energie/Produktion & 197,9 & 194,5 & 184,3 & 172,3 \\
\hline
\end{tabular}




\section{'Trends in Organic Chemistry'}

\section{Frühjahrssymposium}

der Schweizerischen Chemischen Gesellschaft (SCG) gemeinsam mit dem Schweizerischen Chemiker-Verband (SChV) 16. März 1990 an der ETH in Zürich

Supramolecular Chemistry: From Molecular Recognition towards Molecular Devices and Self-Organization

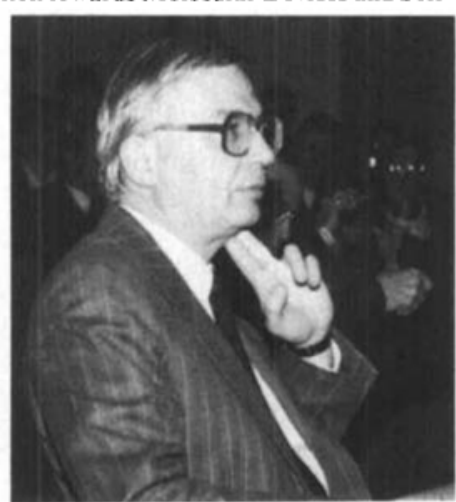

\section{Jean-Marie Lehn}

Université Louis Pasteur, Strasbourg and Collège de France, Paris, France

Molecular recognition rests on the molecular information stored in the interacting species. Together with catalysis and transport, and in combination with polymolecular organization, it opens ways towards molecular and supramolecular devices, defined as structurally organized and functionally integrated chemical systems built on supramolecular architectures. The development of such devices requires the design of molecular components performing a given function (e.g. photoactive, electroactive, ionoactive, thermoactive or chemoactive) and suitable for assembly into an organized array.

Light-conversion devices as well as approaches towards molecular electronic and ionic devices have been investigated.

Of special interest is the possibility to design devices that may form by molecular self-assembling.

Supramolecular chemistry has relied on more or less pre-organized molecular receptors for effecting molecular recognition, catalysis and transport processes. A step beyond consists in the design of systems undergoing self-organization, i.e. systems capable of spontaneously generating a well-defined supramolecular architecture by self-assembling from their components in given set of conditions. The information necessary for the process to take place must be stored in the components and performs via selective molecular interactions. Thus, these programmed molecular systems operate via molecular recognition.

This is the case in particular for the formation of double helical metal complexes, the helicates, from two oligobipyridine strands and copper(I) ions. These compounds also provide a framework for organizing various substituents in space. Thus, the attachment of thymidine groups resulted in the formation of double stranded oligonucleosidic complexes of deoxyribonucleo helicate, DNH, type which represent 'inverted' analogues of nucleic acids. (Abstract by the Author)

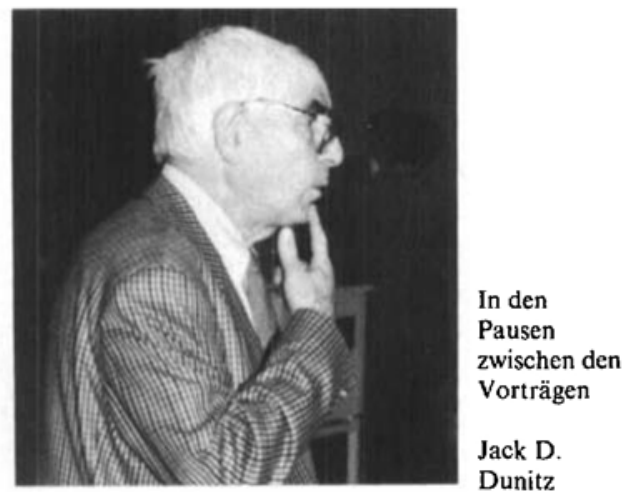

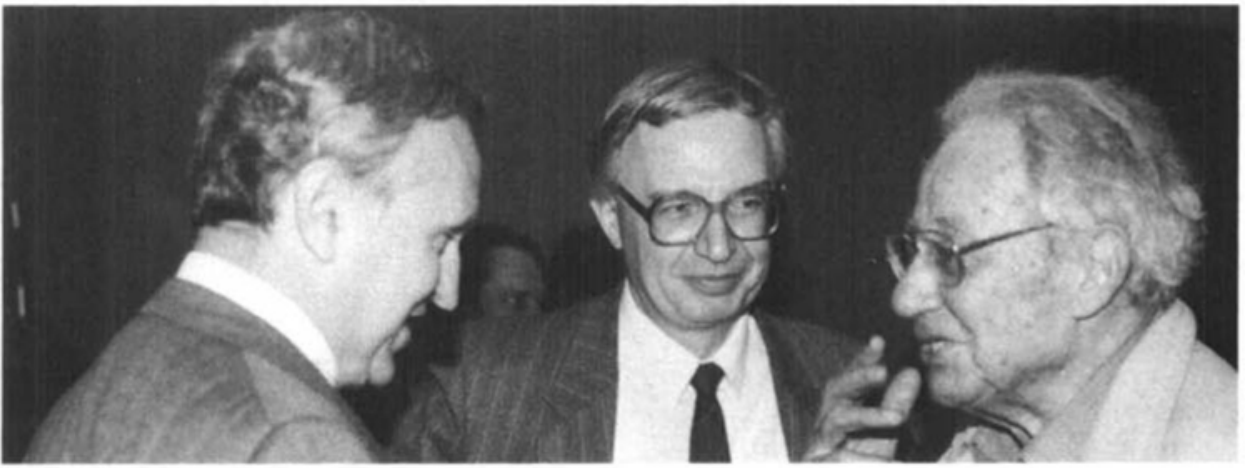

Ronald Breslow

Jean-Marie Lehn

Tadeus Reichstein

The Chelate Effect: Binding, Catalysis, and Chemotherapy

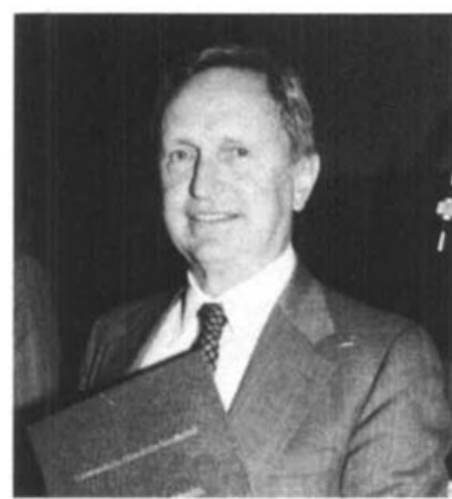

Ronald Breslow

Columbia University, New York, USA

Molecules that can doubly interact with substrate may show very strong binding or catalysis. When two cyclodextrins are linked, the resulting chelation of substrates produces binding constants up to $10^{9} \mathrm{M}^{-1}$ or greater, comparable to many antibodies. Cyclodextrin bis-imidazoles can catalyze the hydrolysis of a bound substrate with simultaneous two-proton transfer mechanisms, isotope effects, and rates similar to those of the enzyme ribonuclease. The correct geometry for bifunctional catalysis was designed based on mechanistic studies. The chelate effect is also useful in the design of cytodifferentiating agents, some of which show promise in the treatment of cancer.

(Abstract by the Author)

Recognition and Catalysis with Model Systems

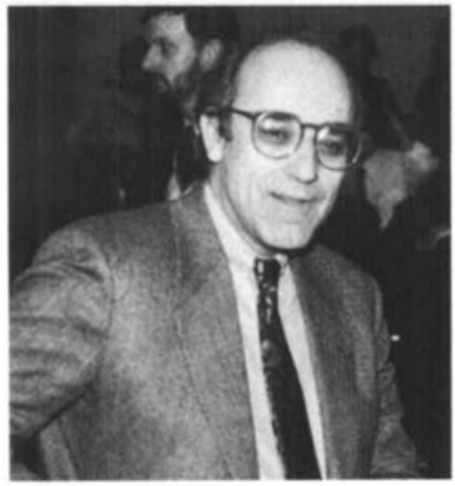

Julius Rebek, jr

Massachusetts Institute of Technology, Cambridge, USA

The development of cleft-like structures as mode systems for molecular recognition was described. The structures feature convergent functional groups having moderately directional hydrogen bonding arrays, held apart by rigid aromatic spacers of varying sizes and shapes. Synthetic receptors with high affinity for smal biologically relevant targets such as peptides and nu- cleotides were described. Their use as catalysts, particularly in the context of self-replicating systems was discussed and applications in organic synthesis as chiral auxiliaries were developed. The lecture appeared as a review in the March, 1990 edition of Angewande Che mie.

Abstract by the Author)

Molecular Recognition of the Immunophilins

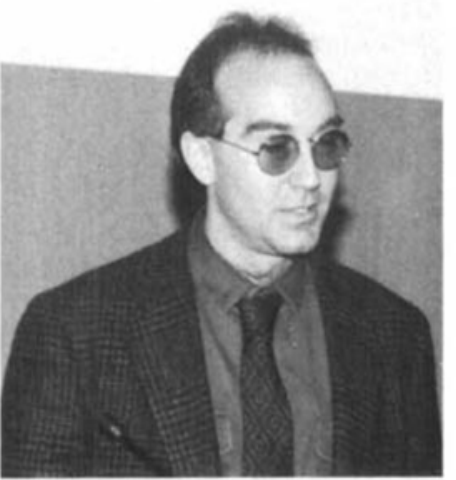

Stuart L. Schreiber

Harvard University, Cambridge, USA

Immunoorganic Chemistry is a term that refers to the research opportunities that exist at the interface of immunology and organic chemistry. One example that is under investigation at Harvard concerns the mechanisms by which signals are transduced between the membrane and the nucleus of the T cell, the so-called black box of the signal transduction cascade. A powerful system for probing the molecular details of this process has been discovered in the form of the $T$ cell signalling inhibitor and immunosuppressant FK506 and its cognate cellular receptor, FKBP. FKBP was found to function as a rotamase enzyme that is potently inhibited by FK506. The chemical synthesis of ${ }^{13} \mathrm{C}$ labeled-FK506 and the biogenic synthesis of FKBP has allowed the first detailed examination of the inhibitory mechanisms of these agents and the basis for their molecular recognition. (Abstract by the Author)

Catalytic Antibodies

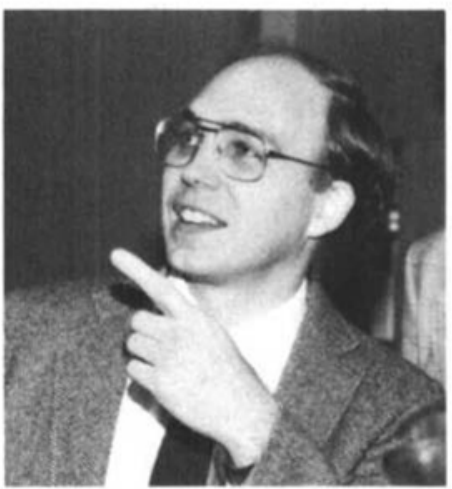

Peter G. Schultz

University of California, Berkeley, USA 


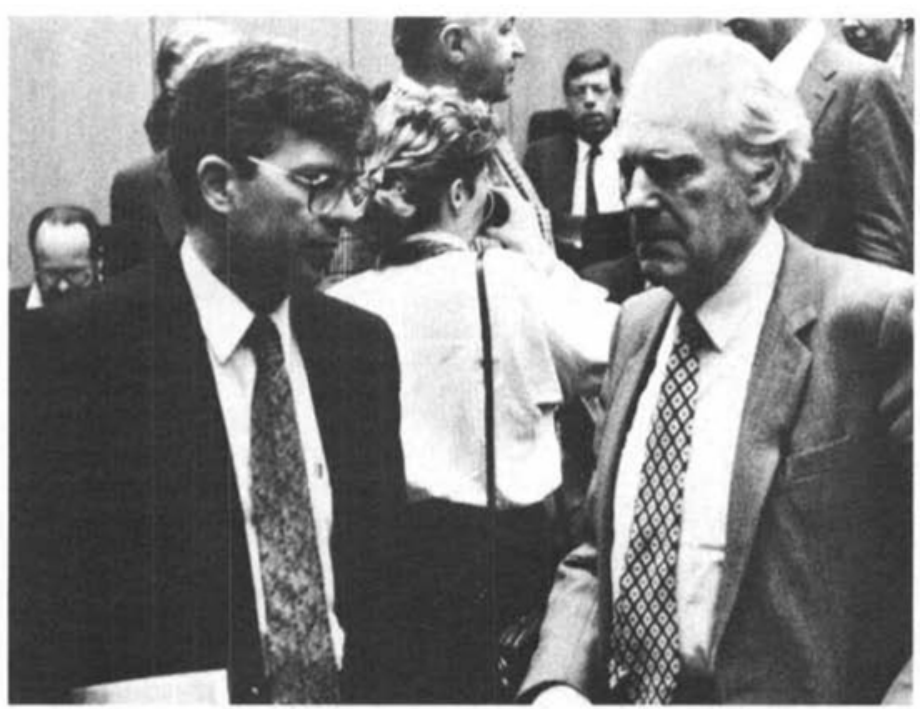

Heinz Frei mit seinem ehemaligen Doktorvater Hans H. Günthard

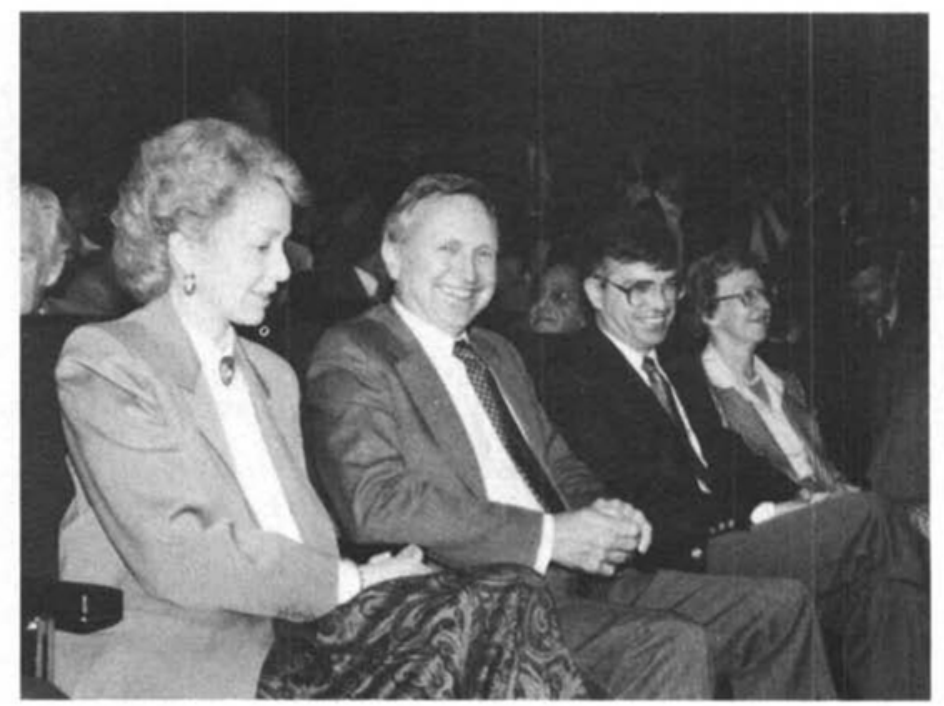

Ronald Breslow mit seiner Gattin
The diversity (over $10^{8}$ molecules in the primary repertoire) and specificity of the immune system have been merged with our understanding of chemical processes to generate catalytic antibodies. Antibodies have been generated that selectively catalyze ester hydrolysis, thymine dimer cleavage, Claisen and Diels-Alder reactions, redox reactions, metallation and elimination reactions. Several strategies have been applied to the generation of catalytic antibodies including transition state stabilization, proximity effects, general base catalysis, mutagenesis and semisynthesis, and the generation of antibodies with cofactor binding sites. This work may not only lead to the development of tailormade catalysts for medical, biological and chemical applications, but is also providing insight into the fundamental mechanisms of enzymic catalysis.

(Abstract by the Author)

(Fotos: K. Zimmermann D. Felix)

\section{Ehrungen}

der Schweizerischen Chemischen Gesellschaft (SCG) anlässlich der Frühjahrsversammlung 16. März 1990 an der ETH in Zürich

Der Präsident verlieh im Namen der SCG den Paracelsus-Preis mit Medaille an Prof. Ronald Breslow (Columbia University, New York) 'in Anerkennung seiner Pionierarbeiten auf dem Gebiet der bio-organischen Chemie' und den Werner-Preis mit Medaille an Dr. Heinz Frei (University of California, Berkeley) 'für seine bedeutenden Beiträge zur Photochemie im Spektralgebiet zwischen sichtbarem Licht und Infrarot'.

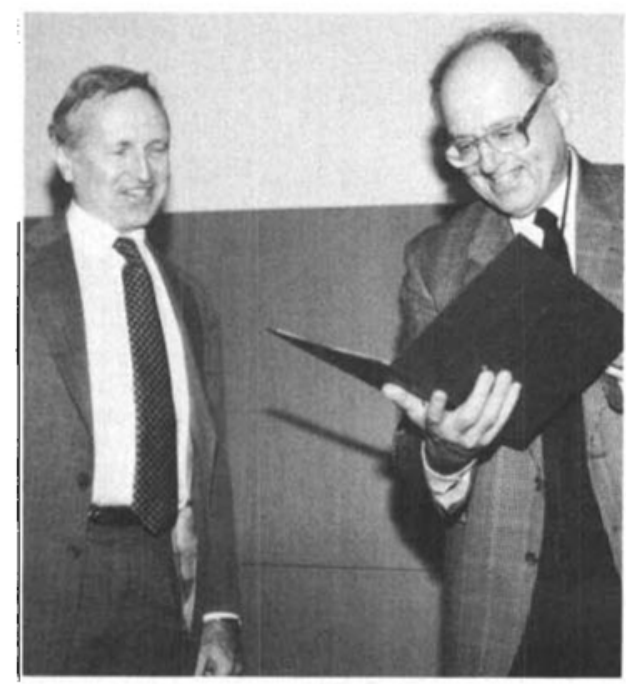

Ronald Breslow

Albert Eschenmoser

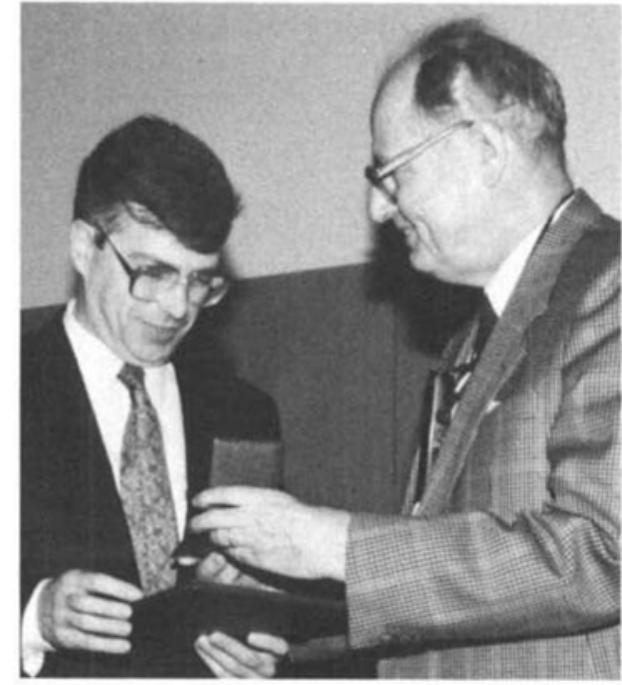

\section{Personalia}

\section{Geburtstage}

Hansjakob Stäger, Dr. sc. techn., Zürich, Mitglied des SChV, feiert am 5.6.90 seinen 65. Geburtstag.

Frank Barfuss, Chemiker HTL, Basel, Mitglied des SChV, feiert am 3.6.90 seinen 70. Geburtstag.

Max Müller-Zimmerli, Chemiker HTL, Langnau a.A., Mitglied des SChV, feiert am 13.6.90 seinen 70. Geburtstag.

Paul Koller, dipl. Chem. TW, St. Gallen, Mitglied des SChV, feiert am 14.6 .90 seinen 70 . Geburtstag.

Hans Georg Erne, Dr. sc. techn., Zürich, Mitglied des SChV, feicrt am 23.6.90 seinen 70. Gcburtstag.

\section{Schweizerischer Chemiker-Verband Swiss Association of Chemists \\ Polymer-Gruppe der Schweiz Polymer Group of Switzerland Schweizerische Chemische Gesellschaft Swiss Chemical Society}

\section{0th International Macromolecular Symposium}

September 20/21, 1990, Interlaken - Switzerland

\section{Polymer Surfaces and Interfaces - Key to High Performance Materials}

Chairman: Dr. Roland Darms

Scientific Committee: Dr Roland Darms, CibaGeigy AG, Marly/Fribourg; Prof. H. J. Kausch, Ecole Polytechnique Fédérale Lausanne; Prof. J. Meissner, Eidg. Technische Hochschule Zürich; Prof. P. Müller, Schweizerischer Chemiker-Verband; Prof. M. Neuenschwander, Universität Bern; Prof. P. Pino †, Eidg. Technische Hochschule Zürich; Prof. U. Suter, Eidg. Technische Hochschule Zürich; Dr. H.J. Schultze, EMS-Chemie, Domat/Ems.

Programme

September 20, 1990

9.00

$9.15-10.15$

$10.15-10.45$

$10.45-11.45$

$11.45-12.45$
Opening of the Symposium General

Prof. G.M. Whitesides, Harvard University, Department of Chemistry, Cambridge, USA

'The Physical-Organic Chemistry of Interfaces'

Coffec break

Dr. Th. Russell, IBM Almaden Research Center, San Jose, USA

Methods for the Characterization of Polymer Surfaces and Interfaces'

Prof. G. Wegner, Max Planck-Institut für Polymerforschung, Mainz, FRG 'Molecular Architecture of Well Defined Surfaces and Interphases of Organic and Polymer Materials' 


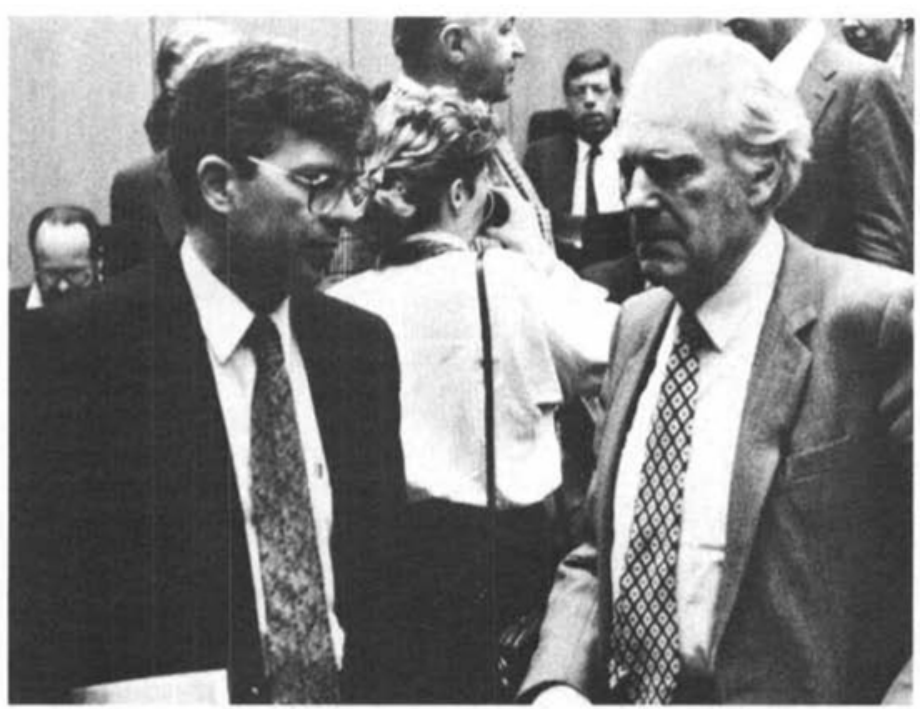

Heinz Frei mit seinem ehemaligen Doktorvater Hans H. Günthard

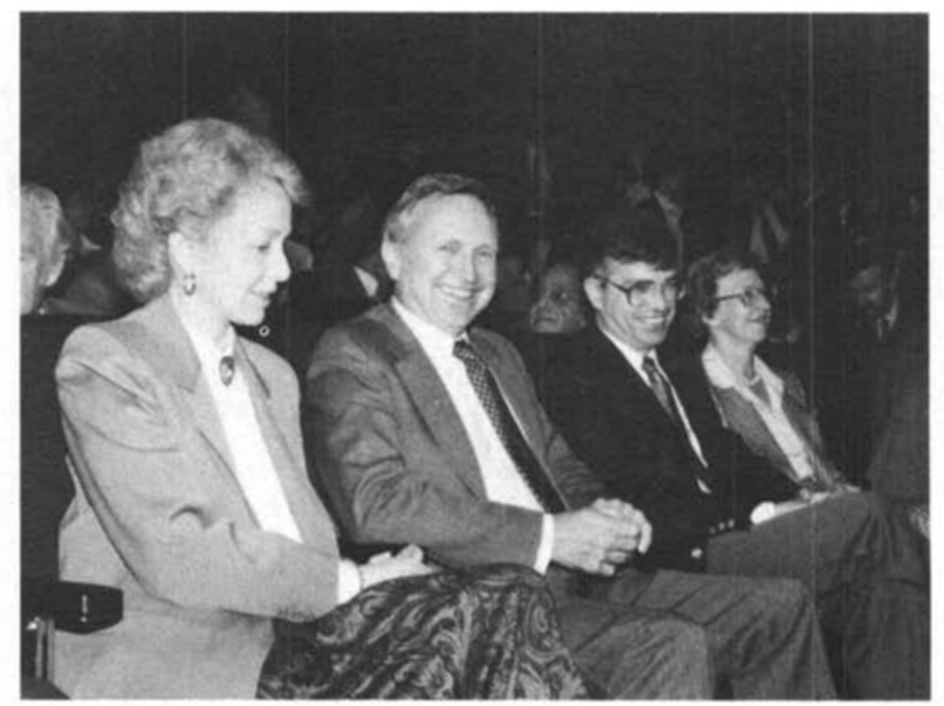

Ronald Breslow mit seiner Gattin
The diversity (over $10^{8}$ molecules in the primary repertoire) and specificity of the immune system have been merged with our understanding of chemical processes to generate catalytic antibodies. Antibodies have been generated that selectively catalyze ester hydrolysis, thymine dimer cleavage, Claisen and Diels-Alder reactions, redox reactions, metallation and elimination reactions. Several strategies have been applied to the generation of catalytic antibodies including transition state stabilization, proximity effects, general base catalysis, mutagenesis and semisynthesis, and the generation of antibodies with cofactor binding sites. This work may not only lead to the development of tailormade catalysts for medical, biological and chemical applications, but is also providing insight into the fundamental mechanisms of enzymic catalysis.

(Abstract by the Author)

(Fotos: K. Zimmermann D. Felix)

\section{Ehrungen}

der Schweizerischen Chemischen Gesellschaft (SCG) anlässlich der Frühjahrsversammlung 16. März 1990 an der ETH in Zürich

Der Präsident verlieh im Namen der SCG den Paracelsus-Preis mit Medaille an Prof. Ronald Breslow (Columbia University, New York) 'in Anerkennung seiner Pionierarbeiten auf dem Gebiet der bio-organischen Chemie' und den Werner-Preis mit Medaille an Dr. Heinz Frei (University of California, Berkeley) 'für seine bedeutenden Beiträge zur Photochemie im Spektralgebiet zwischen sichtbarem Licht und Infrarot'.

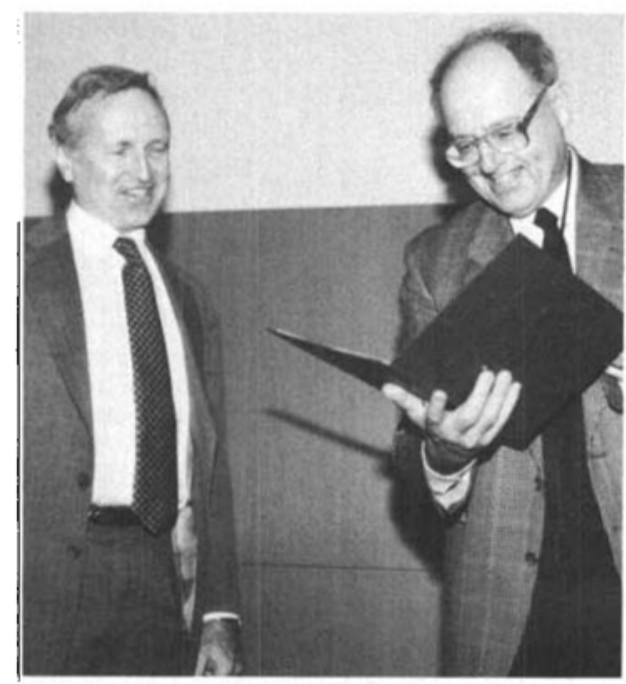

Ronald Breslow

Albert Eschenmoser

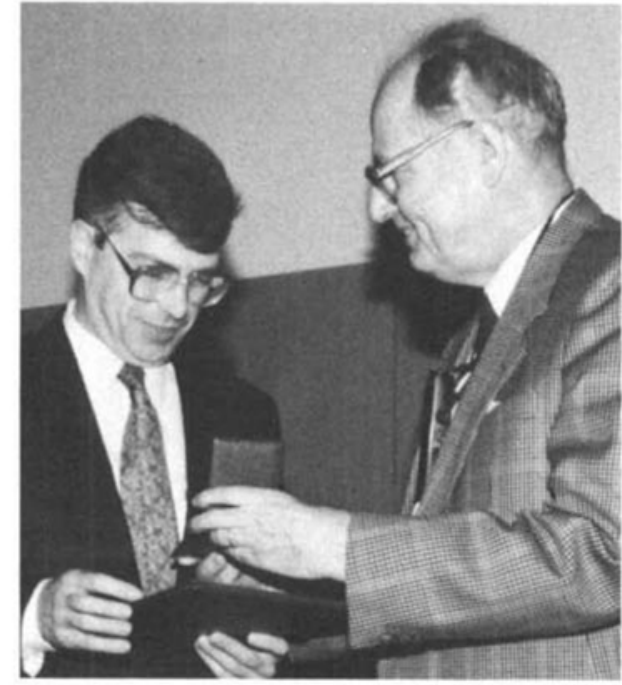

\section{Personalia}

\section{Geburtstage}

Hansjakob Stäger, Dr. sc. techn., Zürich, Mitglied des SChV, feiert am 5.6.90 seinen 65. Geburtstag.

Frank Barfuss, Chemiker HTL, Basel, Mitglied des SChV, feiert am 3.6.90 seinen 70. Geburtstag.

Max Müller-Zimmerli, Chemiker HTL, Langnau a.A., Mitglied des SChV, feiert am 13.6.90 seinen 70. Geburtstag.

Paul Koller, dipl. Chem. TW, St. Gallen, Mitglied des SChV, feiert am 14.6 .90 seinen 70 . Geburtstag.

Hans Georg Erne, Dr. sc. techn., Zürich, Mitglied des SChV, feicrt am 23.6.90 seinen 70. Gcburtstag.

\section{Schweizerischer Chemiker-Verband Swiss Association of Chemists \\ Polymer-Gruppe der Schweiz Polymer Group of Switzerland Schweizerische Chemische Gesellschaft Swiss Chemical Society}

\section{0th International Macromolecular Symposium}

September 20/21, 1990, Interlaken - Switzerland

\section{Polymer Surfaces and Interfaces - Key to High Performance Materials}

Chairman: Dr. Roland Darms

Scientific Committee: Dr Roland Darms, CibaGeigy AG, Marly/Fribourg; Prof. H. J. Kausch, Ecole Polytechnique Fédérale Lausanne; Prof. J. Meissner, Eidg. Technische Hochschule Zürich; Prof. P. Müller, Schweizerischer Chemiker-Verband; Prof. M. Neuenschwander, Universität Bern; Prof. P. Pino †, Eidg. Technische Hochschule Zürich; Prof. U. Suter, Eidg. Technische Hochschule Zürich; Dr. H.J. Schultze, EMS-Chemie, Domat/Ems.

Programme

September 20, 1990

9.00

$9.15-10.15$

$10.15-10.45$

$10.45-11.45$

$11.45-12.45$
Opening of the Symposium General

Prof. G.M. Whitesides, Harvard University, Department of Chemistry, Cambridge, USA

'The Physical-Organic Chemistry of Interfaces'

Coffec break

Dr. Th. Russell, IBM Almaden Research Center, San Jose, USA

Methods for the Characterization of Polymer Surfaces and Interfaces'

Prof. G. Wegner, Max Planck-Institut für Polymerforschung, Mainz, FRG 'Molecular Architecture of Well Defined Surfaces and Interphases of Organic and Polymer Materials' 


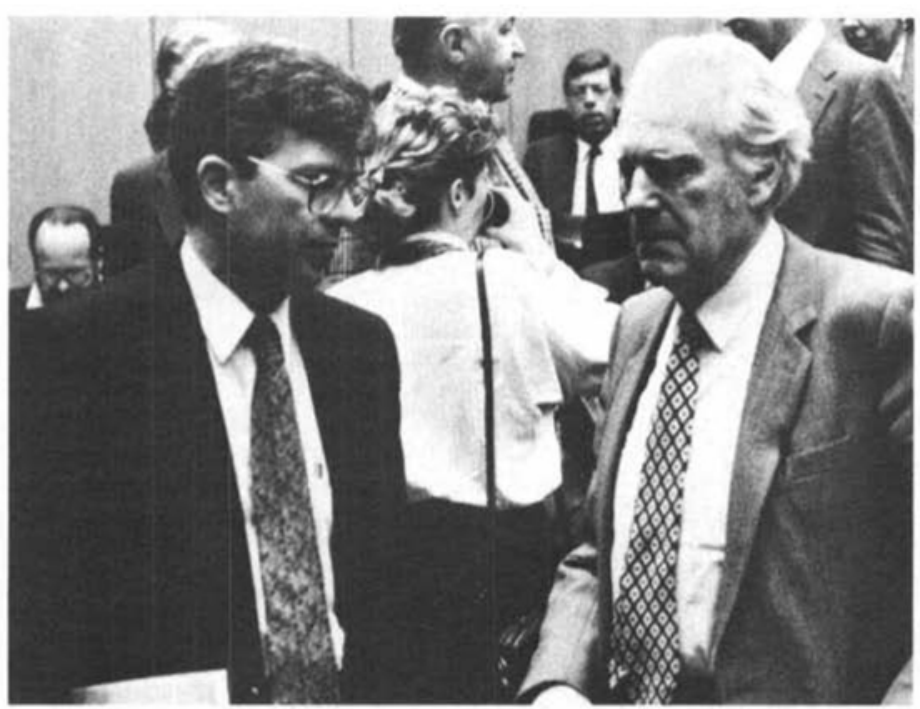

Heinz Frei mit seinem ehemaligen Doktorvater Hans H. Günthard

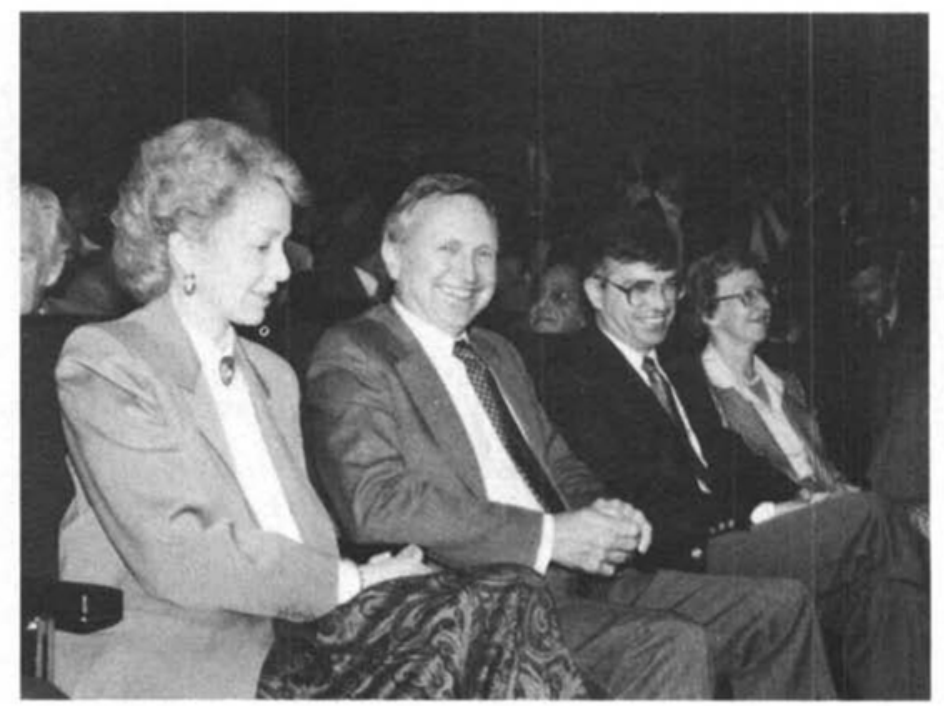

Ronald Breslow mit seiner Gattin
The diversity (over $10^{8}$ molecules in the primary repertoire) and specificity of the immune system have been merged with our understanding of chemical processes to generate catalytic antibodies. Antibodies have been generated that selectively catalyze ester hydrolysis, thymine dimer cleavage, Claisen and Diels-Alder reactions, redox reactions, metallation and elimination reactions. Several strategies have been applied to the generation of catalytic antibodies including transition state stabilization, proximity effects, general base catalysis, mutagenesis and semisynthesis, and the generation of antibodies with cofactor binding sites. This work may not only lead to the development of tailormade catalysts for medical, biological and chemical applications, but is also providing insight into the fundamental mechanisms of enzymic catalysis.

(Abstract by the Author)

(Fotos: K. Zimmermann D. Felix)

\section{Ehrungen}

der Schweizerischen Chemischen Gesellschaft (SCG) anlässlich der Frühjahrsversammlung 16. März 1990 an der ETH in Zürich

Der Präsident verlieh im Namen der SCG den Paracelsus-Preis mit Medaille an Prof. Ronald Breslow (Columbia University, New York) 'in Anerkennung seiner Pionierarbeiten auf dem Gebiet der bio-organischen Chemie' und den Werner-Preis mit Medaille an Dr. Heinz Frei (University of California, Berkeley) 'für seine bedeutenden Beiträge zur Photochemie im Spektralgebiet zwischen sichtbarem Licht und Infrarot'.

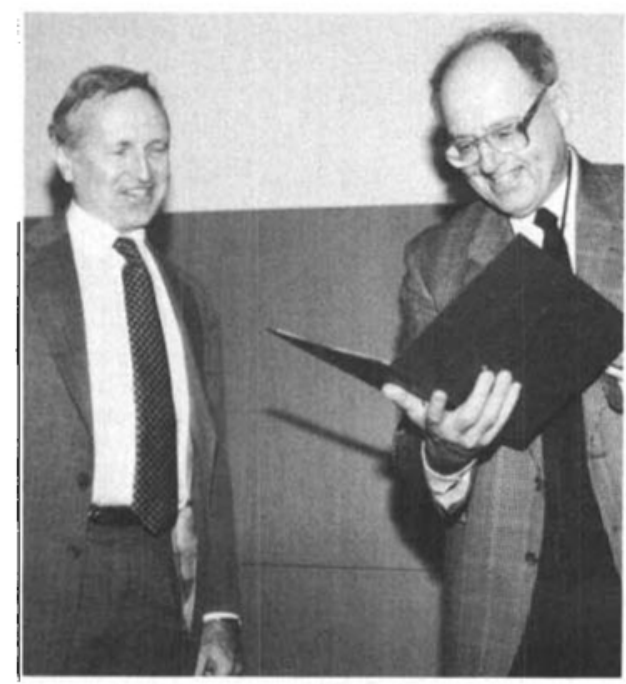

Ronald Breslow

Albert Eschenmoser

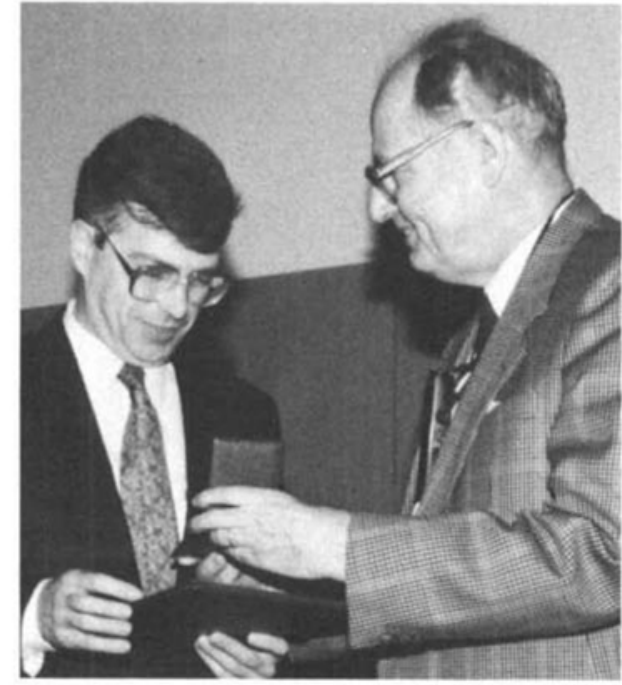

\section{Personalia}

\section{Geburtstage}

Hansjakob Stäger, Dr. sc. techn., Zürich, Mitglied des SChV, feiert am 5.6.90 seinen 65. Geburtstag.

Frank Barfuss, Chemiker HTL, Basel, Mitglied des SChV, feiert am 3.6.90 seinen 70. Geburtstag.

Max Müller-Zimmerli, Chemiker HTL, Langnau a.A., Mitglied des SChV, feiert am 13.6.90 seinen 70. Geburtstag.

Paul Koller, dipl. Chem. TW, St. Gallen, Mitglied des SChV, feiert am 14.6 .90 seinen 70 . Geburtstag.

Hans Georg Erne, Dr. sc. techn., Zürich, Mitglied des SChV, feicrt am 23.6.90 seinen 70. Gcburtstag.

\section{Schweizerischer Chemiker-Verband Swiss Association of Chemists \\ Polymer-Gruppe der Schweiz Polymer Group of Switzerland Schweizerische Chemische Gesellschaft Swiss Chemical Society}

\section{0th International Macromolecular Symposium}

September 20/21, 1990, Interlaken - Switzerland

\section{Polymer Surfaces and Interfaces - Key to High Performance Materials}

Chairman: Dr. Roland Darms

Scientific Committee: Dr Roland Darms, CibaGeigy AG, Marly/Fribourg; Prof. H. J. Kausch, Ecole Polytechnique Fédérale Lausanne; Prof. J. Meissner, Eidg. Technische Hochschule Zürich; Prof. P. Müller, Schweizerischer Chemiker-Verband; Prof. M. Neuenschwander, Universität Bern; Prof. P. Pino †, Eidg. Technische Hochschule Zürich; Prof. U. Suter, Eidg. Technische Hochschule Zürich; Dr. H.J. Schultze, EMS-Chemie, Domat/Ems.

Programme

September 20, 1990

9.00

$9.15-10.15$

$10.15-10.45$

$10.45-11.45$

$11.45-12.45$
Opening of the Symposium General

Prof. G.M. Whitesides, Harvard University, Department of Chemistry, Cambridge, USA

'The Physical-Organic Chemistry of Interfaces'

Coffec break

Dr. Th. Russell, IBM Almaden Research Center, San Jose, USA

Methods for the Characterization of Polymer Surfaces and Interfaces'

Prof. G. Wegner, Max Planck-Institut für Polymerforschung, Mainz, FRG 'Molecular Architecture of Well Defined Surfaces and Interphases of Organic and Polymer Materials' 
Lunch

15.00-16.00 Prof. T.J. McCarthy, University of Massachusetts at Amherst, Polymer Science and Engineering, Amherst, USA

'Organic Chemistry at Chemically Resistant Polymer Surfaces. Modification of Surface Reactivity and Surface Properties'

16.00-16.30 Coffee break

Adhesion/Adhesives

16.30-17.30 Dr. A.J. Kinloch, Department of Mechanical Engineering, Imperial College, London, GB

'Adhesive Bonding: The Importance of Polymeric Interfaces'

$17.30-18.10$ Dr. $K$. Jud, EMS TOGO AG, Romanshorn, Switzerland

'Improvement of Adhesion on Automotive Top Coats by Corona Discharge'

19.00

Mixer at the Hotel Victoria Jungfrau

September 21, 1990

\section{Coatings}

08.30-09.30 Dr. J.M. Loutz, UCB, Specialty Chemicals Division, Drogenbos, Belgium 'Recent Developments in the Field of Powder Coatings'

$09.30 \cdots 10.10$ Dr. H. Liertz, Siemens AG, München, FRG

'The Influence of Coatings on the Fracture Behaviour of Light WaveGuides'

10.10-10.45 Coffee break

Filled Polymer-Systems

10.45-11.45 Dr. T. Kaiser, Asea Brown Boveri, Research Center, Baden, Switzerland

'Role of Particle-Matrix Interface in the Deformation and Fracture Behaviour of Filled Epoxy Resins'

11.45-12.25 Dr. H.P. Schlumpf, Plüss-Staufer AG, Oftringen, Switzerland

'Physico-Chemical Aspects of Filers in Polypropylene'

$12.25 \cdot 13.30 \quad$ Business Lunch

Composites

13.30-14.30 Dr. R.F. Siegmund, Ciba-Geigy Corporation, Composite Materials Department, Anaheim, USA

'Some Newer Applications of Advanced Polymer Composites'

14.30-15.10 Prof. A. Pavan, Dipartimento di Chimica Industriale e Ingegneria Chimica, Politecnico di Milano, Milano, Italy

'A Study on the Toughening of Polymer Matrix Composites by Interphase Modification'

15.10 Closing of the Symposium

Registration

The registration card should be sent to: Secretary's Office for SAC-Symposia, Institute of Organic Chemistry, University of Berne, Freiestrasse 3, CH-3012 Berne, Switzerland, Tel. 031 654311, Telex 912406 uni ch, Fax 031654499.

\section{Seminar in organischer Chemie Sommersemester 1990}

Institut für organische Chemie der Universität Bern, Freiestr. 3, 3012 Bern

Donnerstag, 31. Mai 1990, 11.15, S 379, Prof. B. Carpenter, Cornell University, Ithaca, N.Y., zur Zeit: Institut für Organische Chemie, Universität Hannover, BRD: Cyclooligomerizations.

Mittwoch, 6. Juni 1990, 11.15, S 481, Prof. L.M. Ve nanzi, ETH-Z: Kationische Ubergangsmetalle als homogene Katalysatoren
Mittwoch, 13. Juni 1990, 11.15, S 481, Dr. B. Ernst, Ciba-Geigy AG, Basel: Das eiablage-hemmende Pheromon der Kirschenfliege: Synthese und biologische Eigenschaften

Montag, 18. Juni 1990, 16.30, S 481, PD Dr. M. Karpf, F. Hoffmann-La Roche AG, Basel: Chemische Verfahrensforschung. Die Probleme der Synthese auf dem Weg zur Technik

\section{Alusuisse-Lonza Holding AG}

Die Alusuisse-Lonza Holding AG (Personalbestand am Jahresende 1989:25763 (+5,3\%), welche bis Endc 1989 als Schweizerische Aluminium AG firmierte, ver- zeichnete im abgelaufenen Geschäftsjahr ein starkes Umsatz- und Ertragswachstum. Die strategische Ausrichtung auf Produkte mit hoher Wertschöpfung, verbunden mit ungewöhnlich günstigen konjunkturellen Rahmenbedingungen, führten zu einem sehr guten Ergebnis.

Der Konzern-Nettoumsatz stieg 1989 um $18.5 \%$ von 5978 Millionen Franken auf 7085 Millionen Franken, und der Konzern-Reingewinn nahm um $47 \%$ von 317 Millionen Franken auf 466 Millionen Franken zu.

Der ordentliche Cash-flow (948 Millionen Franken), in Prozent des Umsatzes ausgedrückt, beträgt 13.4\%. Der Vorjahreswert von 658 Millionen Franken resp. $11 \%$ wurde deutlich übertroffen.

Der Reingewinn der Holdinggesellschaft beträgt 130 Millionen Franken. Gegenüber dem Vorjahr mit 86 Millionen Franken bedeutet dies eine Zunahme von $52.5 \%$.

\section{Schweizerische Chemische Gesellschaft Société Suisse de Chimie}

\section{Protokoll}

der Frühjahrsversammlung der

Schweizerischen Chemischen Gesellschaft vom 16. März 1990 in Zürich, ETH Zürich-Zentrum, Rämistr. 101

\section{A. Geschäftlicher Teil}

Der Präsident Prof. A. Eschenmoser eröffnet die Sitzung um 9.30 Uhr.

1. Das Protokoll der Herbstversammlung vom 20. Oktober 1989 in Bern wird mit einer Berichtigung (im Teil B ist im Titel des anorganischen Symposiums 'Role of Surfaces' durch 'New Materials' zu ersetzen) genehmigt.

2. Die Herbstversammlung 1990 wird am 19. Oktober 1990 in Bern, die Frühjahrsversammlung 1991 am Freitag, den 15. März 1991 zum Thema 'Radikalchemie' in Basel mit dem Schweiz. Chemiker-Verband veranstaltet. Weitere gemeinsame Veranstaltungen von SChV und SCG: 'Marketing, Forschung, Produktion', 29.-30. März 1990, Fribourg; 'Frühjahrsversammlung SChV', 27. April 1990, Visp; '10th Int. Macromolecular Symposium: Polymer Surfaces and Interfaces', 20.-21. September 1990, Interlaken; ILMAC, 23.-26. Oktober 1990, Basel; 'Internat. HPLC-Symposium', 22.-26. September 1991, Basel; 'Farbensymposium', 3.-7. Juni 1991, Montreux.

3. Der Bericht des Vorstandes für das Jahr 1989 ist in Annex $l$ abgedruckt. Die Zunahme der Mitglieder gegenüber dem Vorjahr ist vor allem auf die Sektion Medizinische Chemie zurückzuführen. Der Präsident teilt mit, dass die Chimia jetzt auch offizielles Mitteilungsblatt der SCG ist, und dass die Kooperation mit dem SChV schnellere Fortschritte macht als erwartet.

4. Kassabericht und Jahresrechnung 1988 (vgl. Annex 2 und 3) werden vom Schatzmeister Dr. J. Kalvoda erläutert, der darauf hinweist, dass das negative Rechnungsergebnis durch die notwendige Wertberichtigung der Wertschriften zum aktuellen Kurs verursacht wird. Ohne diese hätte die SCG, vor allem auch aufgrund gesenkter Produktionskosten für die HCA, 1989 ein ausgeglichenes Resultat erreicht. Die Rechnung wurde durch die Revisoren Prof. J. Wirz und Dr. P. Zeller geprüft und genehmigt.

5. Als Vertreter des Redaktionskomitees berichtet Prof. Hansen über Helv. Chim. Acta. Die Kosten pro Seite konnten um ca. $2 \%$ gesenkt werden, vor allem deshalb, weil ca. $13 \%$ der Manuskripte jetzt mit Computer bearbeitet werden. Die Publikationsfrist liegt mit durchschnittlich 2,4 Monaten im internationalen Vergleich sehr gut. Beunruhigend ist eine deutliche Abnahme des Anteils der Manuskripte aus Schweizer Hochschulen in den letzten Jahren.
6. In einer von der Versammlung zuvor genehmigten Ergänzung der Traktanden wird Dr. Ado Kaiser (Hoffmann-La Roche, Bascl) zum neuen Mitglied des Redaktionskomitees gewählt.

7. Varia: Keine Wortmeldung.

Schluss der Sitzung: 10.00 Uhr

\section{B. Wissenschaftlicher Teil}

1. Der Präsident verleiht im Namen der SCG den Paracelsus-Preis mil Medaille an Prof. R. Breslow (Columbia University, New York) 'in Anerkennung seiner Pionierarbeiten auf dem Gebiet der bio-organischen Chemie' und den Werner-Preis mit Medaille an Dr. Hein = Frei (University of California, Berkeley) 'für seine bedeutenden Beiträge zur Photochemie im Spektralgebiet zwischen sichtbarem Licht und Infrarot'.

2. Symposium 'Trends in Organic Chemistry' (gemeinsam mit dem Schweiz. Chemiker-Verband) mit Vorträgen von Prof. J.-M. Lelın (Université Louis Pasteur, Strasbourg) 'Perspektiven der supramolekularen Chemie', Prof. R. Breslow (Columbia University, New York) 'The Chelate Effect: Binding, Catalysis, and Chemotherapy', Prof. J. Rebek, jr. (Massachusetts Institute of Technology, Cambridge, U.S.A.) 'Recognition and Catalysis with Model Systems', Prof. S.L. Schreiber (Harvard University, Cambridge, U.S.A.) 'Molecular Recognition of the Immunophilins', Prof. P.G. Schultz (University of California, Berkeley) 'Catalytic Antibodies'

Am 14./15. März fand das Symposium 'Chemistry and Structure' der Schweizerischen Gesellschaft für Kristallographie zu Ehren von Prof. J.D. Dunitz (ETH Zürich) statt.

\section{Der Präsident}

Prof. A. Eschenmoser

Der Sekretär

Annex 1

\section{Jahresbericht des Vorstandes für 1989}

1. Mitglieder

Die Schweizerische Chemische Gesellschaft hatte am 31.12.1989 1551 (1502) Mitglieder, davon 16 (16) Ehren- und 15 (16) Freimitglieder (Zahlen des Vorjahres in Klammern).

Die Gesellschaft hatte im Jahr 1989 den Tod der folgenden 12 Mitglieder zu beklagen: Dr. J. Decrue, Riehen; Dr. A. Gelbert, Geroldswil; Dr. R. Genet, North Caldwell; Prof. D. Ginsburg, Haifa; Prof. K Huber, Ittingen; Prof. H. Mohler (Freimitglied); Prof. H. Musso, Karlsruhe; Dr. R. Schett, Riehen; Dr. L. Valpiana, Reinach; Dr. A. Vogel, Riehen; Dr. H. Waldmann, Birsfelden (Mitglied auf Lebenszeit); Dr. H. Wehrli, Zollikon. 
Lunch

15.00-16.00 Prof. T.J. McCarthy, University of Massachusetts at Amherst, Polymer Science and Engineering, Amherst, USA

'Organic Chemistry at Chemically Resistant Polymer Surfaces. Modification of Surface Reactivity and Surface Properties'

16.00-16.30 Coffee break

Adhesion/Adhesives

16.30-17.30 Dr. A.J. Kinloch, Department of Mechanical Engineering, Imperial College, London, GB

'Adhesive Bonding: The Importance of Polymeric Interfaces'

$17.30-18.10$ Dr. $K$. Jud, EMS TOGO AG, Romanshorn, Switzerland

'Improvement of Adhesion on Automotive Top Coats by Corona Discharge'

19.00

Mixer at the Hotel Victoria Jungfrau

September 21, 1990

\section{Coatings}

08.30-09.30 Dr. J.M. Loutz, UCB, Specialty Chemicals Division, Drogenbos, Belgium 'Recent Developments in the Field of Powder Coatings'

$09.30 \cdots 10.10$ Dr. H. Liertz, Siemens AG, München, FRG

'The Influence of Coatings on the Fracture Behaviour of Light WaveGuides'

10.10-10.45 Coffee break

Filled Polymer-Systems

10.45-11.45 Dr. T. Kaiser, Asea Brown Boveri, Research Center, Baden, Switzerland

'Role of Particle-Matrix Interface in the Deformation and Fracture Behaviour of Filled Epoxy Resins'

11.45-12.25 Dr. H.P. Schlumpf, Plüss-Staufer AG, Oftringen, Switzerland

'Physico-Chemical Aspects of Filers in Polypropylene'

$12.25 \cdot 13.30 \quad$ Business Lunch

Composites

13.30-14.30 Dr. R.F. Siegmund, Ciba-Geigy Corporation, Composite Materials Department, Anaheim, USA

'Some Newer Applications of Advanced Polymer Composites'

14.30-15.10 Prof. A. Pavan, Dipartimento di Chimica Industriale e Ingegneria Chimica, Politecnico di Milano, Milano, Italy

'A Study on the Toughening of Polymer Matrix Composites by Interphase Modification'

15.10 Closing of the Symposium

Registration

The registration card should be sent to: Secretary's Office for SAC-Symposia, Institute of Organic Chemistry, University of Berne, Freiestrasse 3, CH-3012 Berne, Switzerland, Tel. 031 654311, Telex 912406 uni ch, Fax 031654499.

\section{Seminar in organischer Chemie Sommersemester 1990}

Institut für organische Chemie der Universität Bern, Freiestr. 3, 3012 Bern

Donnerstag, 31. Mai 1990, 11.15, S 379, Prof. B. Carpenter, Cornell University, Ithaca, N.Y., zur Zeit: Institut für Organische Chemie, Universität Hannover, BRD: Cyclooligomerizations.

Mittwoch, 6. Juni 1990, 11.15, S 481, Prof. L.M. Ve nanzi, ETH-Z: Kationische Ubergangsmetalle als homogene Katalysatoren
Mittwoch, 13. Juni 1990, 11.15, S 481, Dr. B. Ernst, Ciba-Geigy AG, Basel: Das eiablage-hemmende Pheromon der Kirschenfliege: Synthese und biologische Eigenschaften

Montag, 18. Juni 1990, 16.30, S 481, PD Dr. M. Karpf, F. Hoffmann-La Roche AG, Basel: Chemische Verfahrensforschung. Die Probleme der Synthese auf dem Weg zur Technik

\section{Alusuisse-Lonza Holding AG}

Die Alusuisse-Lonza Holding AG (Personalbestand am Jahresende 1989:25763 (+5,3\%), welche bis Endc 1989 als Schweizerische Aluminium AG firmierte, ver- zeichnete im abgelaufenen Geschäftsjahr ein starkes Umsatz- und Ertragswachstum. Die strategische Ausrichtung auf Produkte mit hoher Wertschöpfung, verbunden mit ungewöhnlich günstigen konjunkturellen Rahmenbedingungen, führten zu einem sehr guten Ergebnis.

Der Konzern-Nettoumsatz stieg 1989 um $18.5 \%$ von 5978 Millionen Franken auf 7085 Millionen Franken, und der Konzern-Reingewinn nahm um $47 \%$ von 317 Millionen Franken auf 466 Millionen Franken zu.

Der ordentliche Cash-flow (948 Millionen Franken), in Prozent des Umsatzes ausgedrückt, beträgt 13.4\%. Der Vorjahreswert von 658 Millionen Franken resp. $11 \%$ wurde deutlich übertroffen.

Der Reingewinn der Holdinggesellschaft beträgt 130 Millionen Franken. Gegenüber dem Vorjahr mit 86 Millionen Franken bedeutet dies eine Zunahme von $52.5 \%$.

\section{Schweizerische Chemische Gesellschaft Société Suisse de Chimie}

\section{Protokoll}

der Frühjahrsversammlung der

Schweizerischen Chemischen Gesellschaft vom 16. März 1990 in Zürich, ETH Zürich-Zentrum, Rämistr. 101

\section{A. Geschäftlicher Teil}

Der Präsident Prof. A. Eschenmoser eröffnet die Sitzung um 9.30 Uhr.

1. Das Protokoll der Herbstversammlung vom 20. Oktober 1989 in Bern wird mit einer Berichtigung (im Teil B ist im Titel des anorganischen Symposiums 'Role of Surfaces' durch 'New Materials' zu ersetzen) genehmigt.

2. Die Herbstversammlung 1990 wird am 19. Oktober 1990 in Bern, die Frühjahrsversammlung 1991 am Freitag, den 15. März 1991 zum Thema 'Radikalchemie' in Basel mit dem Schweiz. Chemiker-Verband veranstaltet. Weitere gemeinsame Veranstaltungen von SChV und SCG: 'Marketing, Forschung, Produktion', 29.-30. März 1990, Fribourg; 'Frühjahrsversammlung SChV', 27. April 1990, Visp; '10th Int. Macromolecular Symposium: Polymer Surfaces and Interfaces', 20.-21. September 1990, Interlaken; ILMAC, 23.-26. Oktober 1990, Basel; 'Internat. HPLC-Symposium', 22.-26. September 1991, Basel; 'Farbensymposium', 3.-7. Juni 1991, Montreux.

3. Der Bericht des Vorstandes für das Jahr 1989 ist in Annex $l$ abgedruckt. Die Zunahme der Mitglieder gegenüber dem Vorjahr ist vor allem auf die Sektion Medizinische Chemie zurückzuführen. Der Präsident teilt mit, dass die Chimia jetzt auch offizielles Mitteilungsblatt der SCG ist, und dass die Kooperation mit dem SChV schnellere Fortschritte macht als erwartet.

4. Kassabericht und Jahresrechnung 1988 (vgl. Annex 2 und 3) werden vom Schatzmeister Dr. J. Kalvoda erläutert, der darauf hinweist, dass das negative Rechnungsergebnis durch die notwendige Wertberichtigung der Wertschriften zum aktuellen Kurs verursacht wird. Ohne diese hätte die SCG, vor allem auch aufgrund gesenkter Produktionskosten für die HCA, 1989 ein ausgeglichenes Resultat erreicht. Die Rechnung wurde durch die Revisoren Prof. J. Wirz und Dr. P. Zeller geprüft und genehmigt.

5. Als Vertreter des Redaktionskomitees berichtet Prof. Hansen über Helv. Chim. Acta. Die Kosten pro Seite konnten um ca. $2 \%$ gesenkt werden, vor allem deshalb, weil ca. $13 \%$ der Manuskripte jetzt mit Computer bearbeitet werden. Die Publikationsfrist liegt mit durchschnittlich 2,4 Monaten im internationalen Vergleich sehr gut. Beunruhigend ist eine deutliche Abnahme des Anteils der Manuskripte aus Schweizer Hochschulen in den letzten Jahren.
6. In einer von der Versammlung zuvor genehmigten Ergänzung der Traktanden wird Dr. Ado Kaiser (Hoffmann-La Roche, Bascl) zum neuen Mitglied des Redaktionskomitees gewählt.

7. Varia: Keine Wortmeldung.

Schluss der Sitzung: 10.00 Uhr

\section{B. Wissenschaftlicher Teil}

1. Der Präsident verleiht im Namen der SCG den Paracelsus-Preis mil Medaille an Prof. R. Breslow (Columbia University, New York) 'in Anerkennung seiner Pionierarbeiten auf dem Gebiet der bio-organischen Chemie' und den Werner-Preis mit Medaille an Dr. Hein = Frei (University of California, Berkeley) 'für seine bedeutenden Beiträge zur Photochemie im Spektralgebiet zwischen sichtbarem Licht und Infrarot'.

2. Symposium 'Trends in Organic Chemistry' (gemeinsam mit dem Schweiz. Chemiker-Verband) mit Vorträgen von Prof. J.-M. Lelın (Université Louis Pasteur, Strasbourg) 'Perspektiven der supramolekularen Chemie', Prof. R. Breslow (Columbia University, New York) 'The Chelate Effect: Binding, Catalysis, and Chemotherapy', Prof. J. Rebek, jr. (Massachusetts Institute of Technology, Cambridge, U.S.A.) 'Recognition and Catalysis with Model Systems', Prof. S.L. Schreiber (Harvard University, Cambridge, U.S.A.) 'Molecular Recognition of the Immunophilins', Prof. P.G. Schultz (University of California, Berkeley) 'Catalytic Antibodies'

Am 14./15. März fand das Symposium 'Chemistry and Structure' der Schweizerischen Gesellschaft für Kristallographie zu Ehren von Prof. J.D. Dunitz (ETH Zürich) statt.

\section{Der Präsident}

Prof. A. Eschenmoser

Der Sekretär

Annex 1

\section{Jahresbericht des Vorstandes für 1989}

1. Mitglieder

Die Schweizerische Chemische Gesellschaft hatte am 31.12.1989 1551 (1502) Mitglieder, davon 16 (16) Ehren- und 15 (16) Freimitglieder (Zahlen des Vorjahres in Klammern).

Die Gesellschaft hatte im Jahr 1989 den Tod der folgenden 12 Mitglieder zu beklagen: Dr. J. Decrue, Riehen; Dr. A. Gelbert, Geroldswil; Dr. R. Genet, North Caldwell; Prof. D. Ginsburg, Haifa; Prof. K Huber, Ittingen; Prof. H. Mohler (Freimitglied); Prof. H. Musso, Karlsruhe; Dr. R. Schett, Riehen; Dr. L. Valpiana, Reinach; Dr. A. Vogel, Riehen; Dr. H. Waldmann, Birsfelden (Mitglied auf Lebenszeit); Dr. H. Wehrli, Zollikon. 
Lunch

15.00-16.00 Prof. T.J. McCarthy, University of Massachusetts at Amherst, Polymer Science and Engineering, Amherst, USA

'Organic Chemistry at Chemically Resistant Polymer Surfaces. Modification of Surface Reactivity and Surface Properties'

16.00-16.30 Coffee break

Adhesion/Adhesives

16.30-17.30 Dr. A.J. Kinloch, Department of Mechanical Engineering, Imperial College, London, GB

'Adhesive Bonding: The Importance of Polymeric Interfaces'

$17.30-18.10$ Dr. $K$. Jud, EMS TOGO AG, Romanshorn, Switzerland

'Improvement of Adhesion on Automotive Top Coats by Corona Discharge'

19.00

Mixer at the Hotel Victoria Jungfrau

September 21, 1990

\section{Coatings}

08.30-09.30 Dr. J.M. Loutz, UCB, Specialty Chemicals Division, Drogenbos, Belgium 'Recent Developments in the Field of Powder Coatings'

$09.30 \cdots 10.10$ Dr. H. Liertz, Siemens AG, München, FRG

'The Influence of Coatings on the Fracture Behaviour of Light WaveGuides'

10.10-10.45 Coffee break

Filled Polymer-Systems

10.45-11.45 Dr. T. Kaiser, Asea Brown Boveri, Research Center, Baden, Switzerland

'Role of Particle-Matrix Interface in the Deformation and Fracture Behaviour of Filled Epoxy Resins'

11.45-12.25 Dr. H.P. Schlumpf, Plüss-Staufer AG, Oftringen, Switzerland

'Physico-Chemical Aspects of Filers in Polypropylene'

$12.25 \cdot 13.30 \quad$ Business Lunch

Composites

13.30-14.30 Dr. R.F. Siegmund, Ciba-Geigy Corporation, Composite Materials Department, Anaheim, USA

'Some Newer Applications of Advanced Polymer Composites'

14.30-15.10 Prof. A. Pavan, Dipartimento di Chimica Industriale e Ingegneria Chimica, Politecnico di Milano, Milano, Italy

'A Study on the Toughening of Polymer Matrix Composites by Interphase Modification'

15.10 Closing of the Symposium

Registration

The registration card should be sent to: Secretary's Office for SAC-Symposia, Institute of Organic Chemistry, University of Berne, Freiestrasse 3, CH-3012 Berne, Switzerland, Tel. 031 654311, Telex 912406 uni ch, Fax 031654499.

\section{Seminar in organischer Chemie Sommersemester 1990}

Institut für organische Chemie der Universität Bern, Freiestr. 3, 3012 Bern

Donnerstag, 31. Mai 1990, 11.15, S 379, Prof. B. Carpenter, Cornell University, Ithaca, N.Y., zur Zeit: Institut für Organische Chemie, Universität Hannover, BRD: Cyclooligomerizations.

Mittwoch, 6. Juni 1990, 11.15, S 481, Prof. L.M. Ve nanzi, ETH-Z: Kationische Ubergangsmetalle als homogene Katalysatoren
Mittwoch, 13. Juni 1990, 11.15, S 481, Dr. B. Ernst, Ciba-Geigy AG, Basel: Das eiablage-hemmende Pheromon der Kirschenfliege: Synthese und biologische Eigenschaften

Montag, 18. Juni 1990, 16.30, S 481, PD Dr. M. Karpf, F. Hoffmann-La Roche AG, Basel: Chemische Verfahrensforschung. Die Probleme der Synthese auf dem Weg zur Technik

\section{Alusuisse-Lonza Holding AG}

Die Alusuisse-Lonza Holding AG (Personalbestand am Jahresende 1989:25763 (+5,3\%), welche bis Endc 1989 als Schweizerische Aluminium AG firmierte, ver- zeichnete im abgelaufenen Geschäftsjahr ein starkes Umsatz- und Ertragswachstum. Die strategische Ausrichtung auf Produkte mit hoher Wertschöpfung, verbunden mit ungewöhnlich günstigen konjunkturellen Rahmenbedingungen, führten zu einem sehr guten Ergebnis.

Der Konzern-Nettoumsatz stieg 1989 um $18.5 \%$ von 5978 Millionen Franken auf 7085 Millionen Franken, und der Konzern-Reingewinn nahm um $47 \%$ von 317 Millionen Franken auf 466 Millionen Franken zu.

Der ordentliche Cash-flow (948 Millionen Franken), in Prozent des Umsatzes ausgedrückt, beträgt 13.4\%. Der Vorjahreswert von 658 Millionen Franken resp. $11 \%$ wurde deutlich übertroffen.

Der Reingewinn der Holdinggesellschaft beträgt 130 Millionen Franken. Gegenüber dem Vorjahr mit 86 Millionen Franken bedeutet dies eine Zunahme von $52.5 \%$.

\section{Schweizerische Chemische Gesellschaft Société Suisse de Chimie}

\section{Protokoll}

der Frühjahrsversammlung der

Schweizerischen Chemischen Gesellschaft vom 16. März 1990 in Zürich, ETH Zürich-Zentrum, Rämistr. 101

\section{A. Geschäftlicher Teil}

Der Präsident Prof. A. Eschenmoser eröffnet die Sitzung um 9.30 Uhr.

1. Das Protokoll der Herbstversammlung vom 20. Oktober 1989 in Bern wird mit einer Berichtigung (im Teil B ist im Titel des anorganischen Symposiums 'Role of Surfaces' durch 'New Materials' zu ersetzen) genehmigt.

2. Die Herbstversammlung 1990 wird am 19. Oktober 1990 in Bern, die Frühjahrsversammlung 1991 am Freitag, den 15. März 1991 zum Thema 'Radikalchemie' in Basel mit dem Schweiz. Chemiker-Verband veranstaltet. Weitere gemeinsame Veranstaltungen von SChV und SCG: 'Marketing, Forschung, Produktion', 29.-30. März 1990, Fribourg; 'Frühjahrsversammlung SChV', 27. April 1990, Visp; '10th Int. Macromolecular Symposium: Polymer Surfaces and Interfaces', 20.-21. September 1990, Interlaken; ILMAC, 23.-26. Oktober 1990, Basel; 'Internat. HPLC-Symposium', 22.-26. September 1991, Basel; 'Farbensymposium', 3.-7. Juni 1991, Montreux.

3. Der Bericht des Vorstandes für das Jahr 1989 ist in Annex $l$ abgedruckt. Die Zunahme der Mitglieder gegenüber dem Vorjahr ist vor allem auf die Sektion Medizinische Chemie zurückzuführen. Der Präsident teilt mit, dass die Chimia jetzt auch offizielles Mitteilungsblatt der SCG ist, und dass die Kooperation mit dem SChV schnellere Fortschritte macht als erwartet.

4. Kassabericht und Jahresrechnung 1988 (vgl. Annex 2 und 3) werden vom Schatzmeister Dr. J. Kalvoda erläutert, der darauf hinweist, dass das negative Rechnungsergebnis durch die notwendige Wertberichtigung der Wertschriften zum aktuellen Kurs verursacht wird. Ohne diese hätte die SCG, vor allem auch aufgrund gesenkter Produktionskosten für die HCA, 1989 ein ausgeglichenes Resultat erreicht. Die Rechnung wurde durch die Revisoren Prof. J. Wirz und Dr. P. Zeller geprüft und genehmigt.

5. Als Vertreter des Redaktionskomitees berichtet Prof. Hansen über Helv. Chim. Acta. Die Kosten pro Seite konnten um ca. $2 \%$ gesenkt werden, vor allem deshalb, weil ca. $13 \%$ der Manuskripte jetzt mit Computer bearbeitet werden. Die Publikationsfrist liegt mit durchschnittlich 2,4 Monaten im internationalen Vergleich sehr gut. Beunruhigend ist eine deutliche Abnahme des Anteils der Manuskripte aus Schweizer Hochschulen in den letzten Jahren.
6. In einer von der Versammlung zuvor genehmigten Ergänzung der Traktanden wird Dr. Ado Kaiser (Hoffmann-La Roche, Bascl) zum neuen Mitglied des Redaktionskomitees gewählt.

7. Varia: Keine Wortmeldung.

Schluss der Sitzung: 10.00 Uhr

\section{B. Wissenschaftlicher Teil}

1. Der Präsident verleiht im Namen der SCG den Paracelsus-Preis mil Medaille an Prof. R. Breslow (Columbia University, New York) 'in Anerkennung seiner Pionierarbeiten auf dem Gebiet der bio-organischen Chemie' und den Werner-Preis mit Medaille an Dr. Hein = Frei (University of California, Berkeley) 'für seine bedeutenden Beiträge zur Photochemie im Spektralgebiet zwischen sichtbarem Licht und Infrarot'.

2. Symposium 'Trends in Organic Chemistry' (gemeinsam mit dem Schweiz. Chemiker-Verband) mit Vorträgen von Prof. J.-M. Lelın (Université Louis Pasteur, Strasbourg) 'Perspektiven der supramolekularen Chemie', Prof. R. Breslow (Columbia University, New York) 'The Chelate Effect: Binding, Catalysis, and Chemotherapy', Prof. J. Rebek, jr. (Massachusetts Institute of Technology, Cambridge, U.S.A.) 'Recognition and Catalysis with Model Systems', Prof. S.L. Schreiber (Harvard University, Cambridge, U.S.A.) 'Molecular Recognition of the Immunophilins', Prof. P.G. Schultz (University of California, Berkeley) 'Catalytic Antibodies'

Am 14./15. März fand das Symposium 'Chemistry and Structure' der Schweizerischen Gesellschaft für Kristallographie zu Ehren von Prof. J.D. Dunitz (ETH Zürich) statt.

\section{Der Präsident}

Prof. A. Eschenmoser

Der Sekretär

Annex 1

\section{Jahresbericht des Vorstandes für 1989}

1. Mitglieder

Die Schweizerische Chemische Gesellschaft hatte am 31.12.1989 1551 (1502) Mitglieder, davon 16 (16) Ehren- und 15 (16) Freimitglieder (Zahlen des Vorjahres in Klammern).

Die Gesellschaft hatte im Jahr 1989 den Tod der folgenden 12 Mitglieder zu beklagen: Dr. J. Decrue, Riehen; Dr. A. Gelbert, Geroldswil; Dr. R. Genet, North Caldwell; Prof. D. Ginsburg, Haifa; Prof. K Huber, Ittingen; Prof. H. Mohler (Freimitglied); Prof. H. Musso, Karlsruhe; Dr. R. Schett, Riehen; Dr. L. Valpiana, Reinach; Dr. A. Vogel, Riehen; Dr. H. Waldmann, Birsfelden (Mitglied auf Lebenszeit); Dr. H. Wehrli, Zollikon. 
Lunch

15.00-16.00 Prof. T.J. McCarthy, University of Massachusetts at Amherst, Polymer Science and Engineering, Amherst, USA

'Organic Chemistry at Chemically Resistant Polymer Surfaces. Modification of Surface Reactivity and Surface Properties'

16.00-16.30 Coffee break

Adhesion/Adhesives

16.30-17.30 Dr. A.J. Kinloch, Department of Mechanical Engineering, Imperial College, London, GB

'Adhesive Bonding: The Importance of Polymeric Interfaces'

$17.30-18.10$ Dr. $K$. Jud, EMS TOGO AG, Romanshorn, Switzerland

'Improvement of Adhesion on Automotive Top Coats by Corona Discharge'

19.00

Mixer at the Hotel Victoria Jungfrau

September 21, 1990

\section{Coatings}

08.30-09.30 Dr. J.M. Loutz, UCB, Specialty Chemicals Division, Drogenbos, Belgium 'Recent Developments in the Field of Powder Coatings'

$09.30 \cdots 10.10$ Dr. H. Liertz, Siemens AG, München, FRG

'The Influence of Coatings on the Fracture Behaviour of Light WaveGuides'

10.10-10.45 Coffee break

Filled Polymer-Systems

10.45-11.45 Dr. T. Kaiser, Asea Brown Boveri, Research Center, Baden, Switzerland

'Role of Particle-Matrix Interface in the Deformation and Fracture Behaviour of Filled Epoxy Resins'

11.45-12.25 Dr. H.P. Schlumpf, Plüss-Staufer AG, Oftringen, Switzerland

'Physico-Chemical Aspects of Filers in Polypropylene'

$12.25 \cdot 13.30 \quad$ Business Lunch

Composites

13.30-14.30 Dr. R.F. Siegmund, Ciba-Geigy Corporation, Composite Materials Department, Anaheim, USA

'Some Newer Applications of Advanced Polymer Composites'

14.30-15.10 Prof. A. Pavan, Dipartimento di Chimica Industriale e Ingegneria Chimica, Politecnico di Milano, Milano, Italy

'A Study on the Toughening of Polymer Matrix Composites by Interphase Modification'

15.10 Closing of the Symposium

Registration

The registration card should be sent to: Secretary's Office for SAC-Symposia, Institute of Organic Chemistry, University of Berne, Freiestrasse 3, CH-3012 Berne, Switzerland, Tel. 031 654311, Telex 912406 uni ch, Fax 031654499.

\section{Seminar in organischer Chemie Sommersemester 1990}

Institut für organische Chemie der Universität Bern, Freiestr. 3, 3012 Bern

Donnerstag, 31. Mai 1990, 11.15, S 379, Prof. B. Carpenter, Cornell University, Ithaca, N.Y., zur Zeit: Institut für Organische Chemie, Universität Hannover, BRD: Cyclooligomerizations.

Mittwoch, 6. Juni 1990, 11.15, S 481, Prof. L.M. Ve nanzi, ETH-Z: Kationische Ubergangsmetalle als homogene Katalysatoren
Mittwoch, 13. Juni 1990, 11.15, S 481, Dr. B. Ernst, Ciba-Geigy AG, Basel: Das eiablage-hemmende Pheromon der Kirschenfliege: Synthese und biologische Eigenschaften

Montag, 18. Juni 1990, 16.30, S 481, PD Dr. M. Karpf, F. Hoffmann-La Roche AG, Basel: Chemische Verfahrensforschung. Die Probleme der Synthese auf dem Weg zur Technik

\section{Alusuisse-Lonza Holding AG}

Die Alusuisse-Lonza Holding AG (Personalbestand am Jahresende 1989:25763 (+5,3\%), welche bis Endc 1989 als Schweizerische Aluminium AG firmierte, ver- zeichnete im abgelaufenen Geschäftsjahr ein starkes Umsatz- und Ertragswachstum. Die strategische Ausrichtung auf Produkte mit hoher Wertschöpfung, verbunden mit ungewöhnlich günstigen konjunkturellen Rahmenbedingungen, führten zu einem sehr guten Ergebnis.

Der Konzern-Nettoumsatz stieg 1989 um $18.5 \%$ von 5978 Millionen Franken auf 7085 Millionen Franken, und der Konzern-Reingewinn nahm um $47 \%$ von 317 Millionen Franken auf 466 Millionen Franken zu.

Der ordentliche Cash-flow (948 Millionen Franken), in Prozent des Umsatzes ausgedrückt, beträgt 13.4\%. Der Vorjahreswert von 658 Millionen Franken resp. $11 \%$ wurde deutlich übertroffen.

Der Reingewinn der Holdinggesellschaft beträgt 130 Millionen Franken. Gegenüber dem Vorjahr mit 86 Millionen Franken bedeutet dies eine Zunahme von $52.5 \%$.

\section{Schweizerische Chemische Gesellschaft Société Suisse de Chimie}

\section{Protokoll}

der Frühjahrsversammlung der

Schweizerischen Chemischen Gesellschaft vom 16. März 1990 in Zürich, ETH Zürich-Zentrum, Rämistr. 101

\section{A. Geschäftlicher Teil}

Der Präsident Prof. A. Eschenmoser eröffnet die Sitzung um 9.30 Uhr.

1. Das Protokoll der Herbstversammlung vom 20. Oktober 1989 in Bern wird mit einer Berichtigung (im Teil B ist im Titel des anorganischen Symposiums 'Role of Surfaces' durch 'New Materials' zu ersetzen) genehmigt.

2. Die Herbstversammlung 1990 wird am 19. Oktober 1990 in Bern, die Frühjahrsversammlung 1991 am Freitag, den 15. März 1991 zum Thema 'Radikalchemie' in Basel mit dem Schweiz. Chemiker-Verband veranstaltet. Weitere gemeinsame Veranstaltungen von SChV und SCG: 'Marketing, Forschung, Produktion', 29.-30. März 1990, Fribourg; 'Frühjahrsversammlung SChV', 27. April 1990, Visp; '10th Int. Macromolecular Symposium: Polymer Surfaces and Interfaces', 20.-21. September 1990, Interlaken; ILMAC, 23.-26. Oktober 1990, Basel; 'Internat. HPLC-Symposium', 22.-26. September 1991, Basel; 'Farbensymposium', 3.-7. Juni 1991, Montreux.

3. Der Bericht des Vorstandes für das Jahr 1989 ist in Annex $l$ abgedruckt. Die Zunahme der Mitglieder gegenüber dem Vorjahr ist vor allem auf die Sektion Medizinische Chemie zurückzuführen. Der Präsident teilt mit, dass die Chimia jetzt auch offizielles Mitteilungsblatt der SCG ist, und dass die Kooperation mit dem SChV schnellere Fortschritte macht als erwartet.

4. Kassabericht und Jahresrechnung 1988 (vgl. Annex 2 und 3) werden vom Schatzmeister Dr. J. Kalvoda erläutert, der darauf hinweist, dass das negative Rechnungsergebnis durch die notwendige Wertberichtigung der Wertschriften zum aktuellen Kurs verursacht wird. Ohne diese hätte die SCG, vor allem auch aufgrund gesenkter Produktionskosten für die HCA, 1989 ein ausgeglichenes Resultat erreicht. Die Rechnung wurde durch die Revisoren Prof. J. Wirz und Dr. P. Zeller geprüft und genehmigt.

5. Als Vertreter des Redaktionskomitees berichtet Prof. Hansen über Helv. Chim. Acta. Die Kosten pro Seite konnten um ca. $2 \%$ gesenkt werden, vor allem deshalb, weil ca. $13 \%$ der Manuskripte jetzt mit Computer bearbeitet werden. Die Publikationsfrist liegt mit durchschnittlich 2,4 Monaten im internationalen Vergleich sehr gut. Beunruhigend ist eine deutliche Abnahme des Anteils der Manuskripte aus Schweizer Hochschulen in den letzten Jahren.
6. In einer von der Versammlung zuvor genehmigten Ergänzung der Traktanden wird Dr. Ado Kaiser (Hoffmann-La Roche, Bascl) zum neuen Mitglied des Redaktionskomitees gewählt.

7. Varia: Keine Wortmeldung.

Schluss der Sitzung: 10.00 Uhr

\section{B. Wissenschaftlicher Teil}

1. Der Präsident verleiht im Namen der SCG den Paracelsus-Preis mil Medaille an Prof. R. Breslow (Columbia University, New York) 'in Anerkennung seiner Pionierarbeiten auf dem Gebiet der bio-organischen Chemie' und den Werner-Preis mit Medaille an Dr. Hein = Frei (University of California, Berkeley) 'für seine bedeutenden Beiträge zur Photochemie im Spektralgebiet zwischen sichtbarem Licht und Infrarot'.

2. Symposium 'Trends in Organic Chemistry' (gemeinsam mit dem Schweiz. Chemiker-Verband) mit Vorträgen von Prof. J.-M. Lelın (Université Louis Pasteur, Strasbourg) 'Perspektiven der supramolekularen Chemie', Prof. R. Breslow (Columbia University, New York) 'The Chelate Effect: Binding, Catalysis, and Chemotherapy', Prof. J. Rebek, jr. (Massachusetts Institute of Technology, Cambridge, U.S.A.) 'Recognition and Catalysis with Model Systems', Prof. S.L. Schreiber (Harvard University, Cambridge, U.S.A.) 'Molecular Recognition of the Immunophilins', Prof. P.G. Schultz (University of California, Berkeley) 'Catalytic Antibodies'

Am 14./15. März fand das Symposium 'Chemistry and Structure' der Schweizerischen Gesellschaft für Kristallographie zu Ehren von Prof. J.D. Dunitz (ETH Zürich) statt.

\section{Der Präsident}

Prof. A. Eschenmoser

Der Sekretär

Annex 1

\section{Jahresbericht des Vorstandes für 1989}

1. Mitglieder

Die Schweizerische Chemische Gesellschaft hatte am 31.12.1989 1551 (1502) Mitglieder, davon 16 (16) Ehren- und 15 (16) Freimitglieder (Zahlen des Vorjahres in Klammern).

Die Gesellschaft hatte im Jahr 1989 den Tod der folgenden 12 Mitglieder zu beklagen: Dr. J. Decrue, Riehen; Dr. A. Gelbert, Geroldswil; Dr. R. Genet, North Caldwell; Prof. D. Ginsburg, Haifa; Prof. K Huber, Ittingen; Prof. H. Mohler (Freimitglied); Prof. H. Musso, Karlsruhe; Dr. R. Schett, Riehen; Dr. L. Valpiana, Reinach; Dr. A. Vogel, Riehen; Dr. H. Waldmann, Birsfelden (Mitglied auf Lebenszeit); Dr. H. Wehrli, Zollikon. 
2. Vorstand

Prof. A. Eschenmoser (Präsident); Prof. W. von Philipsborn (Vize-Präsident); Dr. J. Kalvoda (Schatzmeister); Dr. K. Heusler, Prof. T. Gäumann, Dr. G. Ohloff (Altpräsidenten); Prof. A.E. Merbach, Dr. D. Hauser, Dr. D. Bellus, Prof. D. Scebach (Beisitzer) Prof. E. Heilbronner, Prof. L.M. Venanzi, Prof. H.J. Hansen, Prof. C. Tamm (Vertreter des Redaktionskomitecs Helv. Chim. Acta)

Sekretär: Dr. E. Zass.

Redaktor Helv. Chim. Acta: Dr. M.V. Kısakürek. Rechnungsrevisoren: Prof. J. Wirz, Dr. P. Zeller.

Vorstandssitzungen: 16.3.1989 und 29.6.1989 in Zürich, 19.10.1989 in Bern.

3. Wissenschaftliche Veranstaltungen

Die Gesellschaft hat 1989 die üblichen wissenschaftlichen Veranstaltungen in der Schweiz organisiert. Frühjahrsversammlung am 17. März 1989 in Zürich als Paul Karrer Centennial Symposium (gemeinsam mit dem Kuratorium der Stiftung für die Paul Karrer-Vorlesung) mit Vorträgen von Charles Weissmann (Univ. Zürich), Thomas R. Cech (Univ. of Colorado, Boulder, USA), Alan R. Fersht (Cambridge University, England), Dieter Oesterhelt (MPI für Biochemie, Martinsried, BRD) und der 23. Paul Karrer-Vorlesung von Duilio Arigoni (ETH Zürich).

Herbstversammlung am 20. Oktober 1989 in Bern mit dem Vortrag des Werner-Preisträgers 1989, A Pfaltz (ETH Zürich), dem Symposium 'Inorganic and Coordination Chemistry: New Materials' (Vorträge von H. Schmid, Université de Genève; P.P. Edwards, University of Cambridge/U.K.; L.J. Gauckler, ETH Zürich; M.L.H. Green, University of Oxford/U.K.), 44 Kurzmitteilungen der Sektion Organische Chemie, Hauptvorträgen von C.R. Ganellin (University College London/U.K.) und B. Testa (Université de Lausanne) sowie 10 Kurzmitteilungen der Sektion Medizinische Chemie, mit Kurzmitteilungen in den Sektionen Physikalische Chemie (5), Radiochemie (7), im Minisymposium 'Computational Chemistry' (4), mit 60 Postern der Sektion Anorganische und Koordinationschemie sowie einer Demonstration von Unterrichts-Software für Personal Computer ('Study Group on Computer Assisted Teaching' der Kommission für Unterrichtsfragen im Schweiz. Komitee für Chemie).

4. Preise und Ehrungen

Der Vorstand hat den Werner-Preis mit Medaille 1988 an PD Dr. Andreas Pfaltz (ETH Zürich) 'in Anerkennung seiner bedeutenden Beiträge zur Chemie porphinoider Metallkomplexe und seiner hervorragenden Arbeiten über enantioselektive Katalyse' verliehen. Die Gesellschaft ernannte Dr. Otto Isler (Uttwil TG, vormals Fa. Hoffmann-La Roche, Basel) 'in Anerkennung seiner Pionierleistungen auf dem Gebiete der Synthese von Vitaminen und Carotinoiden und in Würdigung seiner grossen Verdienste um die industrielle chemische Forschung in der Schweiz', und Prof. Rudolf Zahradnik (HeyrovskyInstitut, Czechoslovak. Akad. der Wissenschaften, Prag) 'in Anerkennung seiner bedeutenden Beiträge zur Quantenchemie, welche den internationalen Ruf der Prager Schule begründet haben, und in Würdigung seiner freundschaftlichen Beziehungen $\mathrm{zu}$ Schweizer Chemikern' zu Ehrenmitgliedern.

5. Kooperation der SCG mit dem Schweizerischen Chemiker-Verband

Eine schriftliche Abstimmung unter den Mitgliedern zu einer gemeinsamen Absichtserklärung mit der Frage 'Unterstützen Sie die in der Absichtserklärung formulierten Ziele und vorgeschlagenen Aktivitäten der Vorstände der Schweizerischen Chemischen Gesellschaft und des Schweizerischen Chemikerverbandes?' gab 562 Ja- und 10 Nein-Stimmen bei einer Stimmbeteiligung von $36,5 \%$. Aufgrund eines ähnlich positiven Abstimmungsergebnisses im SChV hat inzwischen ein Koordinationsausschuss seine Arbeit aufgenommen, in dem die SCG durch Prof, von Philipsborn und Prof. Merbach vertreten ist.

6. Schenkungen

Dic Gesellschaft verdankt im Berichtsjahr wiederum namhafte Beiträge von seiten der schweizerischen chemischen Industrie.

Zürich, den 23. Februar 1990

Für den Vorstand

Der Präsident

Der Sekretär

Prof. A. Eschenmoser
Annex 2

\section{Jahresrechnung 1989}

A) Vergleich der Bilanzen und Gewinn- und Verlustrechnungen
31.12 .1989
Fr.

Aktiven

Wertschriftenbestand

Ankaufswert

abzüglich Wertberichtigung

Buchwert

Postcheckguthaben

Bankguthaben

Debitoren ' $\mathrm{HCA}$ '

Vorschüsse Redaktion HCA

Übrige Debitoren

Passiven

Zeitschriftenfonds

Wernerfonds

Total Vermögen

Vorausbezahlte Mitgliederbeiträge

Vorausfakturierte Abonnemente \& Mitgliederbeiträge

Kreditoren

Rückstellungen

Gewinn- und Verlustrechnungen (Zeitschriftenfonds)

Ertrag

Mitgliederbeiträge, Eintrittsgebühren

Mitgliederbeiträge für $\mathrm{HCA}$

laufende Abonnemente HCA

Nachlieferungen früherer Jahrgänge HCA

Inserate

Zinsertrag

Erfolg aus Verkauf von Büchern, Zeitschriften etc.

Ertrag aus Royalties

Kursdifferenzen

Buchgewinne/verluste auf Wertschriften \& Debitoren

Aufwand

Personalaufwand

Beförderungs- und Transportspesen

Reise- \& Versammlungsspesen, Vorträge

Lektoren- \& Expertenhonorare, Beratungen, Aushilfen

Porti, Telefon

Mieten

Produktionskosten (Band 72/Band 72)

Büromaterial, Drucksachen, Werbekosten

Finanzspesen/Versicherungen

Vermögenssteuern

Beiträge, Vergabungen, Geschenke

Ertragssteuern

Verlust/Gewinn

60172 .

68845.70

734975.65

4940

11710.50

149967.44

327.5

4546.85

13894.19

$-57668.11$

991711.77

348447.05

91792.64

53050.81

3865.20

7861.60

22830.25

418248.15

52003.55

29061.36

2000 .

22803.20

1051963.81

$-60252.04$
Spezialfonds

B) Details zur Bilanz und Gewinn- und Verlustrechnung

1. Zeitschriftenfonds

Vermögen am 1. Januar

2534807.09

Verlust/Gewinn

$-60252.04$

$-59655.27$

Vermögen am 31. Dezember

2475151.82

2. Wernerfonds

Vermögen am 1. Januar

+Einnahmen: Zinsen

- Ausgaben: Auszeichnungen

216058.95

10539.6

$-7322.70$

Vermögen am 31. Dezember

219275.90

214572.30

8381.65

-6895 . -

3. Spezialfonds

Vermögen am 1. Januar

+ Einnahmen: Zinsen

Vergabungen

201884.45

10063.25

9000 .

- Ausgaben: Auszeichnungen

$-950 .-$

Vermögen am 31. Dezembe
219997.70 
4. Vergabungen

Ciba-Geigy AG, Basel

Hoffmann-La Roche, Basel

Sandoz AG, Basel

Firmenich, Genève

Lonza AG, Basel

Givaudan SA, Genève

Siegfried AG, Zofingen

Total

Annex 3

\section{Bericht des Schatzmeisters für das Jahr 1989}

Die Bilanz der Schweizerischen Chemischen Gesellschaft schliesst per 31.12.1989 mit einer Vermögensabnahme von Fr. $38921.84 \mathrm{ab}$ (Vorjahr -Fr. 66 162.87). Während sich der Wernerfonds um Fr. 3216.95 und der Spezialfonds um Fr. 18113.25 erhöhten, reduzierte sich der Zeitschriftenfonds um Fr. 60252.04 auf Fr. 2414899.78. De Nominalwert des Gesellschafts-Portefeuilles reduzierte sich um Fr. 250000. - auf Fr. 2850000_-, wobei folgende Transaktionen erfolgten:

Rückzahlungen (Nominal)

Fr. $50000 \ldots 5 \%$ B 5 BC Brown Boveri AG, Baden

1981-1991

Fr. $50000-5 \% \%$ Bernische Kraftwerke AG, Bern

$1981-1991$

1979-1989

F. $50000-3 \frac{3}{4} \%$ Aare Tessin AG

(1989-10

Fr. $50000-41 \% \%$ Grande Dixence SA, Sitten 1977-1989

Fr. $50000-61 / 4 \%$ Kanton Basel-Stadt $1981-1991$

Fr. 350000

Käufe (Nominal)

Fr. $100000-5 \frac{1}{2} \%$ Zuger Kantonalbank

1989-1997

Infolge der niedrigen Anleihenszinssätze wurden die aus dem Rückzahlungsüberschuss zur Verfügung stehenden Mittel vorläufig als Festgeld zu Zinssätzen zwischen 7,5\% - 9\% angelegt.

Per 31.12.1989 betrug der Buchwert des Wertschriftendepots Fr. 2672079.40, wobei im Berichtsjahr eine Wertberichtigung von Fr. 63250.- vorgenommen wurde. Die Differenz zum Ankaufswert von Fr. 2815954.45 ergibt eine Wertberichtigung von insgesamt Fr. 143875.05.

Gegenüber dem Vorjahr reduzierten sich die Gesamteinnahmen der Zeitschriftenrechnung um Fr. 25779.94 au Fr. 991 111.77. Neben den erlittenen Ertragseinbussen aus Abonnementen von insgesamt Fr. 10943.74 resultierten weitere Mindereinnahmen von Fr. 2335.70 aus der Büchervermittlung. Die Abschreibungen auf Debitoren und Wertschriften von Fr. 57668.11 liegen ebenfalls um Fr. 56087.90 über der Vorjahreszahl von Fr. 1580.21 Mehreinnahmen konnten dagegen aus Mitgliederbeiträgen ( + Fr. 1456.05), Inseraten ( + Fr. 4981 - -), Zinserträgen ( + Fr. 14444.90) und Royalties ( + Fr. 3482.35) erzielt werden.

Die Gesamtausgaben reduzierten sich gegenüber dem Vorjahr um Fr. 25183.17 auf Fr. 1051 963.81. Dies is insbesondere auf Einsparungen bei den Produktionskosten für Band 72 der HCA zurückzuführen, die um Fr. 59089.10 unter denjenigen des Vorjahres für Band 71 liegen. Weitere Kostenreduktionen sind bei den Positionen Reise- und Versammlungsspesen (-Fr. 9798.89), Büromaterial und Drucksachen (-Fr. 1643.79) und Steuern (-Fr.6674.45) eingetreten. Mehrausgaben fielen dagegen an bei den Personalkosten, die erneut um rd. Fr. $45100 .-$ anstiegen. Ausserdem wurden auch für Beförderungs- und Transportkosten, Lektoren- und Ex pertenhonorare, Porti und Telefon, Mieten, Finanzspesen und Versicherungen insgesamt Fr. 6941.16 mehr aufgewendet.

In der Zeitschriftenrechnung mit einem Verlust von Fr. 60252.04 (Vorjahr -Fr. 59655.27) ergaben sich gegenüber 1988 folgende detaillierte Veränderungen der Erträge und Aufwendungen:

Veränderungen bei den Erträgen

Mitgliederbeiträge

Nachlieferungen $\mathrm{HCA}$

Büchervermittlung

Ertrag aus Royalties

Buchgewinne/verluste auf Wertschriften \& Debitoren

Abonnemente laufender HCA

Inserate

Zinsertrag

Kursdifferenzen

Total Veränderungen bei den Erträgen

Veränderungen bei den Aufwendungen

Personalaufwand

Beförderungs- und Transportspesen

Reise- und Versammlungsspesen

Lektoren- und Expertenhonorare

Porti, Telefon

Mieten

Produktionskosten HCA

Büromaterial, Drucksachen

Finanzspesen, Versicherungen

Steuern

Beiträge, Vergabungen, Geschenke

Total Veränderungen bei den Aufwendungen

Diese Abweichungen ergeben zusammen eine Ertragsreduktion

des Zeitschriftenfonds gegenüber 1988 von total

Die Vergabungen von total Fr. 9000.-, die wir bestens verdanken, wurden ausschliesslich dem Spezialfond gutgeschrieben. Aus dem Wernerfonds wurde ein Preis von Fr. 5000.- an Herrn Dr. A. Pfalz ausgeschüttet. Fü Urkunden und Ledermappen wurden Fr. 3272.70 ausgegeben, wovon Fr. 950.- dem Spezialfonds belastet wurden. Basel, im Februar 1990

Der Schatzmeister: Dr. J. Kalvoda

\section{Schweizerische Chemische Gesellschaft Société Suisse de Chimie}

Basel, im April 1990

Sehr geehrtes Mitglied,

die diesjährige Herbstversammlung der Schweizerischen Chemischen Gesellschaft findet am Freitag, den 19. Oktober 1990, in Bern statt.

Wir laden Sie zur Anmeldung eines wissenschaftlichen Beitrages ein und bitten Sie, den Titel, die Autoren und für Kurzmitteilungen in den Sektionen für Organische Chemie, Medizinische Chemie, Physikalische Chemie und Computerunterstützte Chemie den Namen des Vortragenden bis spätestens 1. Juli 1990 dem Unterzeichnenden bekanntzugeben. Sie werden gebeten, gegebenenfalls Diapositive der Grösse $5 \times 5$ $\mathrm{cm}$ zu verwenden. Für Beiträge aus den Gebieten der Anorganischen und Koordinationschemie wird eine Postersession stattfinden.

Es ist wiederum vorgesehen, Kurzfassungen der Vorträge oder Posters in Heftform allen Mitgliedern vor der Herbstversammlung zuzustellen. Kurzfassungen, die nach dem 1 . Juli 1990 eintreffen, können nicht mehr in das Referatheft aufgenommen werden.

Für die Anmeldung von Beiträgen und für die Kurz fassungen bitten wir, die beiliegenden Formulare zu benützen

Mit freundlichen Grüssen

Prof. W. von Philipsborn

Org.-Chemisches Institut

Universität Zürich

Winterthurerstr. 190

8057 Zürich

Madame, Monsieur

Bâle, en avril 1990

L'assemblée d'automne de notre Société aura lieu à Berne vendredi 19 octobre 1990

Nous vous invitons à y présenter une communication scientifique et vous prions d'en donner le titre et la liste des auteurs au soussigné avant le ler juillet 1990 . S'il s'agit d'une communication orale dans le cadre de la section de chimie organique, chimie thérapeutique, chimie physique ou chimie assistée par ordinateur nous vous prions d'indiquer le nom de l'auteur qui la présentera. Les conférenciers sont priés d'utiliser des clichés standards de $5 \times 5 \mathrm{~cm}$. Pour les contributions dans le domaine de la chimie de coordination et de la chimie minérale une session par poster aura lieu.

. Il est à nouveau prévu d'envoyer unc copie des résumés des communications ou des posters, sous forme de cahiers à tous les membres de notre Société avant l'assemblée d'automne. Les résumés qui nous parviendraient après le ler juillet 1990 ne pourraient plus être inclus dans le cahier du compte-rendu.

Pour l'annonce des communications, incluant les résumés, nous vous prions d'utiliser les formulaires cijoints.

Veuillez croire, Madame, Monsieur, à l'expression de mes meilleurs sentiments.

Au nom du Comité Prof. W. von Philipsborn Org.-Chemisches Institut Universität Zürich Winterthurerstr. 190 8057 Zürich

45099.10

153.25

$-9798.89$

506.90

250 . -

$-1643.79$

5964.81

$-6674.45$

$-17.20$

$-25183.17$

$-596.77$

Dr. J. Stähelin, ETH Zürich

'Ist der Ozonschild in Gefahr? Diskussion anhand der langjährigen Schweizerischen Messreihen'

27.06.90

Prof. P. Schindler, Universität Bern

'Schwermetalle in der Umwelt'

Gäste willkommen! 
4. Vergabungen

Ciba-Geigy AG, Basel

Hoffmann-La Roche, Basel

Sandoz AG, Basel

Firmenich, Genève

Lonza AG, Basel

Givaudan SA, Genève

Siegfried AG, Zofingen

Total

Annex 3

\section{Bericht des Schatzmeisters für das Jahr 1989}

Die Bilanz der Schweizerischen Chemischen Gesellschaft schliesst per 31.12.1989 mit einer Vermögensabnahme von Fr. $38921.84 \mathrm{ab}$ (Vorjahr -Fr. 66 162.87). Während sich der Wernerfonds um Fr. 3216.95 und der Spezialfonds um Fr. 18113.25 erhöhten, reduzierte sich der Zeitschriftenfonds um Fr. 60252.04 auf Fr. 2414899.78. De Nominalwert des Gesellschafts-Portefeuilles reduzierte sich um Fr. 250000. - auf Fr. 2850000_-, wobei folgende Transaktionen erfolgten:

Rückzahlungen (Nominal)

Fr. $50000 \ldots 5 \%$ B 5 BC Brown Boveri AG, Baden

1981-1991

Fr. $50000-5 \% \%$ Bernische Kraftwerke AG, Bern

$1981-1991$

1979-1989

F. $50000-3 \frac{3}{4} \%$ Aare Tessin AG

(1989-10

Fr. $50000-41 \% \%$ Grande Dixence SA, Sitten 1977-1989

Fr. $50000-61 / 4 \%$ Kanton Basel-Stadt $1981-1991$

Fr. 350000

Käufe (Nominal)

Fr. $100000-5 \frac{1}{2} \%$ Zuger Kantonalbank

1989-1997

Infolge der niedrigen Anleihenszinssätze wurden die aus dem Rückzahlungsüberschuss zur Verfügung stehenden Mittel vorläufig als Festgeld zu Zinssätzen zwischen 7,5\% - 9\% angelegt.

Per 31.12.1989 betrug der Buchwert des Wertschriftendepots Fr. 2672079.40, wobei im Berichtsjahr eine Wertberichtigung von Fr. 63250.- vorgenommen wurde. Die Differenz zum Ankaufswert von Fr. 2815954.45 ergibt eine Wertberichtigung von insgesamt Fr. 143875.05.

Gegenüber dem Vorjahr reduzierten sich die Gesamteinnahmen der Zeitschriftenrechnung um Fr. 25779.94 au Fr. 991 111.77. Neben den erlittenen Ertragseinbussen aus Abonnementen von insgesamt Fr. 10943.74 resultierten weitere Mindereinnahmen von Fr. 2335.70 aus der Büchervermittlung. Die Abschreibungen auf Debitoren und Wertschriften von Fr. 57668.11 liegen ebenfalls um Fr. 56087.90 über der Vorjahreszahl von Fr. 1580.21 Mehreinnahmen konnten dagegen aus Mitgliederbeiträgen ( + Fr. 1456.05), Inseraten ( + Fr. 4981 - -), Zinserträgen ( + Fr. 14444.90) und Royalties ( + Fr. 3482.35) erzielt werden.

Die Gesamtausgaben reduzierten sich gegenüber dem Vorjahr um Fr. 25183.17 auf Fr. 1051 963.81. Dies is insbesondere auf Einsparungen bei den Produktionskosten für Band 72 der HCA zurückzuführen, die um Fr. 59089.10 unter denjenigen des Vorjahres für Band 71 liegen. Weitere Kostenreduktionen sind bei den Positionen Reise- und Versammlungsspesen (-Fr. 9798.89), Büromaterial und Drucksachen (-Fr. 1643.79) und Steuern (-Fr.6674.45) eingetreten. Mehrausgaben fielen dagegen an bei den Personalkosten, die erneut um rd. Fr. $45100 .-$ anstiegen. Ausserdem wurden auch für Beförderungs- und Transportkosten, Lektoren- und Ex pertenhonorare, Porti und Telefon, Mieten, Finanzspesen und Versicherungen insgesamt Fr. 6941.16 mehr aufgewendet.

In der Zeitschriftenrechnung mit einem Verlust von Fr. 60252.04 (Vorjahr -Fr. 59655.27) ergaben sich gegenüber 1988 folgende detaillierte Veränderungen der Erträge und Aufwendungen:

Veränderungen bei den Erträgen

Mitgliederbeiträge

Nachlieferungen $\mathrm{HCA}$

Büchervermittlung

Ertrag aus Royalties

Buchgewinne/verluste auf Wertschriften \& Debitoren

Abonnemente laufender HCA

Inserate

Zinsertrag

Kursdifferenzen

Total Veränderungen bei den Erträgen

Veränderungen bei den Aufwendungen

Personalaufwand

Beförderungs- und Transportspesen

Reise- und Versammlungsspesen

Lektoren- und Expertenhonorare

Porti, Telefon

Mieten

Produktionskosten HCA

Büromaterial, Drucksachen

Finanzspesen, Versicherungen

Steuern

Beiträge, Vergabungen, Geschenke

Total Veränderungen bei den Aufwendungen

Diese Abweichungen ergeben zusammen eine Ertragsreduktion

des Zeitschriftenfonds gegenüber 1988 von total

Die Vergabungen von total Fr. 9000.-, die wir bestens verdanken, wurden ausschliesslich dem Spezialfond gutgeschrieben. Aus dem Wernerfonds wurde ein Preis von Fr. 5000.- an Herrn Dr. A. Pfalz ausgeschüttet. Fü Urkunden und Ledermappen wurden Fr. 3272.70 ausgegeben, wovon Fr. 950.- dem Spezialfonds belastet wurden. Basel, im Februar 1990

Der Schatzmeister: Dr. J. Kalvoda

\section{Schweizerische Chemische Gesellschaft Société Suisse de Chimie}

Basel, im April 1990

Sehr geehrtes Mitglied,

die diesjährige Herbstversammlung der Schweizerischen Chemischen Gesellschaft findet am Freitag, den 19. Oktober 1990, in Bern statt.

Wir laden Sie zur Anmeldung eines wissenschaftlichen Beitrages ein und bitten Sie, den Titel, die Autoren und für Kurzmitteilungen in den Sektionen für Organische Chemie, Medizinische Chemie, Physikalische Chemie und Computerunterstützte Chemie den Namen des Vortragenden bis spätestens 1. Juli 1990 dem Unterzeichnenden bekanntzugeben. Sie werden gebeten, gegebenenfalls Diapositive der Grösse $5 \times 5$ $\mathrm{cm}$ zu verwenden. Für Beiträge aus den Gebieten der Anorganischen und Koordinationschemie wird eine Postersession stattfinden.

Es ist wiederum vorgesehen, Kurzfassungen der Vorträge oder Posters in Heftform allen Mitgliedern vor der Herbstversammlung zuzustellen. Kurzfassungen, die nach dem 1 . Juli 1990 eintreffen, können nicht mehr in das Referatheft aufgenommen werden.

Für die Anmeldung von Beiträgen und für die Kurz fassungen bitten wir, die beiliegenden Formulare zu benützen

Mit freundlichen Grüssen

Prof. W. von Philipsborn

Org.-Chemisches Institut

Universität Zürich

Winterthurerstr. 190

8057 Zürich

Madame, Monsieur

Bâle, en avril 1990

L'assemblée d'automne de notre Société aura lieu à Berne vendredi 19 octobre 1990

Nous vous invitons à y présenter une communication scientifique et vous prions d'en donner le titre et la liste des auteurs au soussigné avant le ler juillet 1990 . S'il s'agit d'une communication orale dans le cadre de la section de chimie organique, chimie thérapeutique, chimie physique ou chimie assistée par ordinateur nous vous prions d'indiquer le nom de l'auteur qui la présentera. Les conférenciers sont priés d'utiliser des clichés standards de $5 \times 5 \mathrm{~cm}$. Pour les contributions dans le domaine de la chimie de coordination et de la chimie minérale une session par poster aura lieu.

. Il est à nouveau prévu d'envoyer unc copie des résumés des communications ou des posters, sous forme de cahiers à tous les membres de notre Société avant l'assemblée d'automne. Les résumés qui nous parviendraient après le ler juillet 1990 ne pourraient plus être inclus dans le cahier du compte-rendu.

Pour l'annonce des communications, incluant les résumés, nous vous prions d'utiliser les formulaires cijoints.

Veuillez croire, Madame, Monsieur, à l'expression de mes meilleurs sentiments.

Au nom du Comité Prof. W. von Philipsborn Org.-Chemisches Institut Universität Zürich Winterthurerstr. 190 8057 Zürich

45099.10

153.25

$-9798.89$

506.90

250 . -

$-1643.79$

5964.81

$-6674.45$

$-17.20$

$-25183.17$

$-596.77$

Dr. J. Stähelin, ETH Zürich

'Ist der Ozonschild in Gefahr? Diskussion anhand der langjährigen Schweizerischen Messreihen'

27.06.90

Prof. P. Schindler, Universität Bern

'Schwermetalle in der Umwelt'

Gäste willkommen! 
4. Vergabungen

Ciba-Geigy AG, Basel

Hoffmann-La Roche, Basel

Sandoz AG, Basel

Firmenich, Genève

Lonza AG, Basel

Givaudan SA, Genève

Siegfried AG, Zofingen

Total

Annex 3

\section{Bericht des Schatzmeisters für das Jahr 1989}

Die Bilanz der Schweizerischen Chemischen Gesellschaft schliesst per 31.12.1989 mit einer Vermögensabnahme von Fr. $38921.84 \mathrm{ab}$ (Vorjahr -Fr. 66 162.87). Während sich der Wernerfonds um Fr. 3216.95 und der Spezialfonds um Fr. 18113.25 erhöhten, reduzierte sich der Zeitschriftenfonds um Fr. 60252.04 auf Fr. 2414899.78. De Nominalwert des Gesellschafts-Portefeuilles reduzierte sich um Fr. 250000. - auf Fr. 2850000_-, wobei folgende Transaktionen erfolgten:

Rückzahlungen (Nominal)

Fr. $50000 \ldots 5 \%$ B 5 BC Brown Boveri AG, Baden

1981-1991

Fr. $50000-5 \% \%$ Bernische Kraftwerke AG, Bern

$1981-1991$

1979-1989

F. $50000-3 \frac{3}{4} \%$ Aare Tessin AG

(1989-10

Fr. $50000-41 \% \%$ Grande Dixence SA, Sitten 1977-1989

Fr. $50000-61 / 4 \%$ Kanton Basel-Stadt $1981-1991$

Fr. 350000

Käufe (Nominal)

Fr. $100000-5 \frac{1}{2} \%$ Zuger Kantonalbank

1989-1997

Infolge der niedrigen Anleihenszinssätze wurden die aus dem Rückzahlungsüberschuss zur Verfügung stehenden Mittel vorläufig als Festgeld zu Zinssätzen zwischen 7,5\% - 9\% angelegt.

Per 31.12.1989 betrug der Buchwert des Wertschriftendepots Fr. 2672079.40, wobei im Berichtsjahr eine Wertberichtigung von Fr. 63250.- vorgenommen wurde. Die Differenz zum Ankaufswert von Fr. 2815954.45 ergibt eine Wertberichtigung von insgesamt Fr. 143875.05.

Gegenüber dem Vorjahr reduzierten sich die Gesamteinnahmen der Zeitschriftenrechnung um Fr. 25779.94 au Fr. 991 111.77. Neben den erlittenen Ertragseinbussen aus Abonnementen von insgesamt Fr. 10943.74 resultierten weitere Mindereinnahmen von Fr. 2335.70 aus der Büchervermittlung. Die Abschreibungen auf Debitoren und Wertschriften von Fr. 57668.11 liegen ebenfalls um Fr. 56087.90 über der Vorjahreszahl von Fr. 1580.21 Mehreinnahmen konnten dagegen aus Mitgliederbeiträgen ( + Fr. 1456.05), Inseraten ( + Fr. 4981 - -), Zinserträgen ( + Fr. 14444.90) und Royalties ( + Fr. 3482.35) erzielt werden.

Die Gesamtausgaben reduzierten sich gegenüber dem Vorjahr um Fr. 25183.17 auf Fr. 1051 963.81. Dies is insbesondere auf Einsparungen bei den Produktionskosten für Band 72 der HCA zurückzuführen, die um Fr. 59089.10 unter denjenigen des Vorjahres für Band 71 liegen. Weitere Kostenreduktionen sind bei den Positionen Reise- und Versammlungsspesen (-Fr. 9798.89), Büromaterial und Drucksachen (-Fr. 1643.79) und Steuern (-Fr.6674.45) eingetreten. Mehrausgaben fielen dagegen an bei den Personalkosten, die erneut um rd. Fr. $45100 .-$ anstiegen. Ausserdem wurden auch für Beförderungs- und Transportkosten, Lektoren- und Ex pertenhonorare, Porti und Telefon, Mieten, Finanzspesen und Versicherungen insgesamt Fr. 6941.16 mehr aufgewendet.

In der Zeitschriftenrechnung mit einem Verlust von Fr. 60252.04 (Vorjahr -Fr. 59655.27) ergaben sich gegenüber 1988 folgende detaillierte Veränderungen der Erträge und Aufwendungen:

Veränderungen bei den Erträgen

Mitgliederbeiträge

Nachlieferungen $\mathrm{HCA}$

Büchervermittlung

Ertrag aus Royalties

Buchgewinne/verluste auf Wertschriften \& Debitoren

Abonnemente laufender HCA

Inserate

Zinsertrag

Kursdifferenzen

Total Veränderungen bei den Erträgen

Veränderungen bei den Aufwendungen

Personalaufwand

Beförderungs- und Transportspesen

Reise- und Versammlungsspesen

Lektoren- und Expertenhonorare

Porti, Telefon

Mieten

Produktionskosten HCA

Büromaterial, Drucksachen

Finanzspesen, Versicherungen

Steuern

Beiträge, Vergabungen, Geschenke

Total Veränderungen bei den Aufwendungen

Diese Abweichungen ergeben zusammen eine Ertragsreduktion

des Zeitschriftenfonds gegenüber 1988 von total

Die Vergabungen von total Fr. 9000.-, die wir bestens verdanken, wurden ausschliesslich dem Spezialfond gutgeschrieben. Aus dem Wernerfonds wurde ein Preis von Fr. 5000.- an Herrn Dr. A. Pfalz ausgeschüttet. Fü Urkunden und Ledermappen wurden Fr. 3272.70 ausgegeben, wovon Fr. 950.- dem Spezialfonds belastet wurden. Basel, im Februar 1990

Der Schatzmeister: Dr. J. Kalvoda

\section{Schweizerische Chemische Gesellschaft Société Suisse de Chimie}

Basel, im April 1990

Sehr geehrtes Mitglied,

die diesjährige Herbstversammlung der Schweizerischen Chemischen Gesellschaft findet am Freitag, den 19. Oktober 1990, in Bern statt.

Wir laden Sie zur Anmeldung eines wissenschaftlichen Beitrages ein und bitten Sie, den Titel, die Autoren und für Kurzmitteilungen in den Sektionen für Organische Chemie, Medizinische Chemie, Physikalische Chemie und Computerunterstützte Chemie den Namen des Vortragenden bis spätestens 1. Juli 1990 dem Unterzeichnenden bekanntzugeben. Sie werden gebeten, gegebenenfalls Diapositive der Grösse $5 \times 5$ $\mathrm{cm}$ zu verwenden. Für Beiträge aus den Gebieten der Anorganischen und Koordinationschemie wird eine Postersession stattfinden.

Es ist wiederum vorgesehen, Kurzfassungen der Vorträge oder Posters in Heftform allen Mitgliedern vor der Herbstversammlung zuzustellen. Kurzfassungen, die nach dem 1 . Juli 1990 eintreffen, können nicht mehr in das Referatheft aufgenommen werden.

Für die Anmeldung von Beiträgen und für die Kurz fassungen bitten wir, die beiliegenden Formulare zu benützen

Mit freundlichen Grüssen

Prof. W. von Philipsborn

Org.-Chemisches Institut

Universität Zürich

Winterthurerstr. 190

8057 Zürich

Madame, Monsieur

Bâle, en avril 1990

L'assemblée d'automne de notre Société aura lieu à Berne vendredi 19 octobre 1990

Nous vous invitons à y présenter une communication scientifique et vous prions d'en donner le titre et la liste des auteurs au soussigné avant le ler juillet 1990 . S'il s'agit d'une communication orale dans le cadre de la section de chimie organique, chimie thérapeutique, chimie physique ou chimie assistée par ordinateur nous vous prions d'indiquer le nom de l'auteur qui la présentera. Les conférenciers sont priés d'utiliser des clichés standards de $5 \times 5 \mathrm{~cm}$. Pour les contributions dans le domaine de la chimie de coordination et de la chimie minérale une session par poster aura lieu.

. Il est à nouveau prévu d'envoyer unc copie des résumés des communications ou des posters, sous forme de cahiers à tous les membres de notre Société avant l'assemblée d'automne. Les résumés qui nous parviendraient après le ler juillet 1990 ne pourraient plus être inclus dans le cahier du compte-rendu.

Pour l'annonce des communications, incluant les résumés, nous vous prions d'utiliser les formulaires cijoints.

Veuillez croire, Madame, Monsieur, à l'expression de mes meilleurs sentiments.

Au nom du Comité Prof. W. von Philipsborn Org.-Chemisches Institut Universität Zürich Winterthurerstr. 190 8057 Zürich

45099.10

153.25

$-9798.89$

506.90

250 . -

$-1643.79$

5964.81

$-6674.45$

$-17.20$

$-25183.17$

$-596.77$

Dr. J. Stähelin, ETH Zürich

'Ist der Ozonschild in Gefahr? Diskussion anhand der langjährigen Schweizerischen Messreihen'

27.06.90

Prof. P. Schindler, Universität Bern

'Schwermetalle in der Umwelt'

Gäste willkommen! 